\title{
Leveraged Exchange Traded Funds and Volatility: An Exploratory Discussion
}

William J. Golden

July 2014 


\section{Contents}

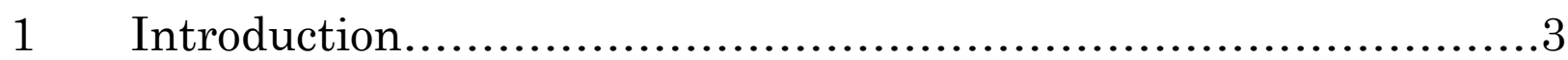

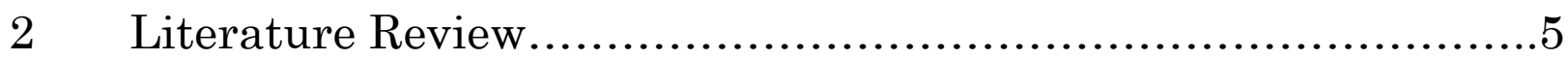

$2.1 \quad$ Market Volatility.............................................

2.1.1 Volatility Modeling.........................................

2.1.2 Generalized Autoregressive Conditional

Heteroskedasticity (GARCH) Model.......................10

2.2 Leveraged Exchange Traded Funds: Not Always as

Advertised........................................................11

2.3 Arguments Against the Link Between LETFs and

Exacerbated

Volatility.............................................................

2.4 LETFs and their Link with Exacerbated Volatility...........14

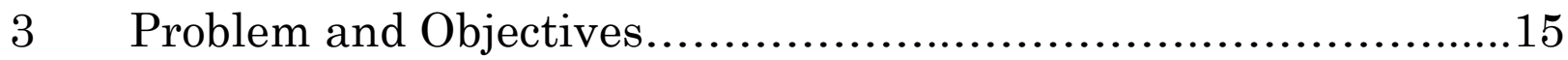

3.1 Problem Background..............................................15

3.2 Problem Statement \& Objectives.................................16

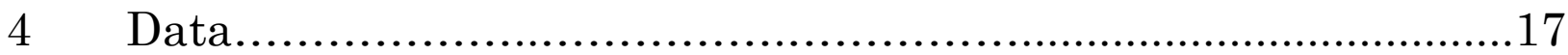

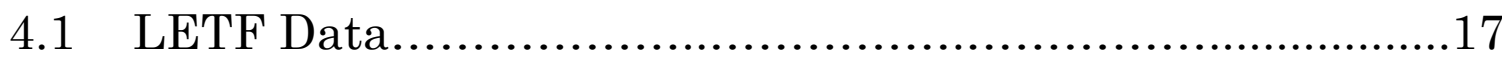

4.2 Data Analysis.......................................................

4.2.1 Correlation Considerations.................................17

4.2.2 Dynamic Conditional Correlation (DCC) GARCH

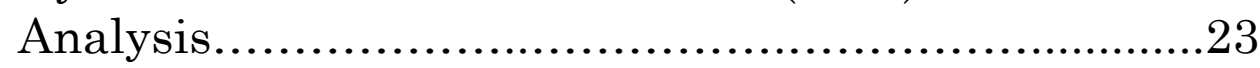

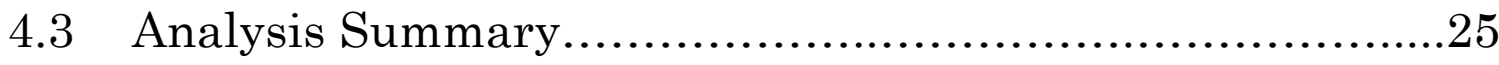

$5 \quad$ Expected Research Contributions....................................25

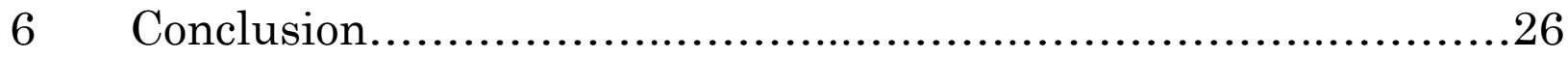

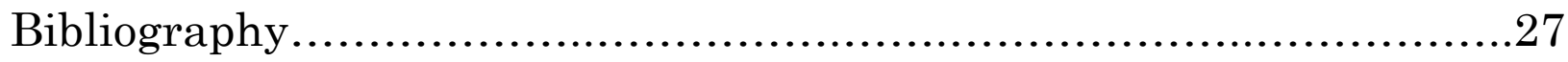

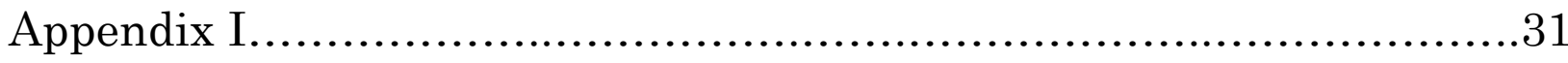

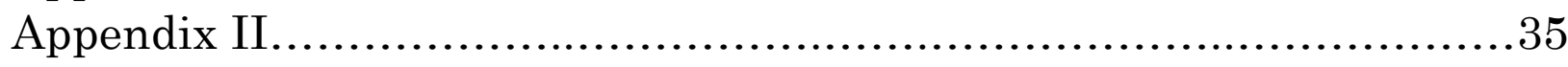

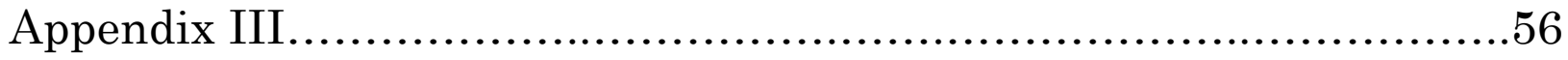

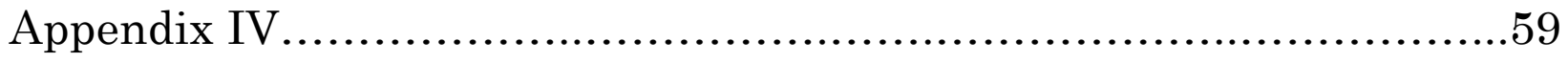




\begin{abstract}
In the late 1980's, futures trading was at the center of every market analyst's mind; surely the remarkable spike in market volatility had to be related to this new investment tool. Over twenty years later, another marked increase in volatility has coincided with the use of a revolutionary investment tool: leveraged exchange traded funds. These investment vehicles, first released in 2006, seek to make multiples or multiple inverses of a given index or commodity. For example, a $2 \mathrm{X}$ leveraged exchange traded fund tracking the S\&P 500 promises to double the performance of that index over a given time period. However, there has been much confusion about the manner in which they are leveraged, the advertised multiple they seek to attain, and how their daily rebalancing influences market volatility.

This research will consider the volatility of leveraged exchange traded funds on intra-day and inter-day intervals. Utilizing different methods of correlation considerations, different leveraged exchanged traded funds and indexes will be considered and their link to widespread volatility studied. Due to the nature of their structure, leveraged exchange traded funds inherently experience increased volatility at certain points throughout the trading day; this paper will investigate the manner in which the volatility demonstrated by leveraged exchange traded funds influences and alters index and market wide volatility trends.
\end{abstract}




\section{Introduction}

A critical component in a larger system, exchange-traded funds (ETFs) are a type of exchange-traded product (ETP), which are traded on exchanges in a method much like stocks. Like some mutual funds, ETFs hold different assets and typically track an index throughout the day. In essence, an ETF is a union between a stock and a mutual fund; their respective value is determined by a blend of assets and their goal is to track an index (like a mutual fund), yet their price is reflected on an exchange and they can be bought and sold throughout the market day (like a stock). While a mutual fund has its net-asset value (NAV) calculated at the end of each business day, the price of a given ETF changes throughout the day, tracking its NAV. An investor does not buy or sell an ETF directly from the ETF; ETFs are typically sold to large investment companies in "creation units" which are large blocks of shares (often 50,000). For an individual to buy or sell an ETF, they are acquired and sold on a secondary market, such as a securities exchange.

ETFs were first introduced in 1993; the first ETF was the SPDR S\&P 500 Index, which strives to mirror the performance of the S\&P 500 Index [52]. By November 2013, there were approximately 5,000 exchange-traded products with total assets under management (AUM) of $\$ 2.4$ trillion and the SPDR S\&P 500 had

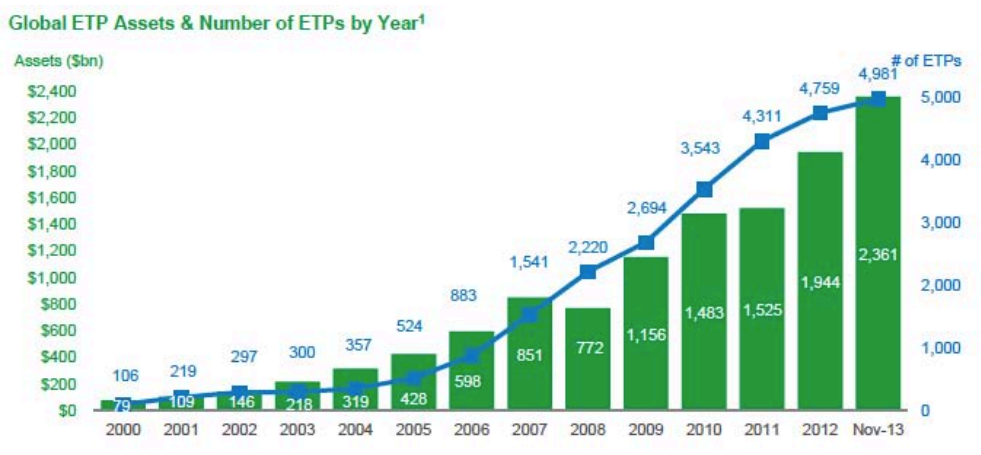
850 million shares outstanding with total net assets amassing to $\$ 155$ billion, the largest ETF in the world [52]. In just twenty 
years, the growth of ETPs has exploded; since 2000, ETPs have experienced a growth rate of $4600 \%$ [52].

In 2006, ProShares established the first leveraged and inverse ETFs. Like the original ETFs, these newer vehicles tracked an index, but they attempted to either magnify or perform in the opposite direction of a given index [34]. As aforementioned, the SPDR S\&P 500 Index attempts to deliver $1 \mathrm{X}$ the index return for any given time period. An inverse S\&P 500 ETF (for example, the ProShares Short S\&P $500 \mathrm{ETF}$ ), is designed to deliver the negative of the index return, or -1X, of the S\&P 500. Leveraged ETFs seek to earn a multiple of the index; instead of $1 \mathrm{X}$ the S\&P 500, the goal could range from $2 \mathrm{X}$ or $3 \mathrm{X}$ to $-2 \mathrm{X}$ to $-3 \mathrm{X}$. Leveraged ETFs allow the investor to acquire a leveraged position without doing any personal borrowing; the mechanics of the leverage are encompassed in the ETF structure. A critical aspect of the inverse and leveraged ETFs is the manner in which they set their goals; the vast majority of these tools seek to earn their given multiple for only one day; at the end of every day, a leveraged or inverse ETF is then rebalanced and its respective market exposure altered.

While analysis has been conducted regarding the effect of leveraged ETFs on market volatility, it has focused on the aggregate influence of all leveraged and inverse vehicles on their respective benchmarks. In this paper, we will consider the influence that LETFs have on their respective indexes (e.g.: the behavior of the S\&P 500 relative to its largest respective LETFs) over different time intervals.

Additionally, we will explore the possibility of volatility spillover between different 
indexes and its relationship with LETFs. The relationships will be considered using a variety of models, including simple linear covariance models, the inspection of conditional covariance matrices, exponential weighted moving averages, and a bivariate Dynamic Conditional Correlation GARCH model. We will demonstrate that these vehicles are volatile by design and that while their behavior is strongly correlative to other indexes, there is no evidence of a causal relationship between LETFs and naturally occurring market volatility.

This paper will continue by discussing the relevant research and literature that has been published regarding market volatility, LETFs, and volatility modeling. Section three will consider the research objectives and discuss the analysis methods that we will employ exploring our objectives. Section four will examine the available data that will be utilized and how it will be applied in our research. Section five and six will conclude the paper by considering the expected contributions of this research.

\section{Literature Review}

\subsection{Market Volatility}

The most relevant and fundamental question to ask when considering this research: why are we considering market volatility? The consideration of market volatility is not a new concept; in [36], Officer considers the origins of market variability between 1897 and 1969; at the time, many believed that the decrease of volatility after the Great Depression was a result of the formation of the SEC and 
new margin requirements. However, Officer empirically demonstrates that both of these major changes occurred after variability in the market had already started to decrease and shows that policy changes did not propel the market into a more stable environment. Schwert argues in [18] that aggregate stock market volatility cannot be explained by an individual factor or with a simple model. He continues to demonstrate that the crashes of 1929 and 1987 and subsequent recessions were correlated with high market volatility, but is very clear in pointing out that macroeconomic factors did not make clear why the crash happened.

The method used to measure stock market volatility is another critical consideration. Traditionally, volatility examines the variability in a given asset's returns. When referring to the volatility of a given asset, one is typically referencing the magnitude of the standard deviation of the asset's returns. For most studies of volatility, log-returns are used:

$$
R_{\mathrm{t}}=\ln \left(P_{\mathrm{t}+1}\right)-\ln \left(P_{\mathrm{t}}\right)
$$

where $R_{\mathrm{t}}$ is the return at time t, $P_{\mathrm{t}+1}$ is the price at time t+1, $P_{\mathrm{t}}$ is the price at time $\mathrm{t}$ and $\ln$ is the natural logarithm. 
As explained in [40], there are a number of reasons why using logarithmic returns is advantageous. Logarithmic returns can be interpreted as continuously

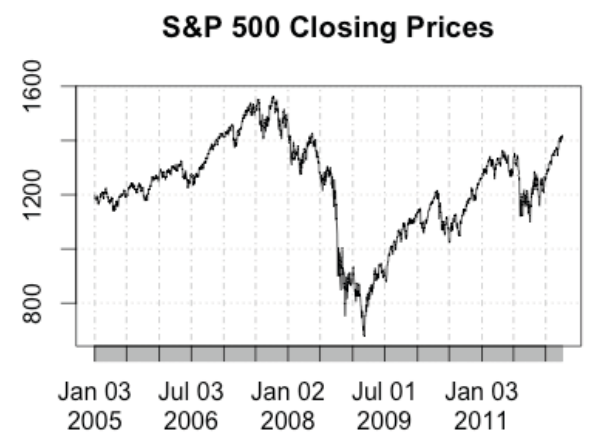

compounded, are easy to consider for multi-period inspection, are standardized, and are approximately equal (in size) to normal returns. There are, however, several drawbacks: logarithmic returns do not provide a direct measurement of wealth change and the mean of logarithmic returns and the mean of real returns over time are not necessarily equivalent. For the remainder of this paper, when we consider returns, we will be considering logarithmic returns.
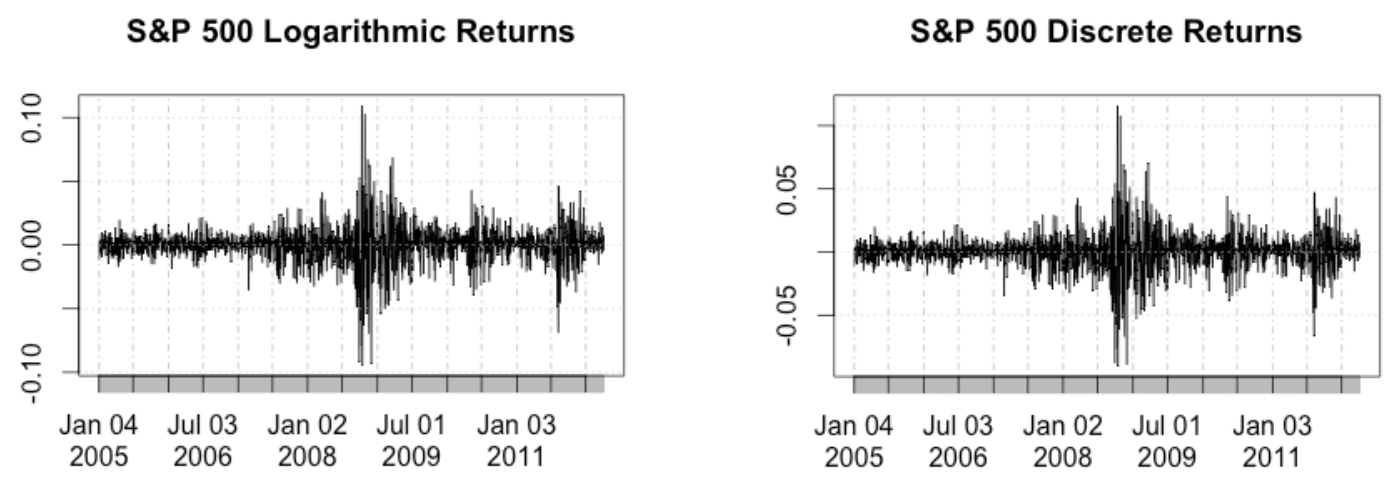

Myriad models have been developed in order to capture the volatility of returns. The most basic and aforementioned method to capture volatility is variance in an asset's returns. However, this simple method does not consider the 
distribution of returns; as pointed out in [1, $35,36,37,38,39,40,41]$, stock market returns are not necessarily normally distributed, negatively altering the efficacy of the standard deviation. Volatility clusters occur naturally across different

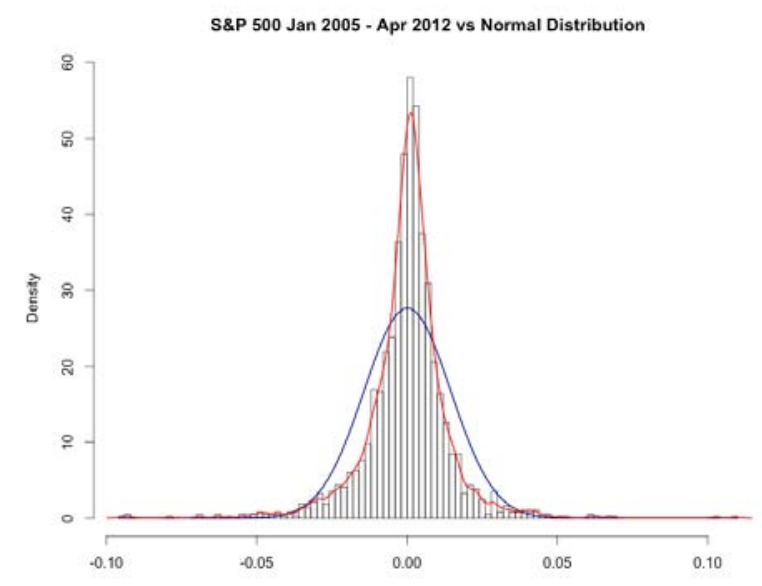
assets and indexes $[1,18,19,35,36,37,38,39,40]$. In other words, periods of high volatility are followed by periods of low volatility across all assets and exchanges. All financial data is a form of time series data; a time series $\left\{r_{t}\right\}$ is "weakly stationary if the mean of $r_{\mathrm{t}}$ and the covariance between $r_{\mathrm{t}}$ and $r_{\mathrm{t}-1}$ are time invariant, where $l$ is an arbitrary integer [36]." It follows that variance/covariance is not constant but is time varying, a trait referred to as heteroskedasticity [40].

\subsubsection{Volatility Modeling}

In 1982, Robert Engle won the Nobel Prize for his Autoregressive Conditional Heteroskedasticity $(\mathrm{ARCH})$ model. Engle explains in $[36,43]$ that an $\mathrm{ARCH}(\mathrm{m})$ model assumes:

$$
a_{t}=\sigma_{t} \epsilon_{t}, \quad \sigma_{t}^{2}=\alpha_{0}+\alpha_{1} a_{t-1}^{2}+\cdots+\alpha_{m} a_{t-m}^{2}
$$

where $\epsilon_{t}$ is a sequence of iid random variables, $\sigma_{t}$ are observed standard deviations at time $t, a_{t}$ are the volatility estimates at time $t$, and $\sigma_{t}^{2}$ is the $\mathrm{ARCH}$ variance.

Drawbacks were noted in this model, however, which led to the development of other volatility models. For example, ARCH models assumed that positive and negative shocks have the same impacts, they do not provide any way to determine the source of volatility, they frequently over predict volatility, and most 
importantly, it has been empirically demonstrated that they require a high number of observations in order to accurately capture conditional volatility.

Before discussing developments caused by $\mathrm{ARCH}$ models, it is useful to consider autoregressive (AR) models, moving average (MA) models, and autoregressive moving average (ARMA) models. An $\mathrm{AR}(p)$ model is defined as:

$$
r_{t}=\phi_{0}+\sum_{i=1}^{p} \phi_{i} r_{t-i}+a_{t},
$$

where $r_{t}$ is the return at time $t, \phi_{0}$ is the constant term, $\phi_{i}$ is the coefficient of $r_{t-i}$, and $a_{t}$ is white noise with mean zero and variance one [36]. This model is similar to simple linear regression, where $r_{t-i}$ is the independent variable and $r_{t}$ is the dependent variable.

The parameters for an $\operatorname{AR}(p)$ model are estimated using least squares, initiating with the $(p+1)$ observation [36]. Next, we consider moving average (MA) models. MA models can be considered as infinite-order AR models, where the value of the model is a linear regression of all previous observations. An MA(q) model can be defined as:

$$
r_{t}=c_{0}+a_{t}-\sum_{i=1}^{q} \theta_{i} a_{t-i},
$$

where $c_{0}$ is a constant and $a_{t}$ is a white noise series; the remainder of the model is discussed in [36].

Due to the fact that they are linear combinations of a white noise sequence where the first two moments are time-invariant, MA models are always weakly stationary [36]. The ARMA model, introduced in 1951 by Peter Whittle [44] combines the concepts found in AR and MA models in an effort to limit the number of necessary parameters. An $\operatorname{ARMA}(p, q)$ model can be defined as:

$$
r_{t}=\phi_{0}+\sum_{i=1}^{p} \phi_{i} r_{t-i}+a_{t}-\sum_{i=1}^{q} \theta_{i} a_{t-i}
$$


where $a_{t}$ is a white noise series, $(p, q) \in \mathbb{Z}^{+}$, and that there are no common factors between the AR and

MA polynomials (otherwise the model can be simplified) [36]. The remainder of the model is discussed in [36].

\subsubsection{Generalized Autoregressive Conditional Heteroskedasticity (GARCH) Model}

In 1986, Tim Bollerslev introduced the GARCH model [45]. Considering a return series $r$, where $a_{t}=r_{t}-\mu_{t}, a_{t}$ follows a $\operatorname{GARCH}(m, s)$ model if:

$$
a_{t}=\sigma_{t} \epsilon_{t}, \quad \sigma_{t}^{2}=\alpha_{0}+\sum_{i=1}^{m} \alpha_{i} a_{t-i}^{2}+\sum_{j=1}^{s} \beta_{j} \sigma_{t-j}^{2},
$$

"where $\epsilon_{t}$ is a sequence of iid r.v. with mean 0 and variance $1, \alpha_{0}>0, \alpha_{i} \geq 0, \beta_{j} \geq 0$, and $\sum_{i=1}^{\max (m, s)}\left(\alpha_{i}+\beta_{i}\right)<1 \ldots$ The constraint on $\alpha_{i}+\beta_{i}$ implies that the unconditional variance of $a_{t}$ is finite, whereas its conditional variance $\sigma_{t}^{2}$ evolves over time [36]."

GARCH models have been used extensively for the modeling of volatility in financial returns. There are many GARCH models in use; as Bollerslev remarked:

Rob Engle's seminal Nobel Prize winning 1982 Econometrica article on the AutoRegressive Conditional Heteroskedastic (ARCH) class of models spurred a virtual "arms race" into the development of new and better procedures for modeling and forecasting time-varying financial market volatility [42].

Multivariate GARCH models provide an avenue to consider the effect, or spillover, that different assets have on one another. In 1990, Bollerslev introduced the Constant Conditional Correlation (CCC) GARCH model [47]. In the CCC-GARCH model, the multivariate conditional covariance matrix is time invariant and can be expressed as:

$$
H_{t}=D_{t} P D_{t},
$$

"where $D_{t}=\operatorname{diag}\left(h_{1}^{\frac{1}{2}}, \ldots, h_{N t}^{\frac{1}{2}}\right)$ and $\boldsymbol{P}=\left[\rho_{i j}\right]$ is positive definite with $\rho_{i i}=1, i=1, \ldots, N[47]$ ".

Furthermore, we can define the off-diagonal elements of the conditional covariance matrix as: 


$$
\left[\mathbf{H}_{t}\right]_{i j}=h_{i t}^{\frac{1}{2}} h_{j t}^{\frac{1}{2}} \rho_{i j}, \quad i \neq j,
$$

where $1 \leq i, j \leq N$ [47]. This model is discussed further in [47].

Using the conditional covariance matrix above, we then model the variance of the returns as a univariate $\operatorname{GARCH}(\mathrm{q}, \mathrm{p})$ model of the form:

$$
h_{t}=\omega+\sum_{j=1}^{q} A_{j} r_{t-i}^{(2)}+\sum_{j=1}^{p} B_{j} h_{t-j}
$$

"where $\omega$ is a $N \times 1$ vector, $A_{j}$ and $B_{j}$ are diagonal $N \times N$ matrices, and $r_{t}^{(2)}=r_{t} \odot r_{t}$." This model is discussed further in [47].

In 2002, Engle developed an extension to the CCC model and introduced the Dynamic Conditional Correlations (DCC) GARCH Model [42, 49]. Engle states in [49] that the only difference between the DCC and CCC model is in the conditional correlation matrix ( $P$ above). In the DCC model, $P$ is time varying. The utility of the DCC-GARCH model in examining LETF volatility will be examined in greater detail in section 4 .

\subsection{Leveraged Exchange Traded Funds: Not Always as Advertised}

The literature regarding LETFs has grown substantially in the last several years. Much of the extant literature examines the ability of a LETF to accurately track a given index at its prescribed multiple. In $[1,3,8,9,24,25,26,27,28,29$, $30,31,32,33]$ the feasibility for a given LETF to attain its multiple on different time steps is analyzed with many methods and varying verdicts. In [1], Trainor and Baryla, using Monte Carlo simulation, demonstrate that the expected return on a 2X LETF only actually returns $1.4 \mathrm{X}$ the index. Additionally, LETFs carry an increased risk due to their leveraged position. As made clear in [1] and [8], the 
expected volatility for a given LETF is $x \sigma$, where $x$ is how levered the ETF is and $\sigma$ is the volatility of the LETF's respective index. Lu et. al discuss the ability of a LETF to deviate substantially from its respective index, especially over periods greater than one month in [33]. During periods of high market volatility, there are examples of extreme deviations from benchmarks over short time periods [27, 30, 31]. The prospectus for any given LETF, however, makes the leverage goal clear at the fund's inception (i.e.: daily or monthly) and LETFs usually meet their target multiple [33]; LETFs are highly sought after by many individual investors [5] and the Securities and Exchange Commission (SEC) felt the need to issue an alert in an attempt to educate uninformed investors about common misconceptions in the LEFT market [25].

Cheng and Madhavan [8] explain how a LETF changes its exposure and rebalances over a given interval to follow through on its advertised multiple. All LETFs, including inverse ETFs, always rebalance in the same direction of the market. In other words, if we consider a time interval $t_{n}$ to $t_{n+1}$ and a fund with a NAV of $V$, the amount of exposure that the given fund needs to have rebalanced can be expressed as:

$$
\begin{gathered}
\Delta t_{n+1}=V t_{n}\left(x^{2}-x\right) r_{n, n+1} \\
\text { Where: } \\
x: \text { multiple by which the ETF is levered } \\
r: \text { return on the respective index from } n \text { to } n+1 \\
V: \text { NAV of the ETF } \\
t: \text { time }
\end{gathered}
$$


In [9], Bai et al. also uses the above formula, referring to $\Delta t_{n+1}$ as the index rebalancing demand (IRB). It can be observed from the above formula that the greater the leverage of the ETF, the greater the IRB.

\subsection{Arguments Against the Link Between LETFs and Exacerbated Volatility}

Trainor opens [2] with a quote from Franklin Edward, reminding us that whenever the market experiences a turbulent period, the tendency is to blame whatever is new. Indeed, whenever the utilization of a new investment medium and high volatility have occurred simultaneously, there has been a tendency to investigate the former as the culprit [18]. Over twenty years ago, when futures trading was relatively new, it was hypothesized that they were the cause for the high volatility. When the market experienced a time of high volatility in the late 1980's, Schwert [19] and Edwards [17] sought to debunk the perception that futures trading was culpable for the uptick in volatility.

Trainor continues by reminding the reader that when the financial market crisis occurred in 2008, LETFs were another obvious scapegoat. However, he sheds light on two reasons why LETFs were not the cause of the highly volatile period: first, the growth of LETFs has continued while the volatility of the market has decreased substantially and second, the high volatility that accompanied the crisis should have been expected based on historical evidence. Trainor concludes by decisively stating that his "study has not found evidence that volatility has systematically increased due to the rebalancing issue associated with leveraged 
ETFs." Additionally, in 2011, Credit Suisse released a report [20] claiming that LETFs were not capable of causing such drastic changes in volatility due to the fact that they comprise less than $2 \%$ of the day's trading.

\subsection{LETFs and their Link with Exacerbated Volatility}

As the number of LETFs has continued to grow, especially in the last few years, there has been a growing interest in the effect that daily rebalancing has on the end of day market volatility. We can see in $[3,9,21,22,23,27,28,29,30,31]$ that there is a growing belief that the rebalancing of LETFs does in fact alter the state of the market. Cheng and Madhavan argue in [8] while LETFs do not compose a major share of the entire market, the volume of trades executed by these funds at the end of the day is clearly capable of accelerating volatility in the market. In [9], Bai et al. candidly states that they "find that late day LETF rebalancing activity significantly moves the price of component stocks [and] increases their volatility." Bai et al. specifically examines the impact that LETFs have on smaller indexes (in this case, the REIT exchange). Part of the foundation for Trainor's argument was the fact that even in an already volatile and respectively smaller arena, LETFs composed such a small amount of the overall trading volume that they could not cause major changes to the index's volatility. In [9], Bai et al. also argue that the magnitude of trading at the close of the day does in fact cause a notable increase in market volatility. Leung and Sircar demonstrate how the intrinsic volatilities of LETFs eventually lead to a significant if not complete attrition of fund value for a given investor in [3]. 
Corbet, in [22], provides interesting empirical evidence using GARCH and EGARCH analysis showing the effects of LETFs on market volatility; the model used in [22] demonstrates that LETFs cause an increase in volatility in commodities markets. The increase in end of day trades is specifically addressed in [29]: in 2006, $20.7 \%$ of stock trading volume in the S\&P 500 occurred in the last hour (the year LETFs were first available); by November 2008, the volume of trades in the last hour had increased to $26.2 \%$.

\section{Problem and Objectives}

\subsection{Problem Background}

Substantial work has been conducted examining the relationship between LETFs and market volatility. The vast majority of these studies have utilized various regression models and explored the manner in which LETFs have been the causal factor in volatility spikes. With the inception of ETPs occurring just over twenty years ago and the birth of LETFs in only 2006, these vehicles have been labeled as only levered "bullish" (1X, $2 \mathrm{X}$, or $3 \mathrm{X})$ or "bearish" $(-1 \mathrm{X},-2 \mathrm{X},-3 \mathrm{X})$ funds. Yet, we have already observed that within the LETF structure, the manner in which they obtain their leverage and the periodicity during which they rebalance can have great implications on their performance and their respective index. 


\subsection{Problem Statement \& Objectives}

In order to further our grasp of LETF structure and behavior, I intend to examine the relationship between LETF behavior and volatility spikes in market indexes. I will analyze the correlation between periods of high variability across indexes and related/unrelated LETFs. The behavior of returns will be considered on different time steps (ranging from minute by minute, daily, weekly, and monthly) in order to identify an either correlative or causal relationship between volatile behaviors in an index as well as in specific LETFs. The goal is to identify index wide disturbances; we will not be considering the possible volatility demonstrated by LETF constituent assets. While many of these investment tools will exhibit behavior similar to their respective index by design, we will also be examining whether or not variability is amplified due to their existence. We will initially inspect trends over different time intervals by creating several stationary covariance matrices of the form:

$$
\rho_{x y}=\frac{\sum_{i=1}^{n}\left(x_{i}-\bar{x}\right)\left(y_{i}-\bar{y}\right)}{\sqrt{\sum_{i=1}^{n}\left(x_{i}-\bar{x}\right)^{2}\left(y_{i}-\bar{y}\right)^{2}}}
$$

From the given observations, we will the more closely examine the indexes and LETFs that exhibit a relationship.

\section{Data}

\subsection{LETF Data}

I will be utilizing minute-by-minute data for forty-five different ETFs and LETFs between August 2013 and February 2014. The assets will be grouped into 
different categories; they will be broken down by index into five different categories (S\&P 500, Dow Jones Industrial Average, Commodities, MSCI EAFE, MSCI EAFE Emerging Markets) and into different time intervals. After analysis is conducted on standardized return volatility, the volume of trades will also be inspected (again, available at minute-by-minute intervals).

\subsection{Data Analysis}

\subsubsection{Correlation Considerations}

The first index considered is the S\&P 500; SPY will represent the returns of the S\&P 500, SDS is an LETF that seeks to return -2X of the S\&P 500, SSO is an LETF that seeks to return $2 \mathrm{X}$ of the S\&P 500, and MDY is a $1 \mathrm{X}$ ETF seeking to emulate the S\&P 500 MidCap 400.

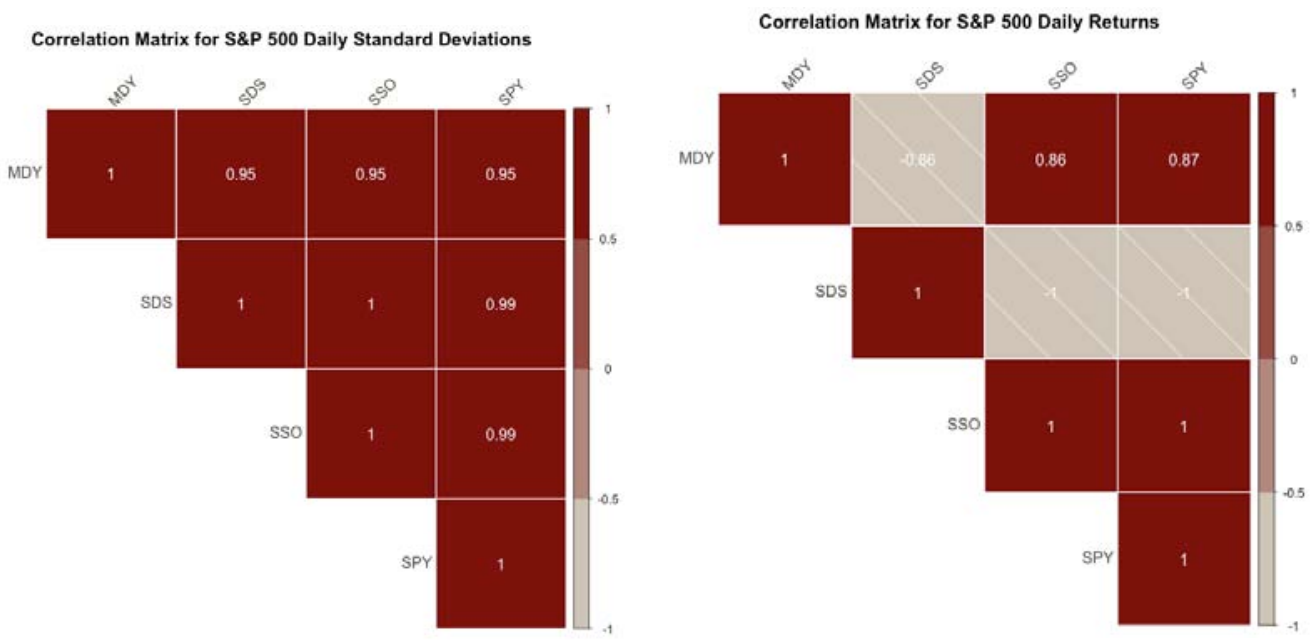


Correlation Matrix for S\&P 500 Hourly Standard Deviations

Correlation Matrix for S\&P 500 Hourly Returns
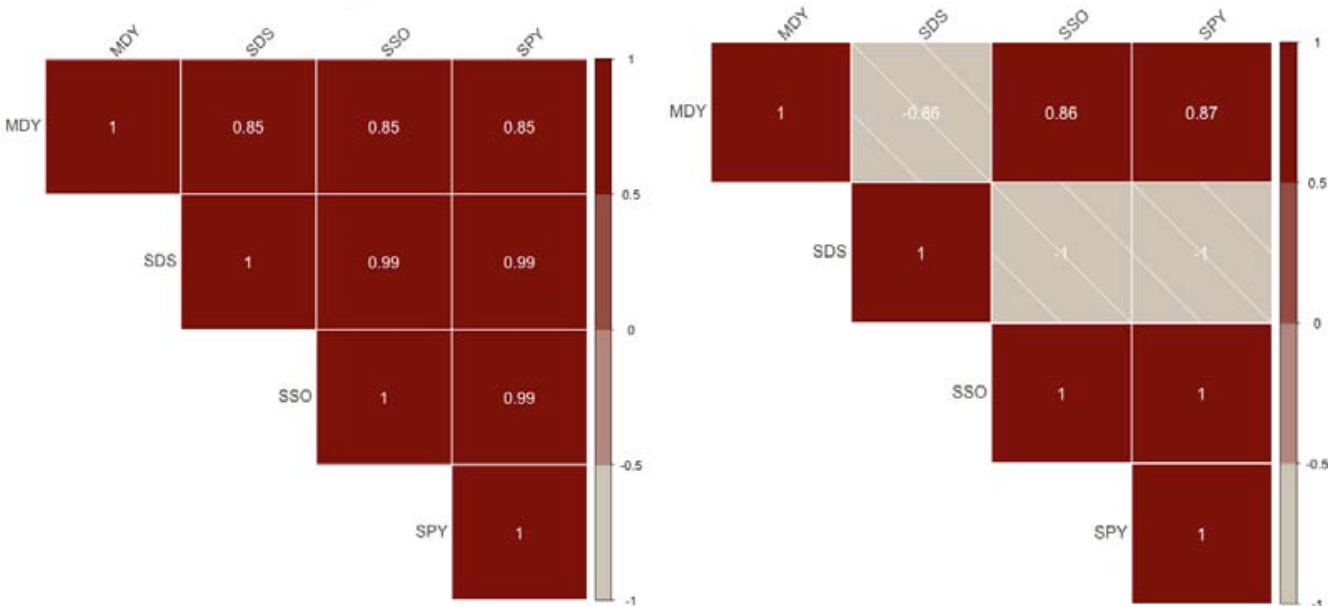

The remaining correlation matrices for the other indexes can be found in Appendix I.
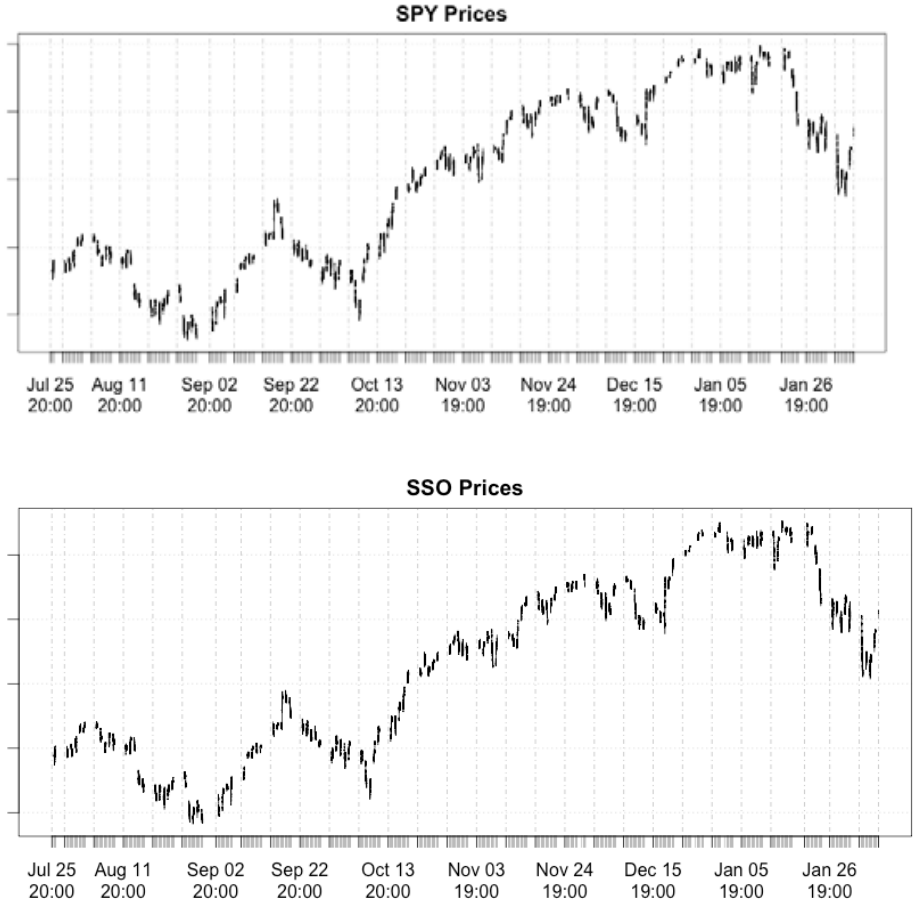

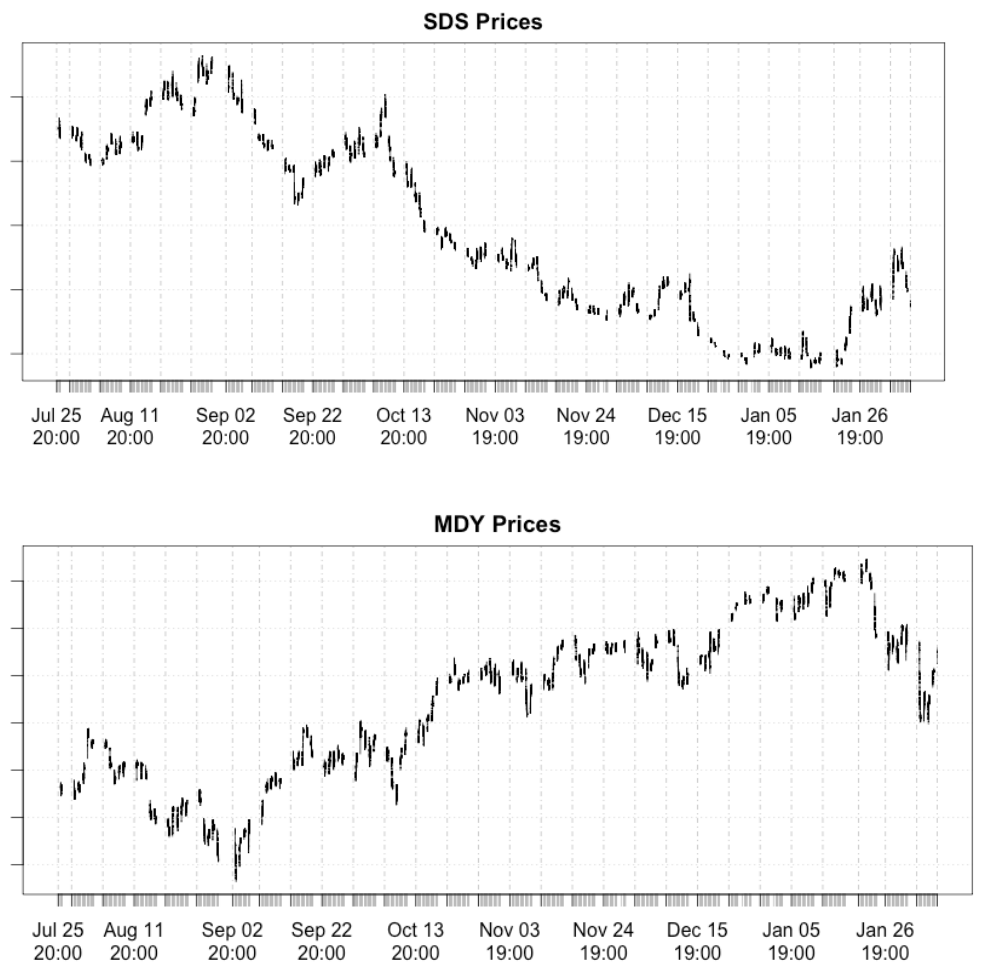

From the graphs above, it is clear that the S\&P 500 exhibited the strongest correlations with SSO and SDS (which should occur by design). I then explored the correlations between the S\&P 500 and these LETFs (all graphs are based on hourly returns using minute-by-minute data).

7-day rolling correlations for SPY and SDS

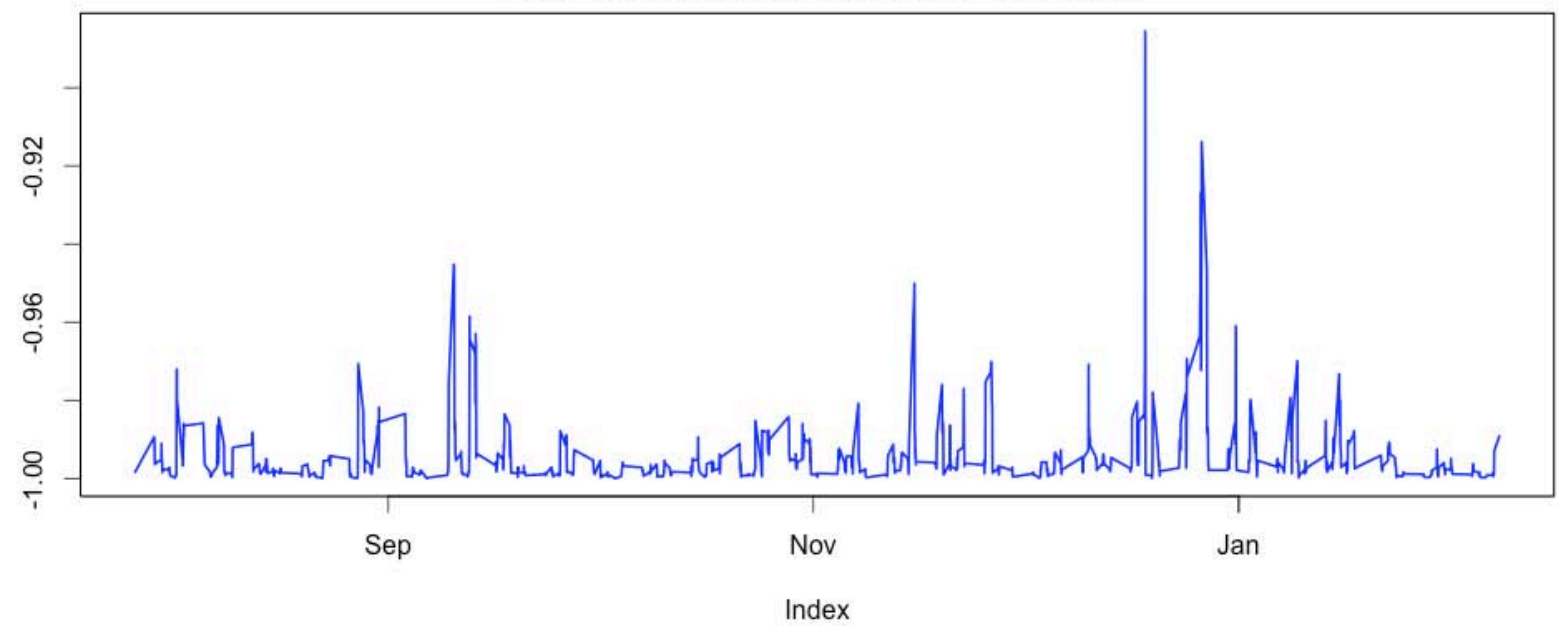


I first considered the exponentially weighted moving averages (EWMA) between the S\&P 500 and SSO. The EWMA model used has the following form:

$$
\sigma_{12, t}=(1-\lambda) r_{1, t-1} r_{2, t-1}+\lambda \sigma_{12, t}-1
$$

where $\sigma_{12, t}$ is the covariance between assets 1 and 2 at time $t, \lambda$ is the smoothing or decay factor, and $r$ is the returns of the respective asset [35].

For our model, it is clear that the two assets experience volatility shocks together from observing the graphs below; as the value of $\lambda$ increases, we can note the increased covariance between the two assets. If one asset reacted more strongly to the other's historical behavior, a decreased value of $\lambda$ would exhibit an increase in covariance between the two assets ( $\lambda$ is always between 0 and 1 ) [35]. The initial value of $\lambda$ of .94 is used for considering EWMA Variance by RiskMetrics ${ }^{\mathrm{TM}}$ for estimating volatility and is persistently used in many volatility models [50]. The higher value of $\lambda$ used here, .99, demonstrates a persistent but not as reactive model [50].
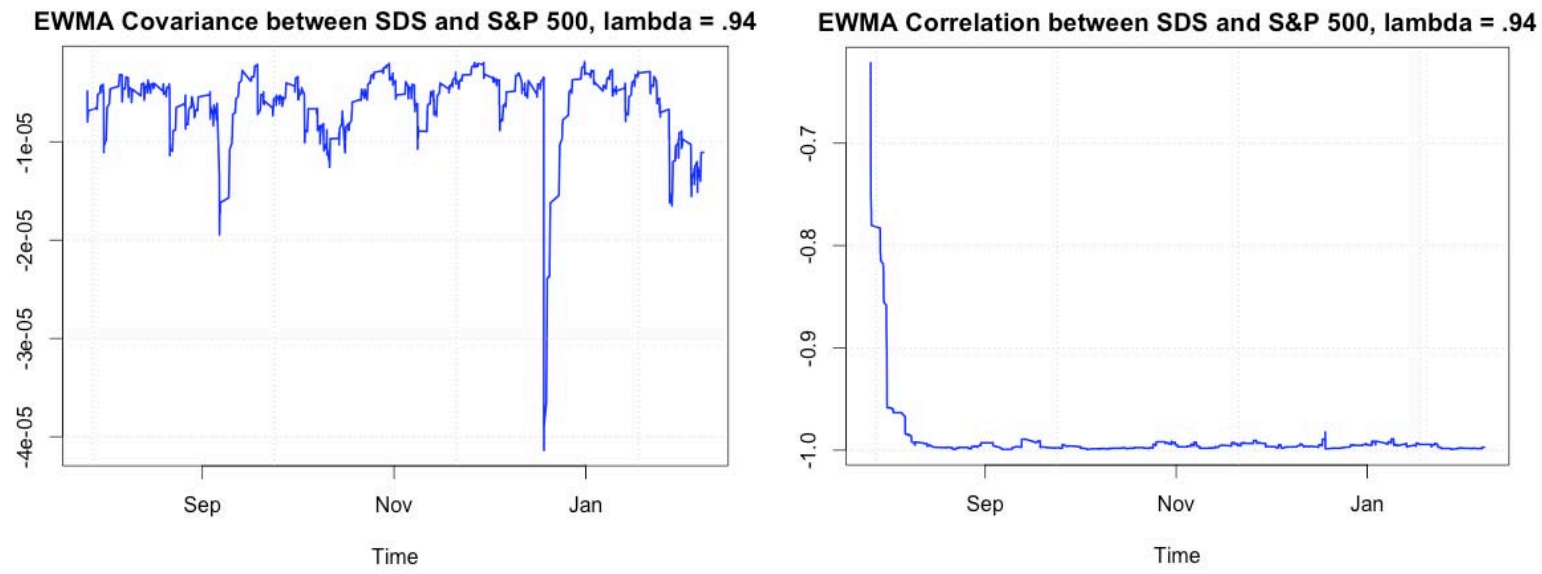

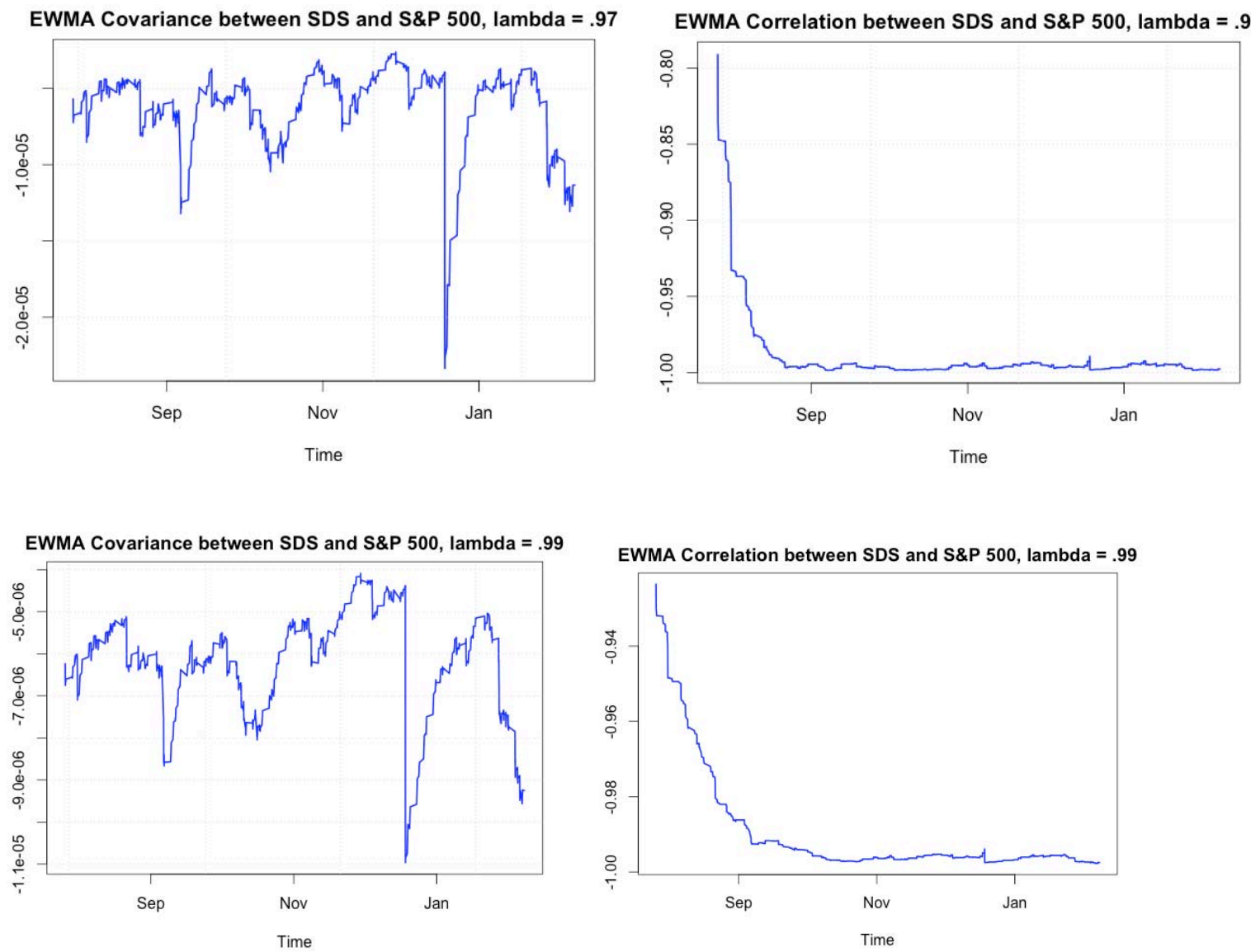

As aforementioned, all the graphs above use hourly returns to examine the relationships between SDS and the S\&P 500. The results are substantially different when examining the minute-by-minute returns of SDS and the S\&P 500:
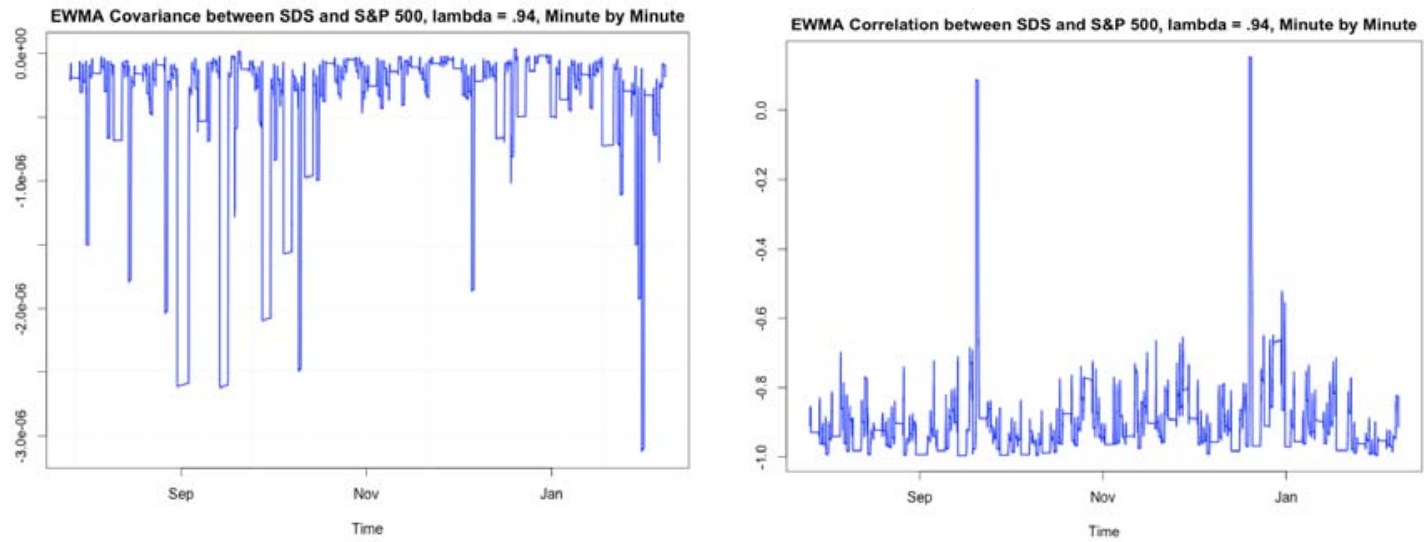

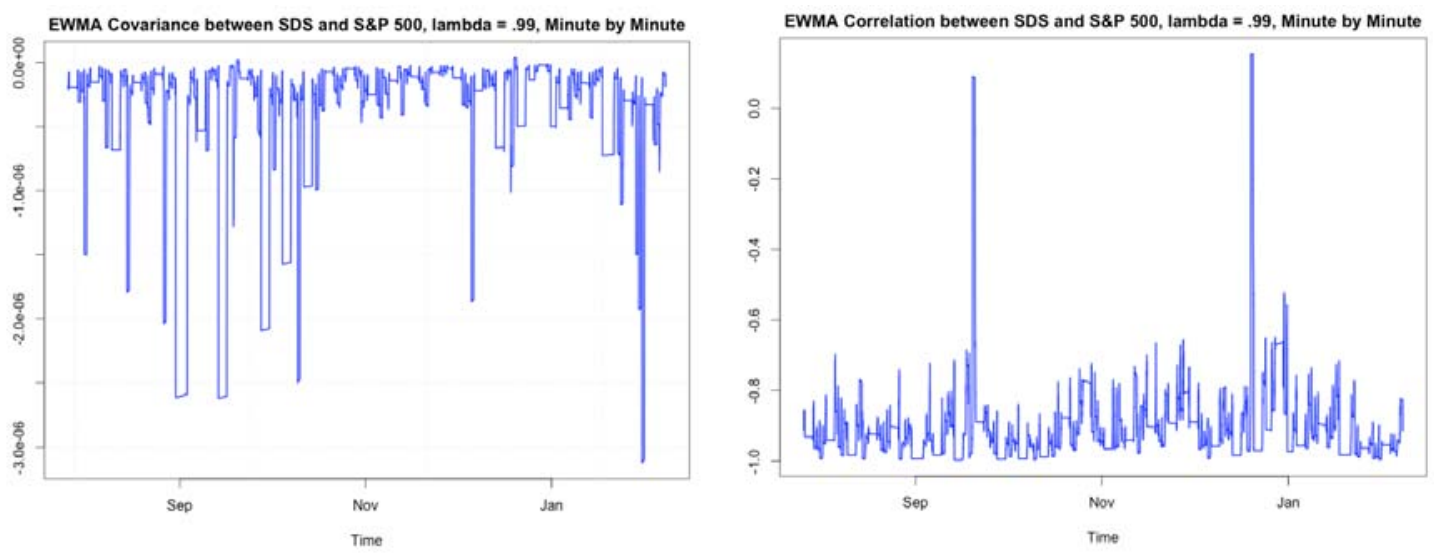

(The graphs demonstrating the EWMA relationships between the remaining LETFs and their respective indexes can be found in Appendix II.)

Examination of the correlation coefficient between the Dow Jones Inustrial Avergae (DJIA) (the ETF DIA was used) and its largest LETFs provided predictable results; the returns for both the $2 \mathrm{x}$ and $-2 \mathrm{x}$ LETFs were highly correlated with the performance of the DJIA. While the correlation between the volatility of the LETFs and the index was less correlated than the returns, it still strongly correlated.

Between different commodities ETFs and LETFs, the LETFs still closely tracked their baseline ETFs (for example, there was strong correlation between GDX, NYSE Arca Gold Minders Index ETF, and NUGT/DUST, 3X and -3X NYSE Arca Gold Minders Index LETFs, respectively). There was, however, apparent spillover between the performances of seemingly unrelated ETFs/LETFs. XLF (1X Financial Select Sector ETF) and ERF (-3X Energy Select Sector LETF) exhibited strong correlations between hourly volatilities/returns as well as daily volatilities/returns $\left(\rho_{\text {vol,daily }}=.75, \rho_{r, \text { daily }}=-.76, \rho_{\text {vol, hourly }}=.81, \rho_{r, \text { hourly }}=-.82\right)$. The MSCI Emerging markets ETFs and LETFs did not exhibit surprising trends, as the LETFs tracked their respective ETF with $\rho>.9$ for hourly and daily volatilities and returns. The MSCI EAFE LETFs and ETFs did provide some interesting results, however. The 
LETFs tracked their parent ETF closely with respect to returns (daily and hourly), however, the hourly and daily volatility for both LETFs considered (DPK and DZK) was less correlated to their parent ETF than any other LETF considered in this survey $\left(\rho_{D P K, \text { vol,daily }}=.76, \rho_{D P K, r, \text { daily }}=-.98, \rho_{D P K, \text { vol,hourly }}=.52, \rho_{D P K, r, \text { hourly }}=-.26\right.$;

$\left.\rho_{D Z K, \text { vol,daily }}=.86, \rho_{D Z K, r, \text { daily }}=.98, \rho_{D Z K, \text { vol,hourly }}=.63, \rho_{D Z K, r, \text { hourly }}=.86\right)$.

The EWMA models were then considered between LETFs and ETFs; the smoothing factor utilized in each study provided insight into the behavior of LETFs. Two values of $\lambda$ were used, .94 and .99. The higher smoothing factor value tracks how closely correlated instantaneous changes in volatility are felt between funds. The EWMA results concur with the linear correlation results and provide additional information; over a longer time interval, the volatilities of LETFs and their parent ETFs are closely correlated, however, if we consider the minute by minute returns of a given LETF and its respective ETF, it is impossible for the funds to immediately reflect the multiple they advertise. Additionally, the results show periods of extremely high divergence between LETFs and their respective ETFs; in every instance, this can be attributed to a more volatile interval experienced by the underlying index and the reactionary structure of a LETF.

\subsubsection{Dynamic Conditional Correlations (DCC) GARCH Considerations}

After exploring the linear and EWMA correlations between LETFs and their underlying indexes, we consider a DCC GARCH model to further examine the relationships regarding volatility. We first consider the underlying statistics 
regarding each ETF and LETF; the results confirm the assumption that returns are generally not normal. The results (on hourly and daily intervals, listed in Appendix III) for all indexes and LETFs show that the returns exhibit skewness and kurtosis that is either less or greater than a normal distribution.

The DCC GARCH model provided results in line with what we have already observed using the linear and EWMA correlation models, but provided additional details. As discussed in the literature review, we first built a GARCH model for the returns of each index/LETF, and with the results built a bivariate DCC GARCH model. The two coefficients estimated, $\alpha$ and $\beta$, detailed the manner in which the behavior of an index influenced its respective LETF or vice versa (results listed in Appendix IV). Additionally, the $p$ value for each coefficient is provided to make clear which are significant. We also only considered cases where we have already observed some level of correlation from the linear and EWMA relationships. In all examples, $\beta>\alpha$, signifying that the current behavior of volatility is influenced heavily by past variances [51]. Also, in all cases where $\beta$ is close to zero, there is a high persistence of volatility in the time series [51]. Lastly, the values of $\beta+\alpha$ is close to 1 in most cases, showing that the conditional variances between the indexes and ETFs are highly persistent [51]. The results from the DCC GARCH models indicate that the LETFs all exhibit trends that are predictable based on the behavior of their underlying index. 


\subsection{Analysis Summary}

The correlations between LETFs and their indexes were considered using linear correlation models, EWMA correlation models, and DCC GARCH models. The empirical results in each of these models do not show that there is any evidence of volatility spillover from LETFs to their respective indexes; we do however observe that volatility shocks felt in a given index are clearly demonstrated by LETFs attempting to track said index. Additionally, periods of high volatility observed in an index are experienced by LETFs at a magnitude often greater than their said multiple. LETFs with a large volume (the LETFs considered tracking the S\&P 500 and DJIA) were still unable to exacerbate the volatility of their given index; these findings are not surprising, however, due to the fact that the LETFs are still substantially smaller than the underlying indexes in regards to volume.

\section{Expected Research Contributions}

LETFs, in comparison to ETFs and mutual funds, are still in their infancy and are worthy of further consideration. An important topic for further research, and outside the scope of this survey, is the influence that LETFs have on their constituent stocks. While it is our belief that LETFs do not cause volatility shocks within their parent indexes, it is certainly possible (and probable) that the rebalancing that occurs at the end of each trading day increases the variance in the tools used to generate the necessary multiple for a respective LETF. If a certain asset is being shorted/held to generate a given multiple within a large LETF, a 
substantial change in the parent index (which would clearly influence the behavior of the LETF) could have a substantially exacerbated impact on a single stock.

Also, the rebalancing intervals studied here were all daily rebalancing methods. As the use of LETFs continue to grow, the manner in which alternative rebalancing intervals influence the returns/behaviors of a given LETF are another important aspect to consider.

\section{Conclusion}

We conducted a survey of LETF structure and considered the ways in which LETFs experience increased volatility due to their structure. Furthermore, we considered the possibility of increased volatility within index performance due to LETF rebalancing and behaviors. We began by considering why stock market volatility is worth studying and the different ways in which it can be measured. Subsequently, we considered the extant research regarding LETF structure and arguments for and against the capacity of LETFs to create market wide volatility. We then used the data for forty-five ETFs and LETFs to examine market volatility through linear correlation models, EWMA models, and DCC GARCH models. While LETFs experience higher volatilities than their underlying index, we did not observe any increased volatility within the underlying index as a result of LETF behaviors. However, as LETFs continue to grow and their structure evolve, the ability of LETFs to create an environment of increased variance should be periodically reassessed with various means in the future. 
Bibliography

[1] Trainor, Jr., William J.Baryla, Jr.,Edward A. "Leveraged ETFs: A Risky Double that Doesn't Multiply by Two." Journal of Financial Planning 21.5 (2008): 48. Web $<$ http://search.ebscohost.com/login.aspx?direct=true\&db=oih\&AN=31955073 \&site=ehost-live $>$.

[2] William Trainor, Jr. "Do Leveraged ETFs Increase Volatility?" Technology and Investment 1.3 (2010): 215-220.

[3] Leung, Tim and Ronnie Sircar. "Implied Volatility of Leveraged ETF Options." Diss. Princeton University, August 6, 2013.

[4] Grande, John J., Traudy F. Grande and John S. Grande. "Are Exchange Traded Funds the New Mutual Funds?" Ophthalmology Times (2013).

[5] Yu, Susana and Gwendolyn Webb. "The Effects of ETF Splits on Returns, Liquidity, and Individual Investors." Managerial Finance 35.9 (2009): 754 771.

[6] Harz, Jon. "The Current State of Exchange Traded Products." Journal Of Taxation \& Regulation Of Financial Institutions 25.4 (2012): 39-48.

[7] Li, Mingsheng, Dan Klein and Xin Zhao. "Empirical Analysis of ETF Intraday Trading." Financial Services Review 21.2 (2012): 149.

[8] Cheng, Minder and Ananth Madhavan. "The Dynamics of Leveraged and Inverse Exchange-Traded Funds." Journal Of Investment Management (JOIM) Fourth Quarter (2009).

[9] Bai, Qing, Shaun A. Bond and Brian C. Hatch . "The Impact of Leveraged and Inverse ETFs on Underlying Stock Returns." 46th Annual AREUEA Conference Paper (2012).

[10] Agapova and Anna. "Conventional Mutual Index Funds Versus Exchange Traded Funds." Journal of Financial Markets 14.2 (2011): 323-343.

[11] Bell, Peter N. Beta Estimates for Leveraged ETF Diss. : University of Munich, Germany, 2010.

[12] Svetina, M. "Exchange-Traded Funds: Performance and Competition." Journal of Applied Finance 20.2 (2010): 130-145.

[13] Punj, Girish and David W. Stewart. "Cluster Analysis in Marketing Research: Review and Suggestions for Application." Journal of Marketing Research 20.2 (1983): 134-148. Web <http://www.jstor.org/stable/3151680>.

[14] Hansen, Pierre and Brigitte Jaumard. "Cluster Analysis and Mathematical Programming." Mathematical Programming 79.1-3 (1997): 191-215.

[15] Peters, Georg. "Rough Clustering and Regression Analysis." Ed. Yao, JingTao, et al. Rough Sets and Knowledge Technology.: Springer Berlin Heidelberg, 2007.

[16] Krause, Timothy and Yiuman Tse. "Volatility and Return Spillovers in Canadian and U.S. Industry ETFs." International Review of Economics \& Finance Elsevier.25 (2013): 244-259. 
[17] Edwards, Franklin R. "Does Futures Trading Increase Stock Market Volatility?" Financial Analysts Journal 44.1 (1988): 63-69. Web $<$ http://www.jstor.org/stable/4479091>.

[18] Schwert, G. William. "Why does Stock Market Volatility Change Over Time?" The Journal of Finance 44.5 (1989): 1115-1153. Web $<$ http://www.jstor.org/stable/2328636>.

[19] Schwert, G. William. "Stock Market Volatility." Financial Analysts Journal 46.3 (1990): 23-34. Web <http://www.jstor.org/stable/4479327>.

[20] Mackintosh, Phil and Victor Lin. ETF Trade Strategy. North America: Credit Suisse, 2011.

[21] Holzhauer, Hunter Matthew, et al. "Bad News Bears: Effects of Expected Market Volatility on Daily Tracking Error of Leveraged Bull and Bear ETFs." Managerial Finance 39.12 (2013): 1169-1187.

[22] Corbet, Shaen. Quantifying the Effects of New Derivative Introduction on Exchange Volatility, Efficiency and Liquidity. Diss. : National University of Ireland Maynooth, 2012.

[23] Jeanneau, Serge and Marian Micu. "Volatility and Derivatives Turnover: A Tenuous Relationship." BIS Quarterly Review, March 2003 (March 2003): 5766.

[24] Hill, J. and G. Foster. "Understanding Returns of Leveraged and Inverse Funds, J. Indexes." Journal of Indexes (2009).

[25] Jarrow, R. A. "Understanding the Risk of Leveraged ETFs." Finance Research Letters 7 (2010): 135-139.

[26] Giese, Guido. "On the Risk-Return Profile of Leveraged and Inverse ETFs." Journal of Asset Management Vol. 11, 4, 11.4 (2010): 219-228.

[27] Charupat, Narat and Peter Miu. "The Pricing and Performance of Leveraged Exchange-Traded Funds." Journal of Banking \& Finance 35 (2011): 966-977.

[28] Haugh, Martin B. "A Note on Constant Proportion Trading Strategies." Operations Research Letters 39.3 (2011).

[29] Lauricella, Tom, Susan Pulliam and Diya Gullapalli. "Are ETFs Driving Late-Day Turns?" The Wallstreet Journal. 12/15/2008 2008.

[30] Trainor Jr., William. "Daily Vs. Monthly Rebalanced Leveraged Funds." Journal of Finance and Accountancy.

[31] Zweig, Jason. "How Managing Risk with ETFs can Backfire." The Wallstreet Journal. 2/28/2009 2009.

[32] Charupat, Narat and Peter Miu. "Recent Developments in Exchange-Traded Fund Literature." Managerial Finance 39.5 (2013): 427-443.

[33] Lu, Lei, Jun Wang and Ge Zhang. "Long Term Performance of Leveraged ETFs." Financial Services Review (2012): 63-80.

[34] Little, Patricia Knain. "Inverse and Leveraged ETFs: Not Your Father's ETF." The Journal of Index Investing 1.1 (2010): 83-89.

[35] Officer, R.R. "The Variability of the Market Factor of the New York Stock Exchange." The Journal of Business, Vol. 46, No. 3 (July 1973), 434-453. 
[36] Tsay, R. (2005). Analysis of Financial Time Series. Hoboken: John Wiley \& Sons, Inc..

[37] Engle, Robert F., Focardi, Sergio M., Fzabozzi, Frank J., "ARCH/GARCH Models in Applied Financial Econometrics.” (November 2007). Working Paper.

[38] Engle, Robert F., "GARCH 101: The Use of ARCH/GARCH Models in Applied Econometrics." The Journal of Economic Perspectives 15.4 (2001). 157-168.

[39] Wurtz, Diethelm, Chalabi, Yohan, Luksan, Ladislav. "Parameter Estimation of ARMA Models with GARCH/APARCH Errors: An R and SPlus Software Implementation." Working Paper.

[40] Fabozzi, F. J. (2007). Robust portfolio optimization and management. Hoboken, N.J.: John Wiley.

[41] Hudson, Robert and Gregoriou, Andros, "Calculating and Comparing Security Returns is Harder than you Think: A Comparison between Logarithmic and Simple Returns." (February 7, 2010).

(SSRN:http://ssrn.com/abstract=1549328 or http://dx.doi.org/10.2139/ssrn.154 9328)

[42] Bollerslev, Tim. "Glossry to ARCH (GARCH)." Volatility and Time Series Econometrics: Essays in Honour of Robert F. Engle. (February 2009).

[43] Engle, Robert F. "Autoregressive Conditional Heteroscedasticity with Estimates of the Variance of United Kingdom Inflation." Econometrica, Vol. 50, No. 4 (Jul., 1982), 987-1007.

[44] Whittle, Peter. "The Analysis of Multiple Stationary Time Series." The Journal of the Royal Statistical Society. Series B. 15.1 (1953). 125-139.

[45] Bollerslev, Tim. "Generalized Autoregressive Conditional Heteroscedasticity." Journal of Economics 31. (1986). 307-327.

[46] Tsay, R. S. (2013). An Introduction To Analysis Of Financial Data With R. Hoboken, N.J.: Wiley.

[47] Silvennoinen, Annastiina and Terasvirta, Timo. "Multivariate GARCH Models." Economics and Finance No. 669. (2007).

[48] Bauwens, Luc; Laurent, Sebastien; Rombouts, Jeroen V.K. "Multivariate GARCH Models: A Survey." Journal of Applied Econometrics. 21. (2006). 79-109.

[49] Engle, Robert F. "Dynamic Conditional Correlation: A Simple Class of Multivariate Generalized Autoregressive Conditional Heteroskedasticity Models.” Journal of Business \& Economic Statistics, Vol. 20, No. 3 (Jul., 2002), 339-350.

[50] Alexander, C. 2008. Moving Average Models for Volatility and Correlation, and Covariance Matrices. Handbook of Finance. III:5:62.

[51] Dajcman, Silvo and Festic, Mejra. "Interdependence Between the Slovenian and European Stock Markets: A DCC-GARCH Analysis." Economic Research Vol. 25.2 (2012), 379-396.

[52] Kittsley, Dodd and Raj Seshadri. ETP LANDSCAPE: Industry Highlights.: BlackRock, 2013. 
[53] Analyses conducted in $R$ and Excel with the following $R$ packages and code used: Alexios Ghalanos, RMGARCH: Multivariate GARCH Models. (2014).

[54] Zivot, Eric. R Examples for Lectures on Multivariate GARCH Models. (2014). http://faculty.washington.edu/ezivot/

[55] Stock prices retrieved via Bloomberg Terminal. July 26, 2013 - February 7, 2014, via Bloomberg LP.

[56] Profiles for ETFs and LETFs considered accessed via Yahoo! Finance, http://finance.yahoo.com 


\section{Appendix I}

DJIA Correlation Matrices
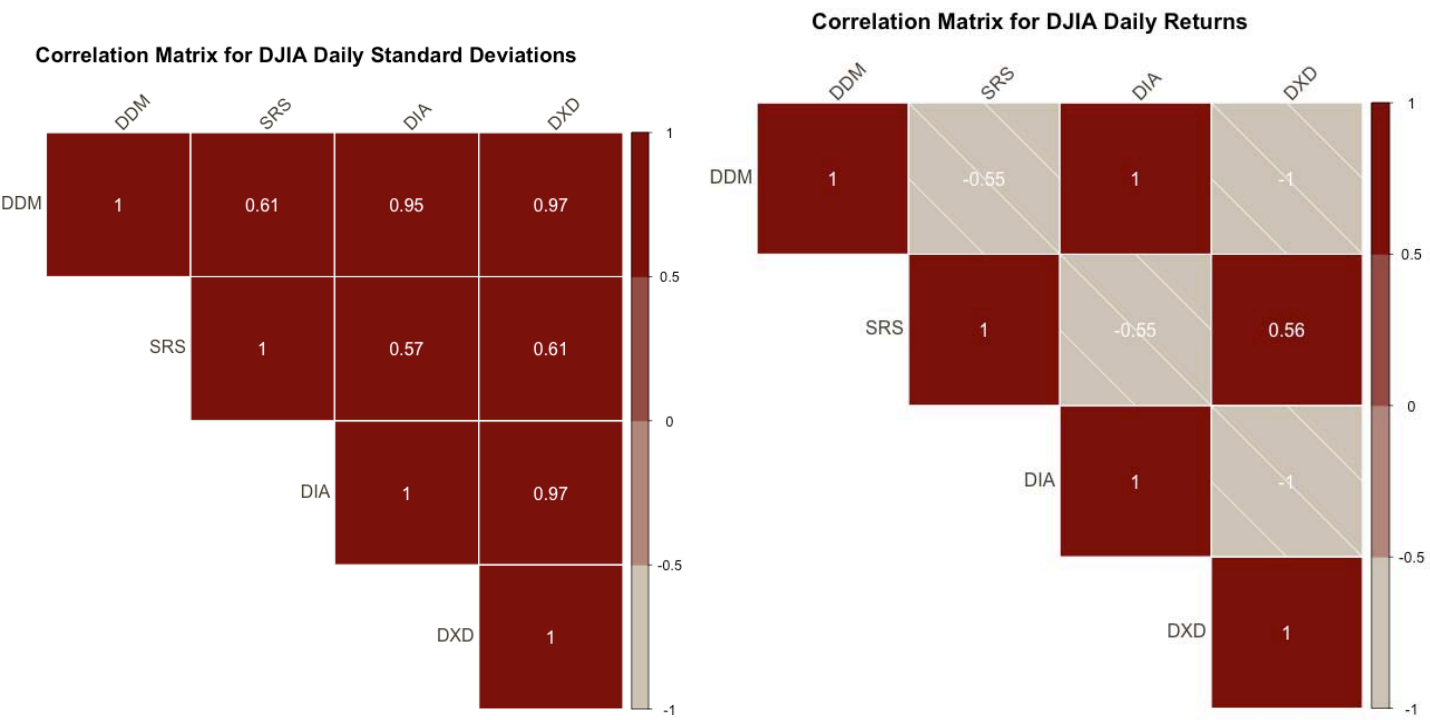

\section{Correlation Matrix for DJIA Hourly Standard Deviations}

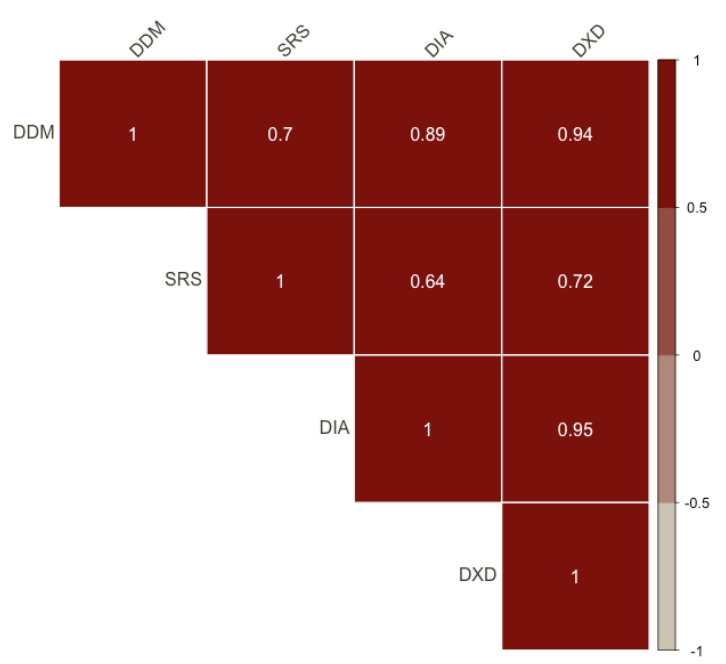

Correlation Matrix for DJIA Hourly Returns

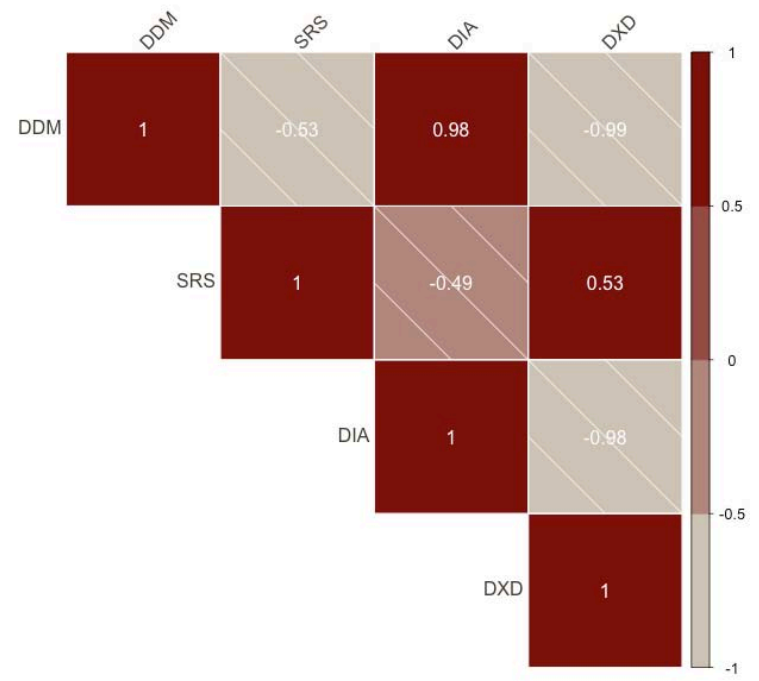

Commodities Market Correlation Matrices 

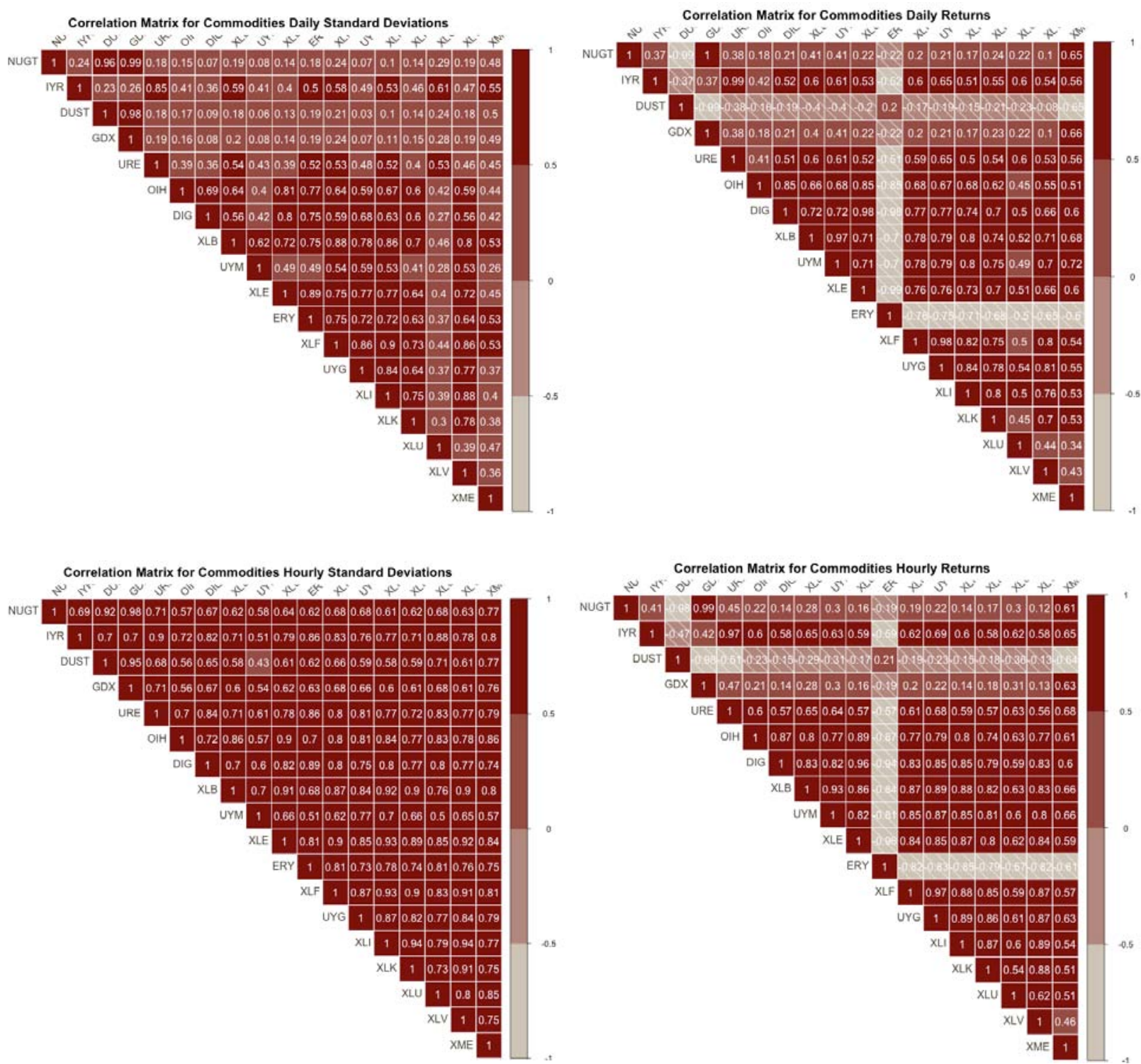


\section{MSCI EAFE Correlation Matrices}

Correlation Matrix for MSCI EAFE Standard Deviations, Hourly

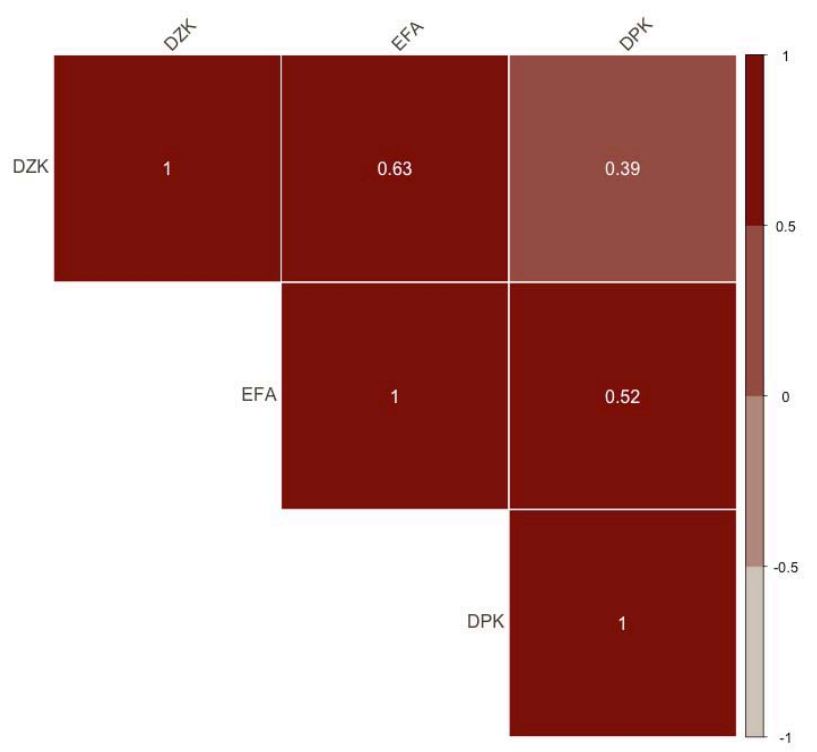

Correlation Matrix for MSCI EAFE Returns, Hourly

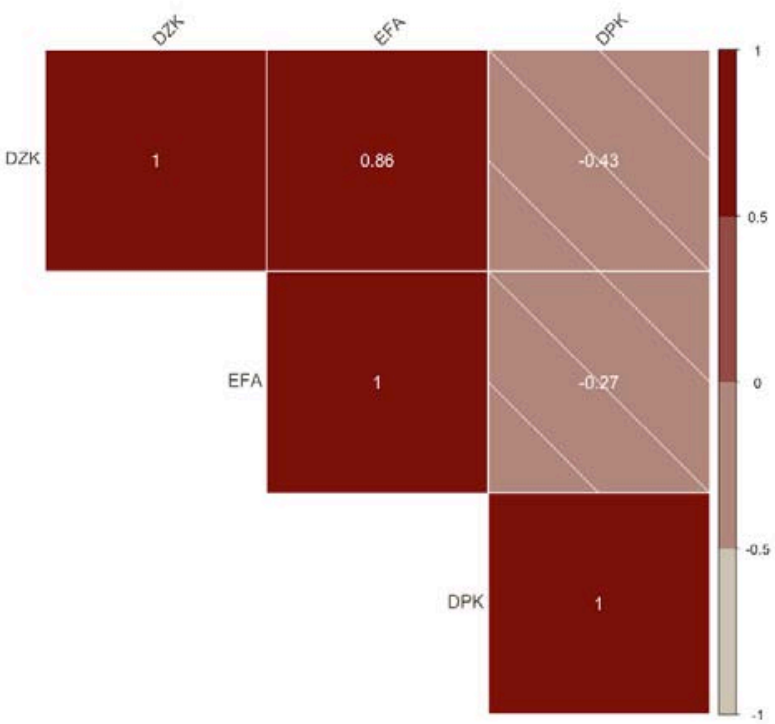

Correlation Matrix for MSCI EAFE Returns, Daily

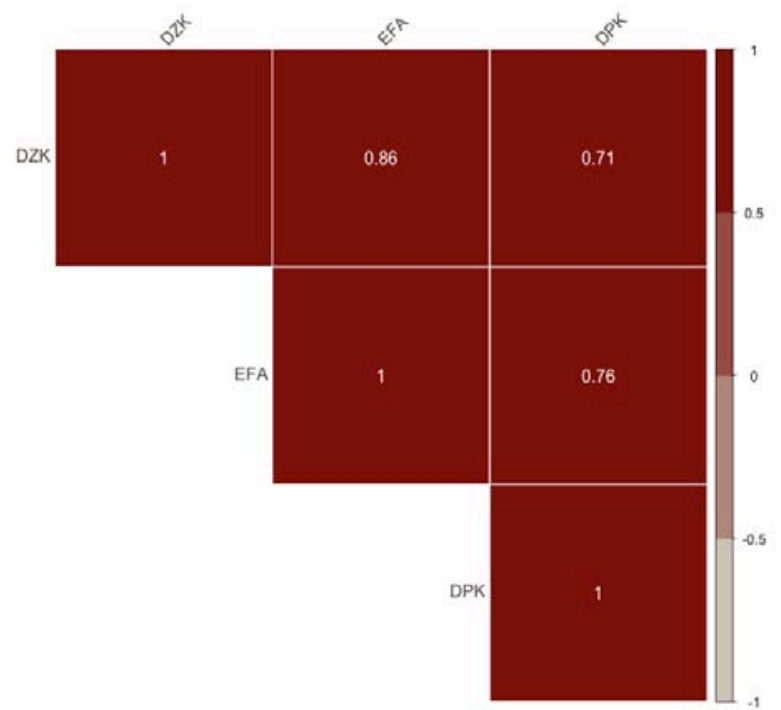

ot

$e^{2}$

$8^{+t}$
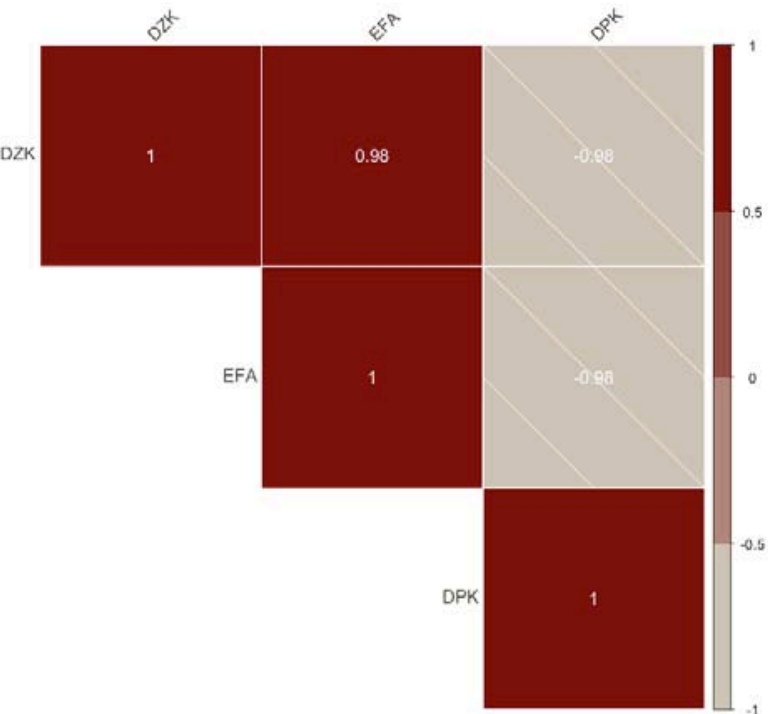


\section{MSCI Emerging Markets Correlation Matrices}

Correlation Matrix for MSCI Emerging Markets Standard Deviations, Hourly

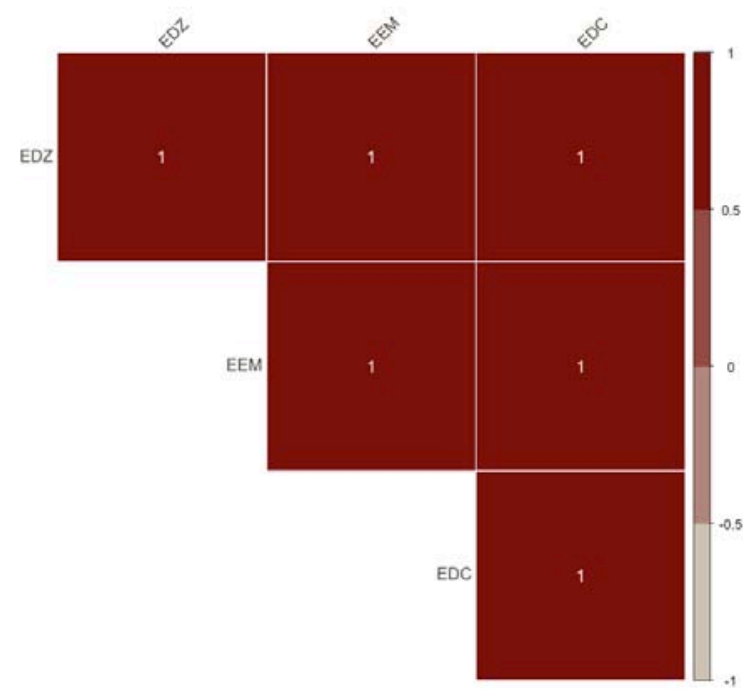

Correlation Matrix for MSCI Emerging Markets Returns, Hourly

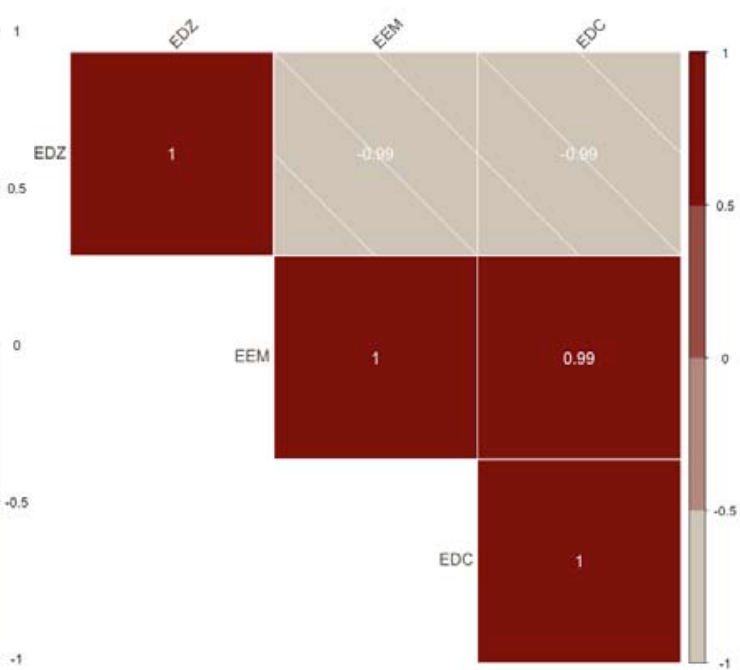

Correlation Matrix for MSCI Emerging Markets Standard Deviations, Daily

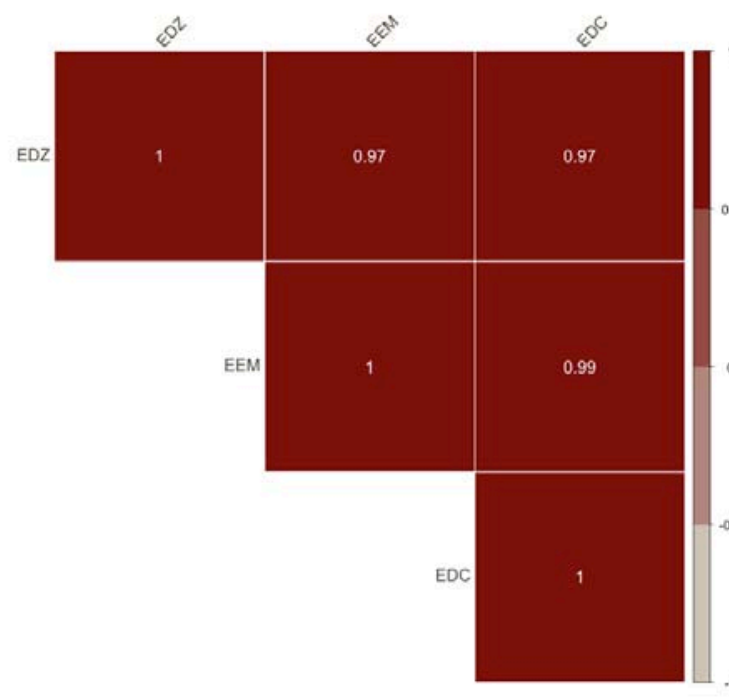

Correlation Matrix for MSCI Emerging Markets Returns, Daily

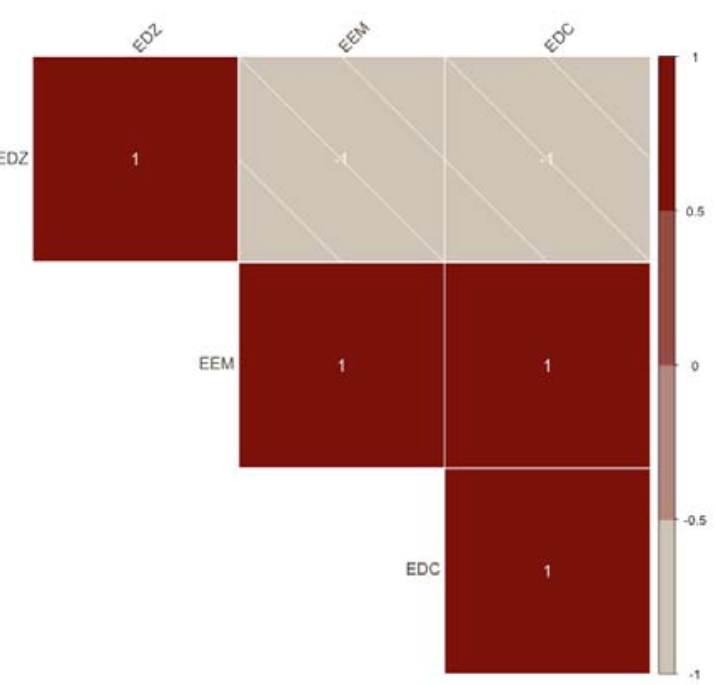




\section{Appendix II}

\section{S\&P 500/SSO}
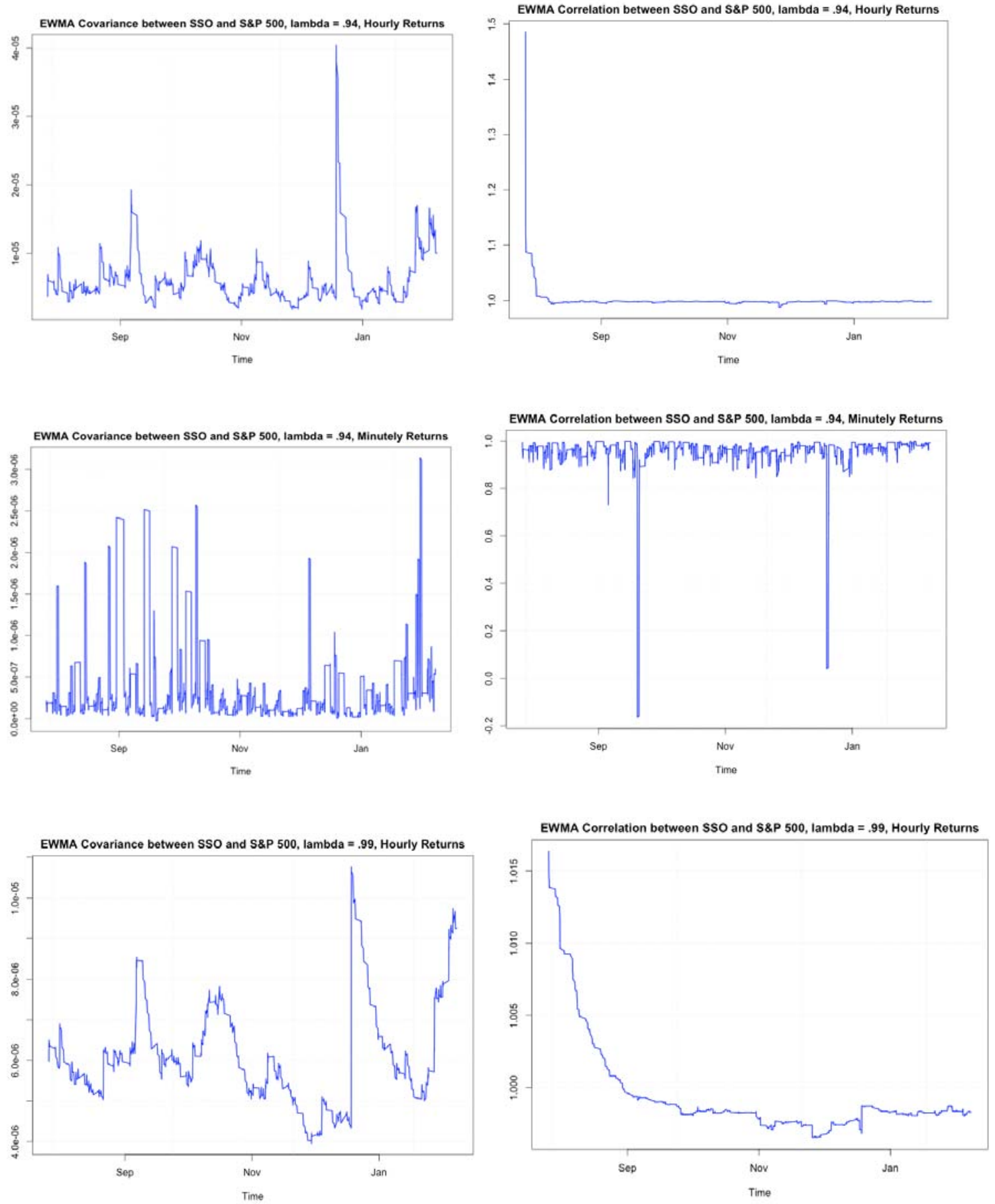

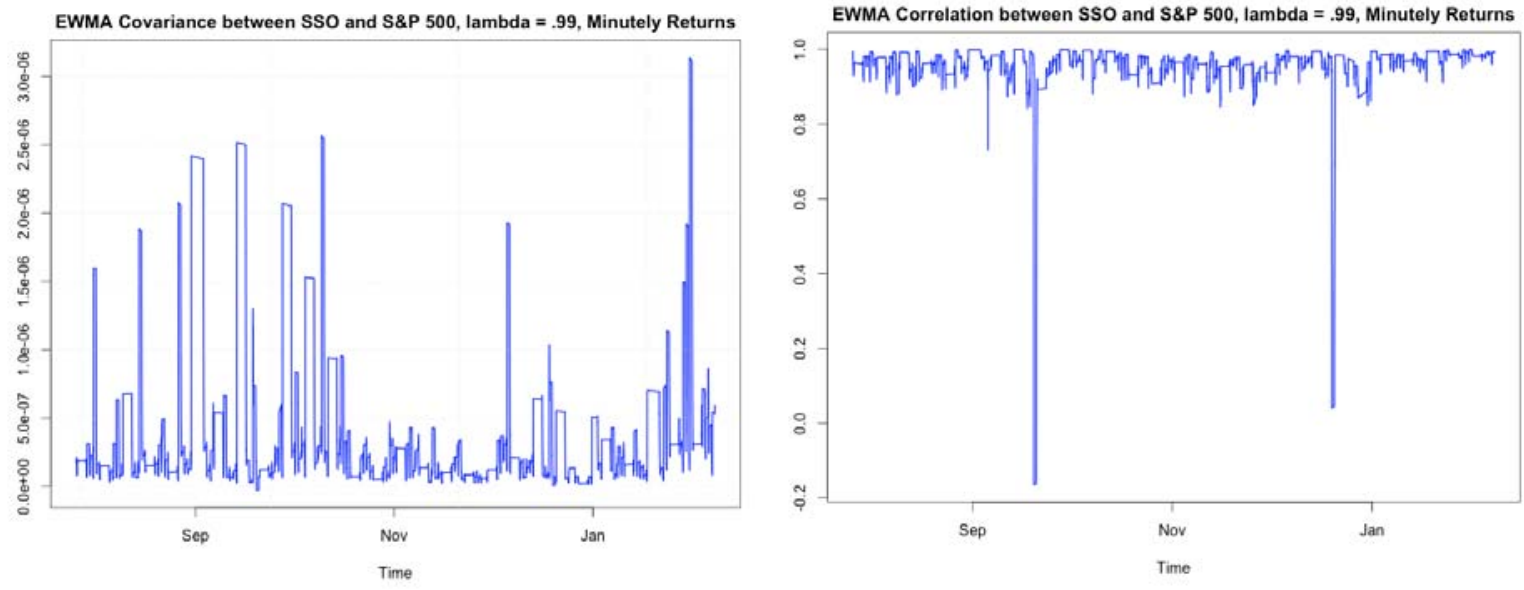

\section{S\&P 500/MDY}
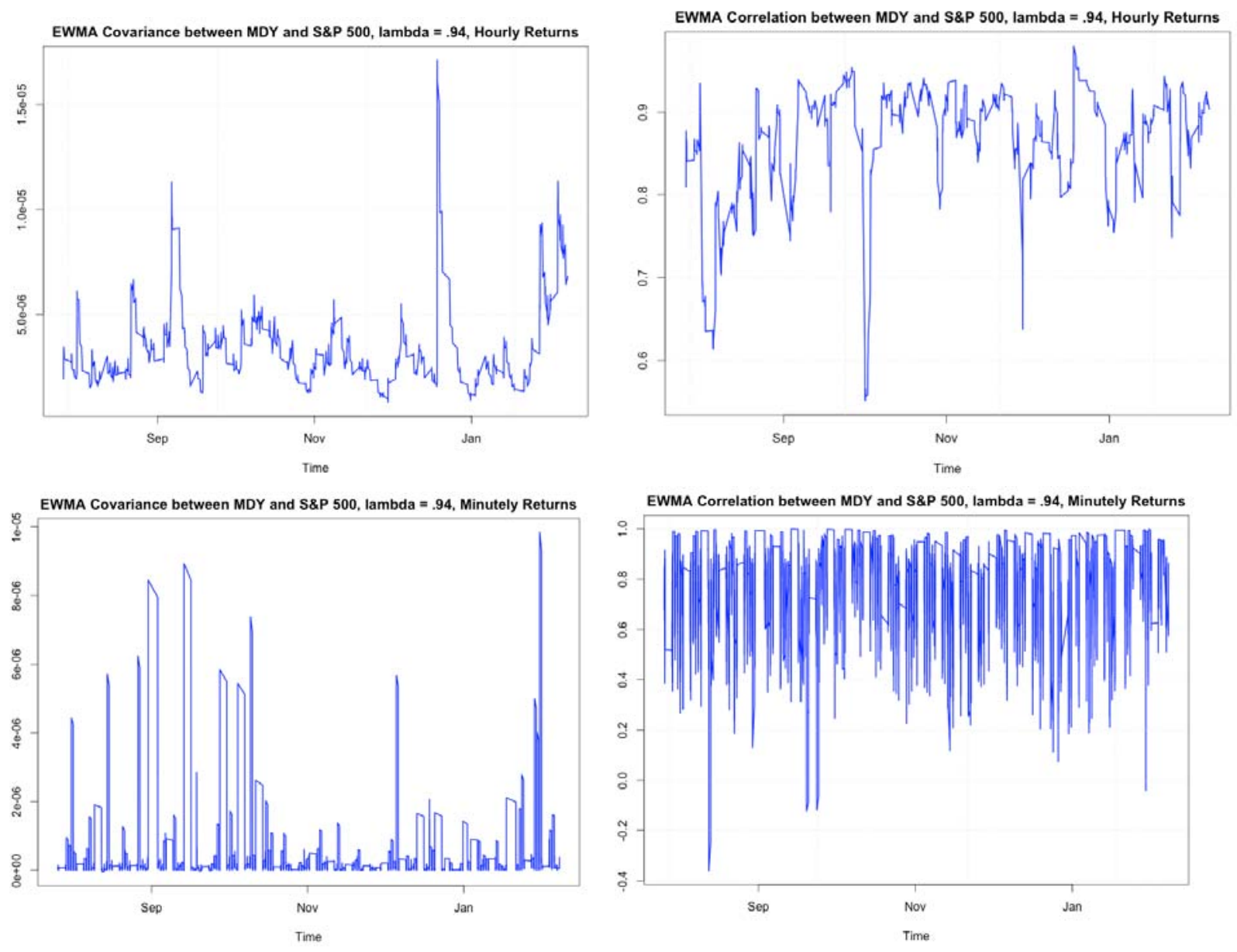

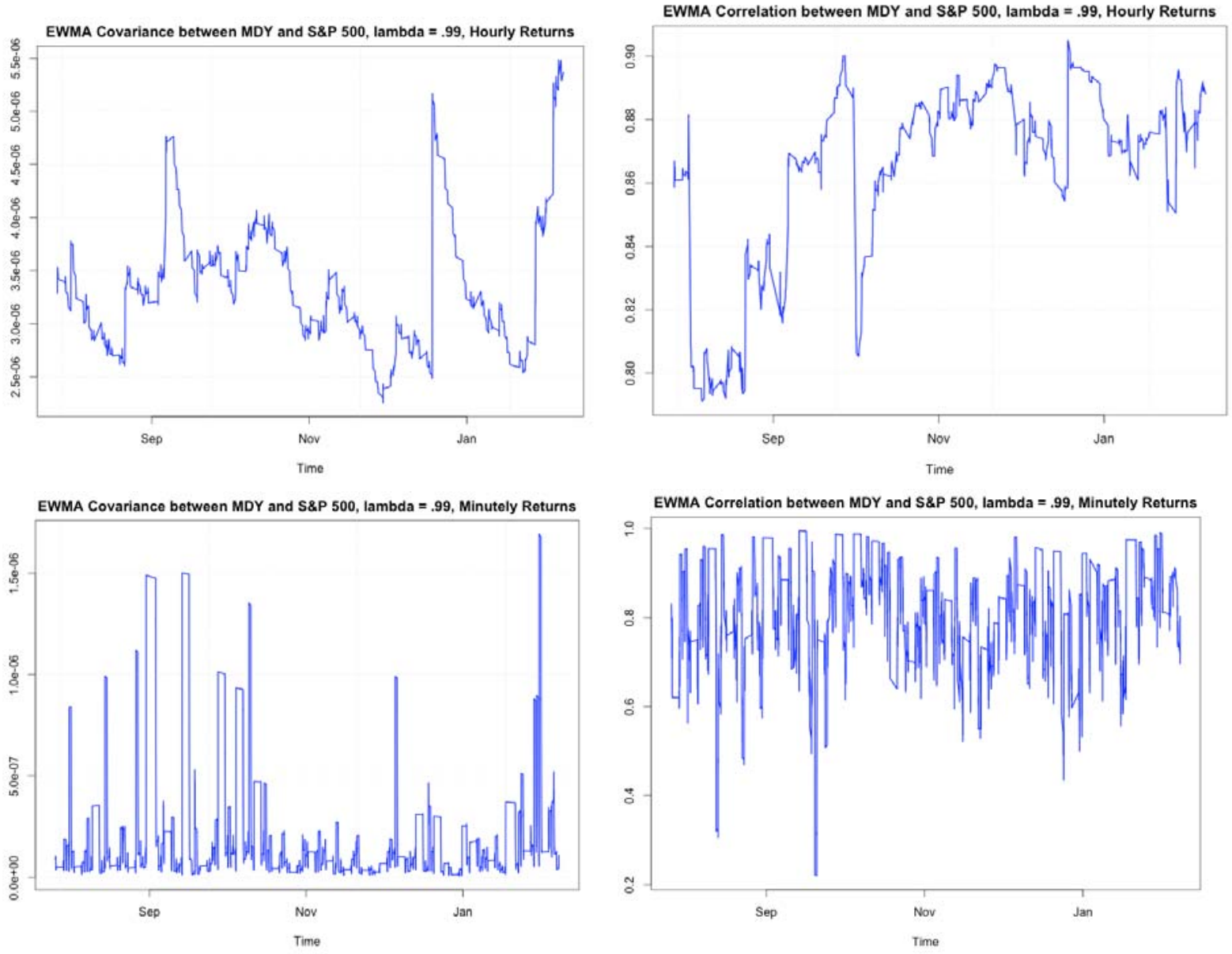


\section{DJIA/DDM}
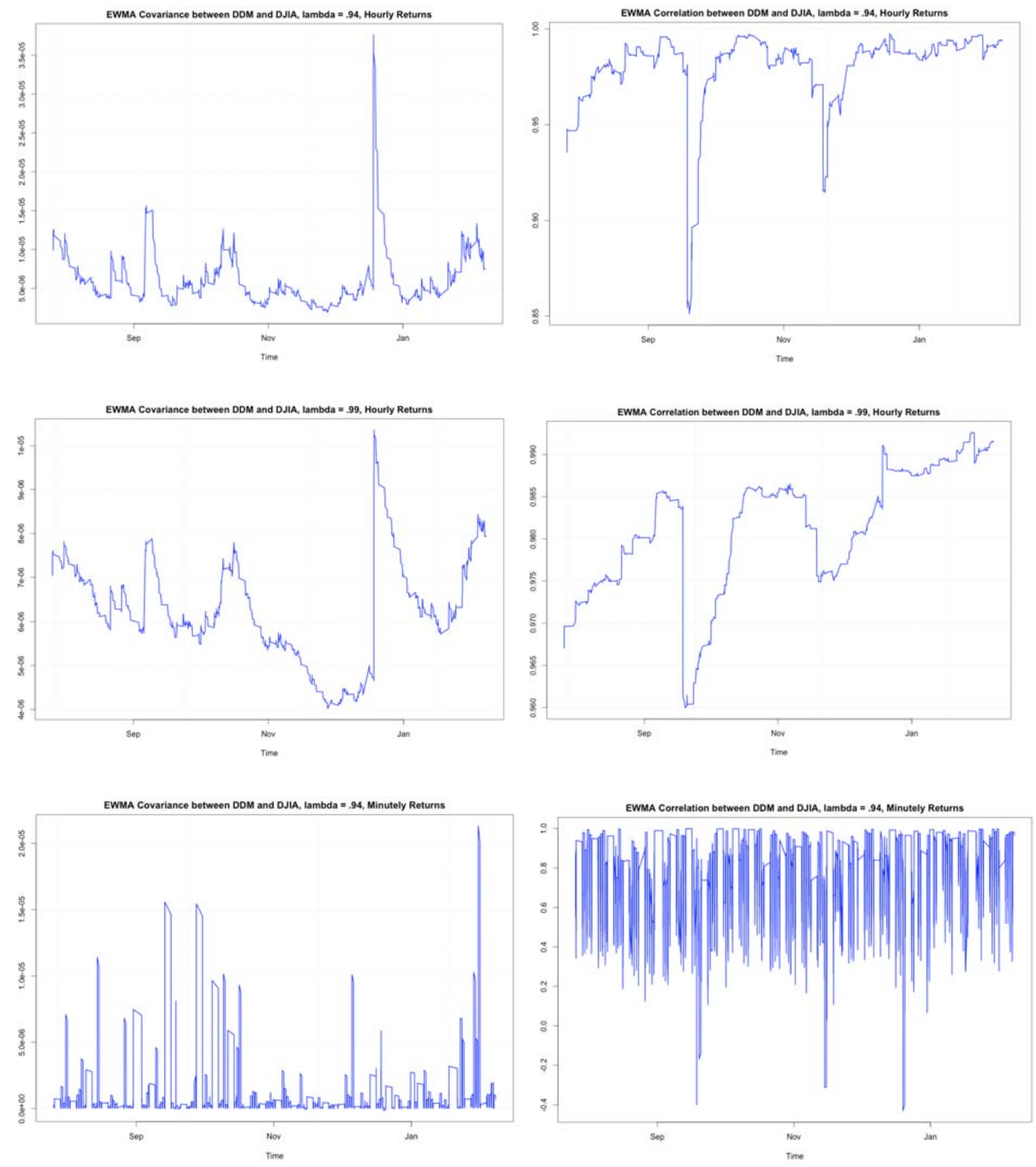

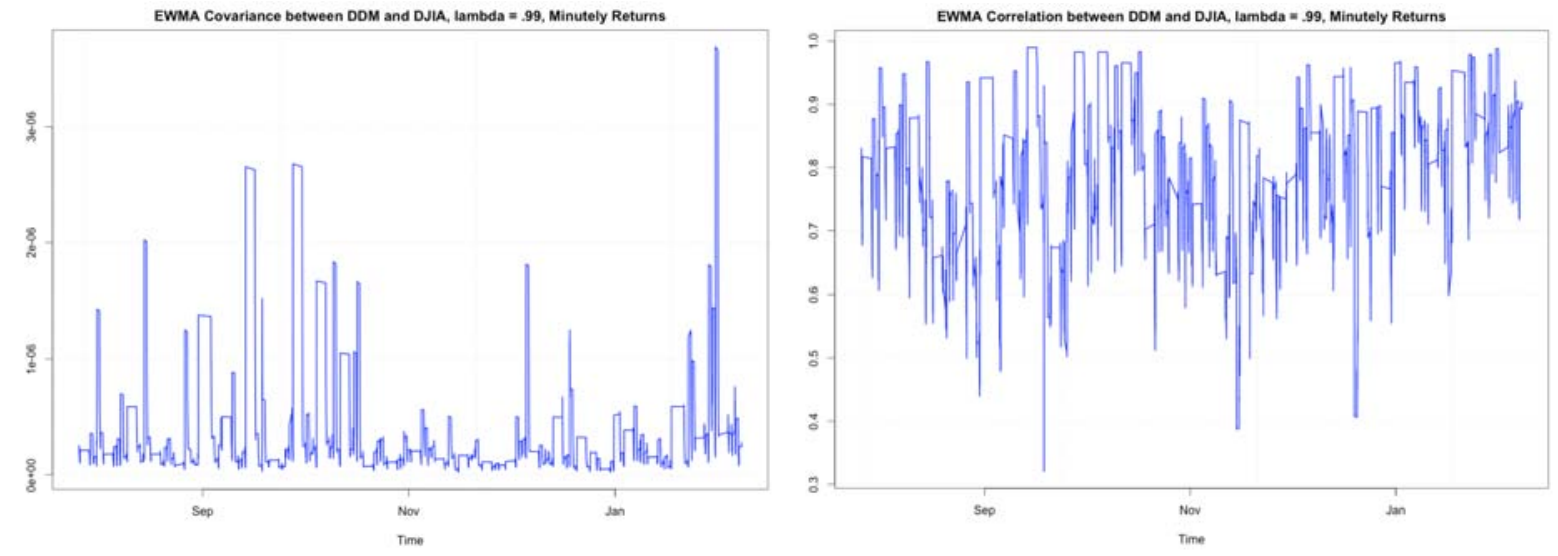

\section{DJIA/DXD}
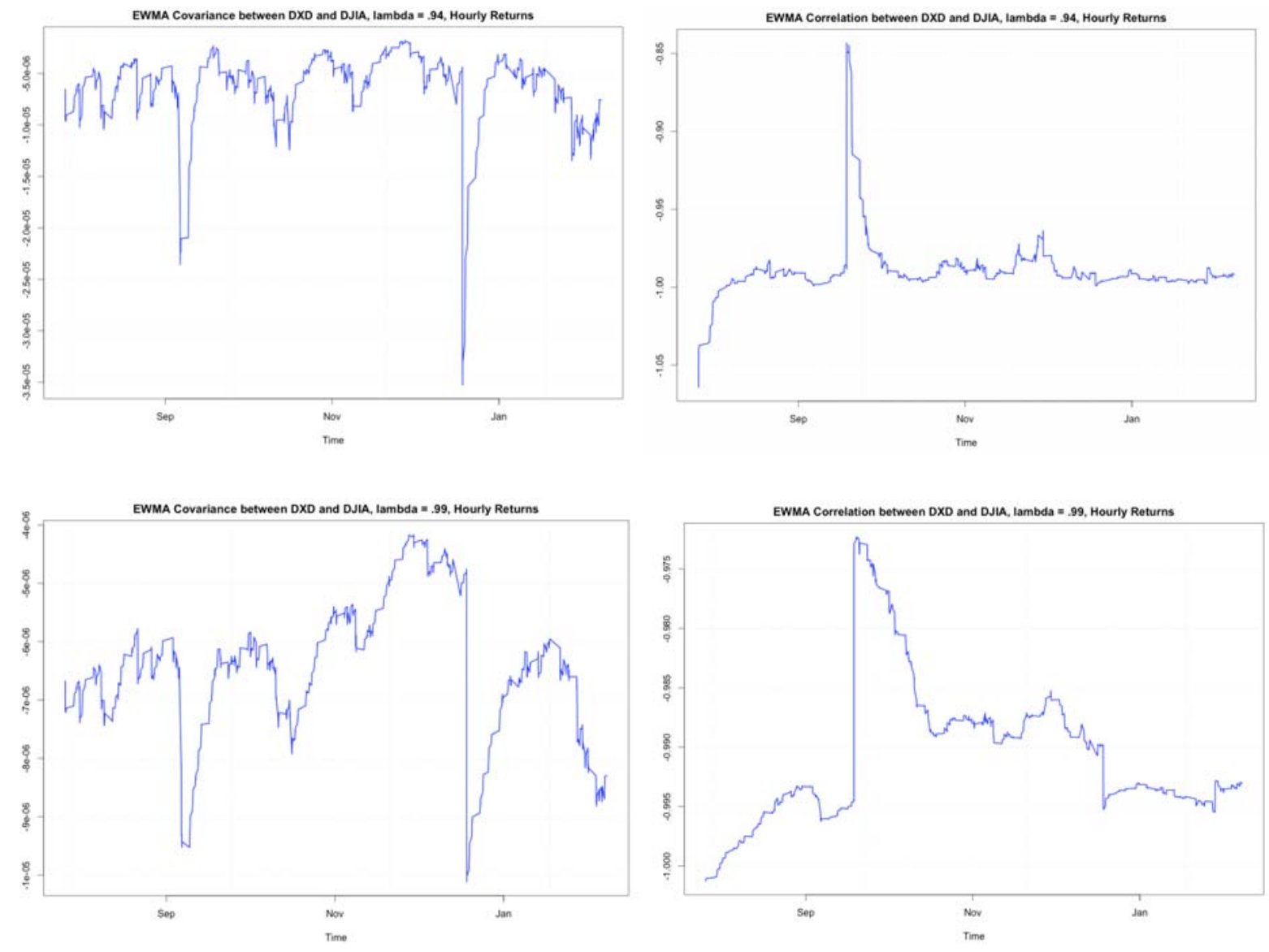

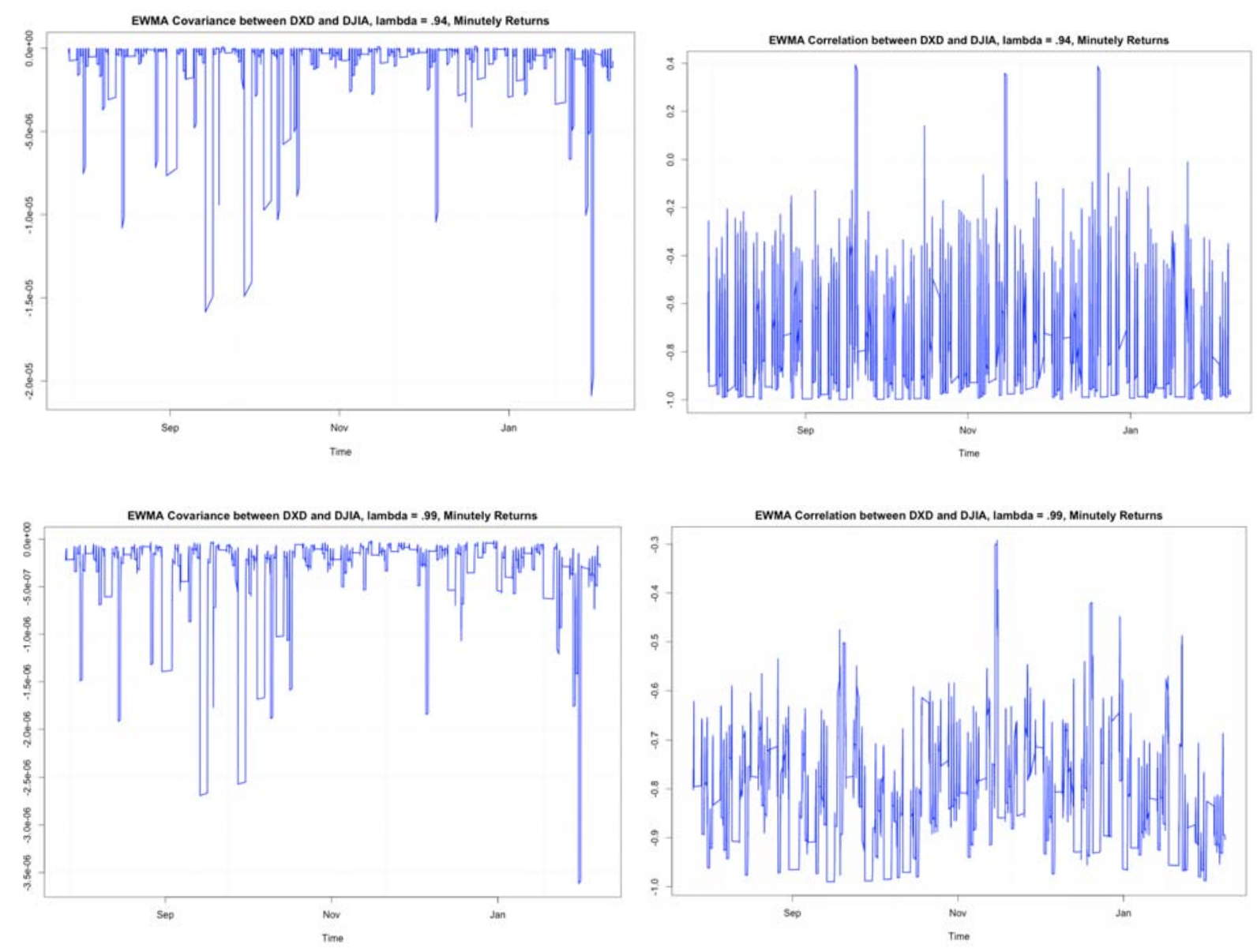

\section{DJIA/SRS}
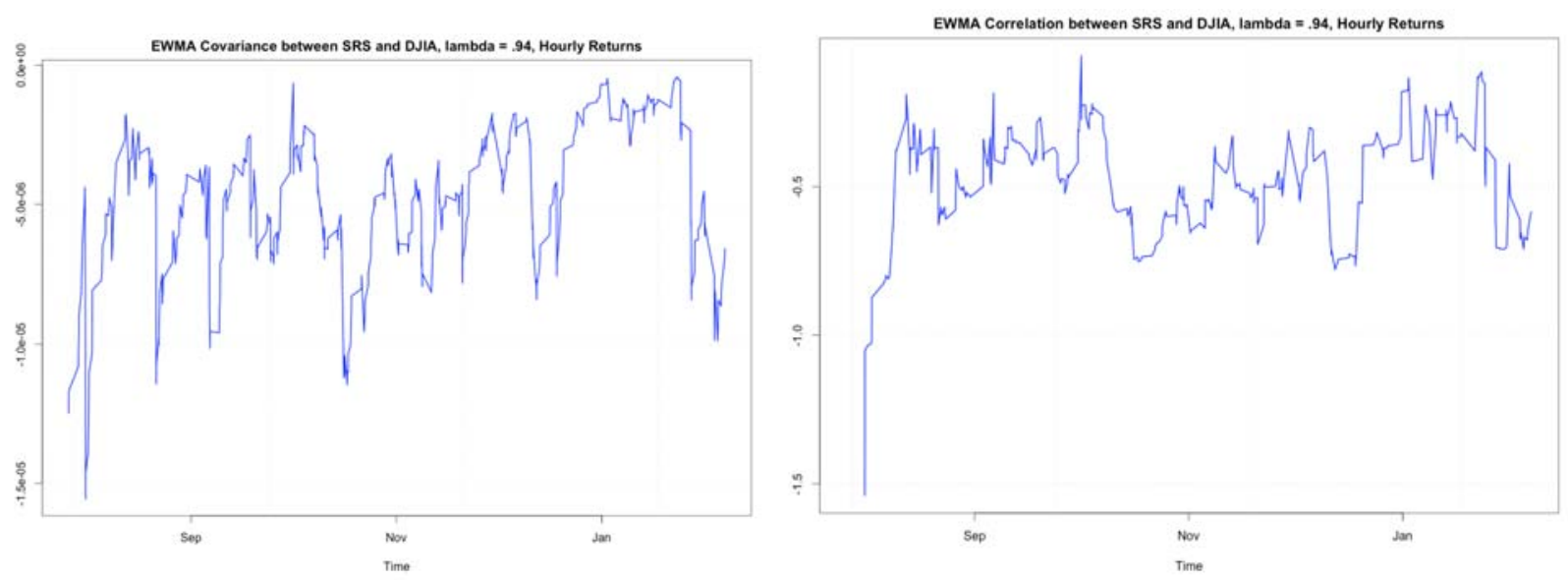

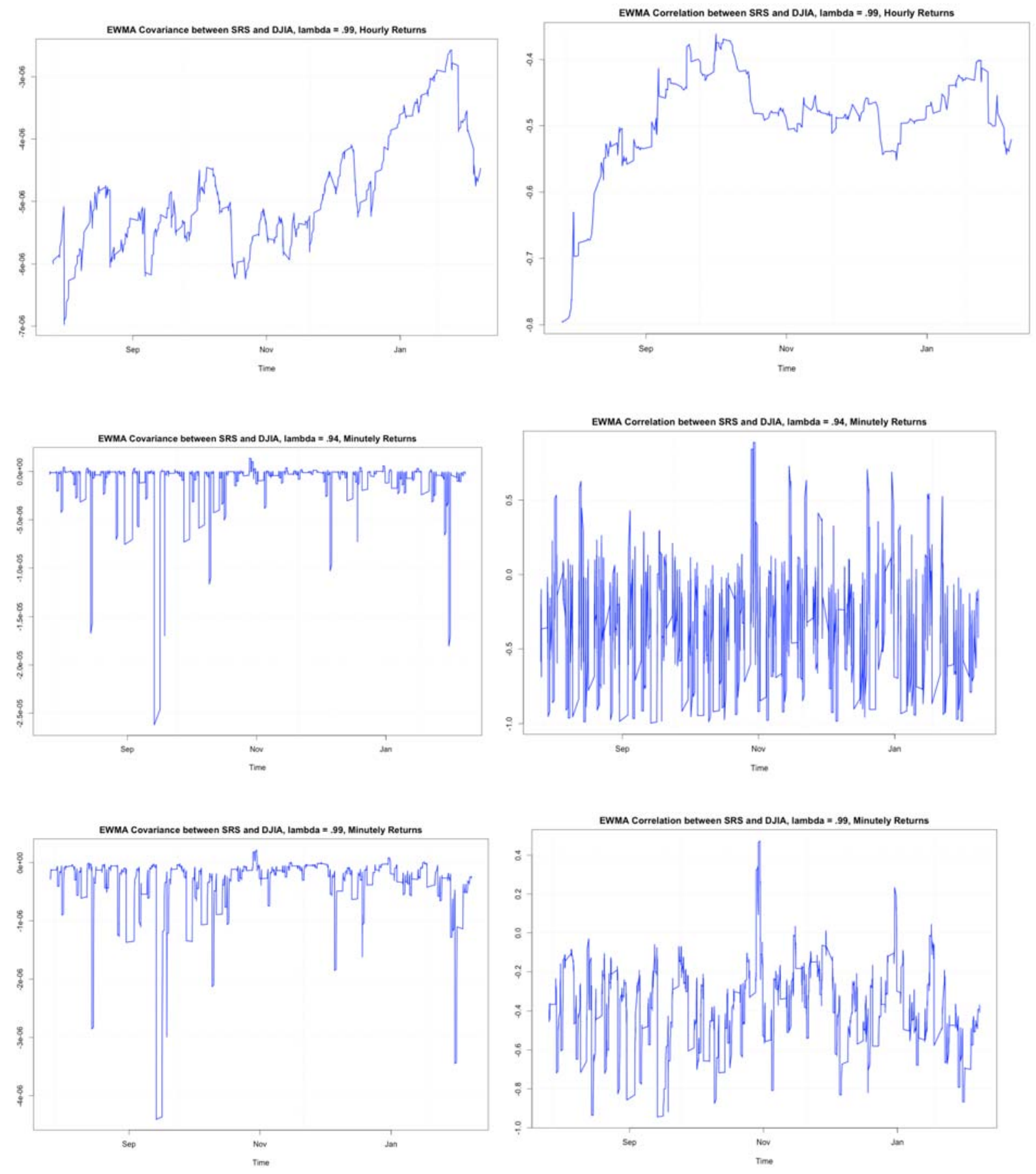


\section{Commodities}

\section{Gold}

\section{GDX/NUGT}
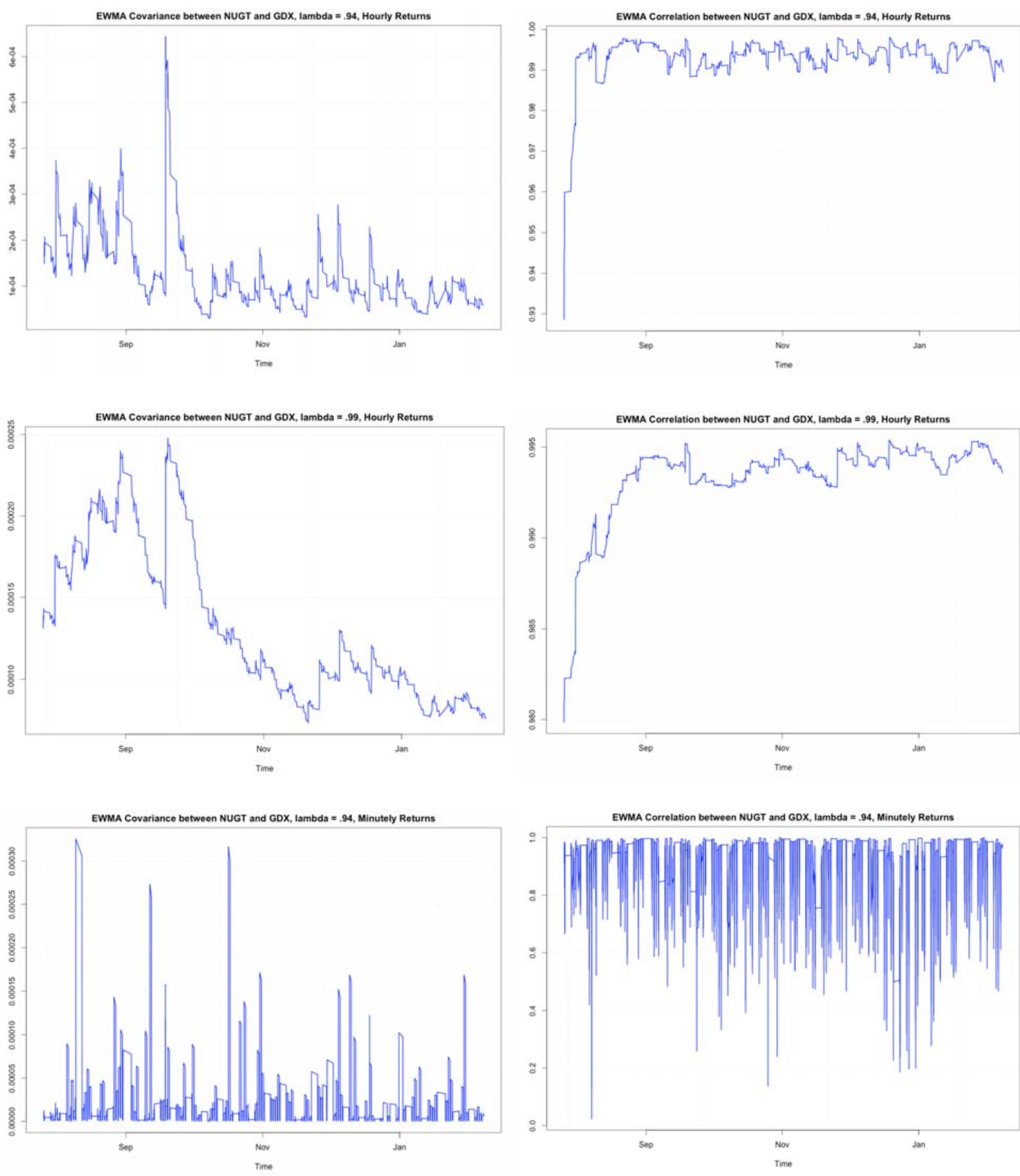

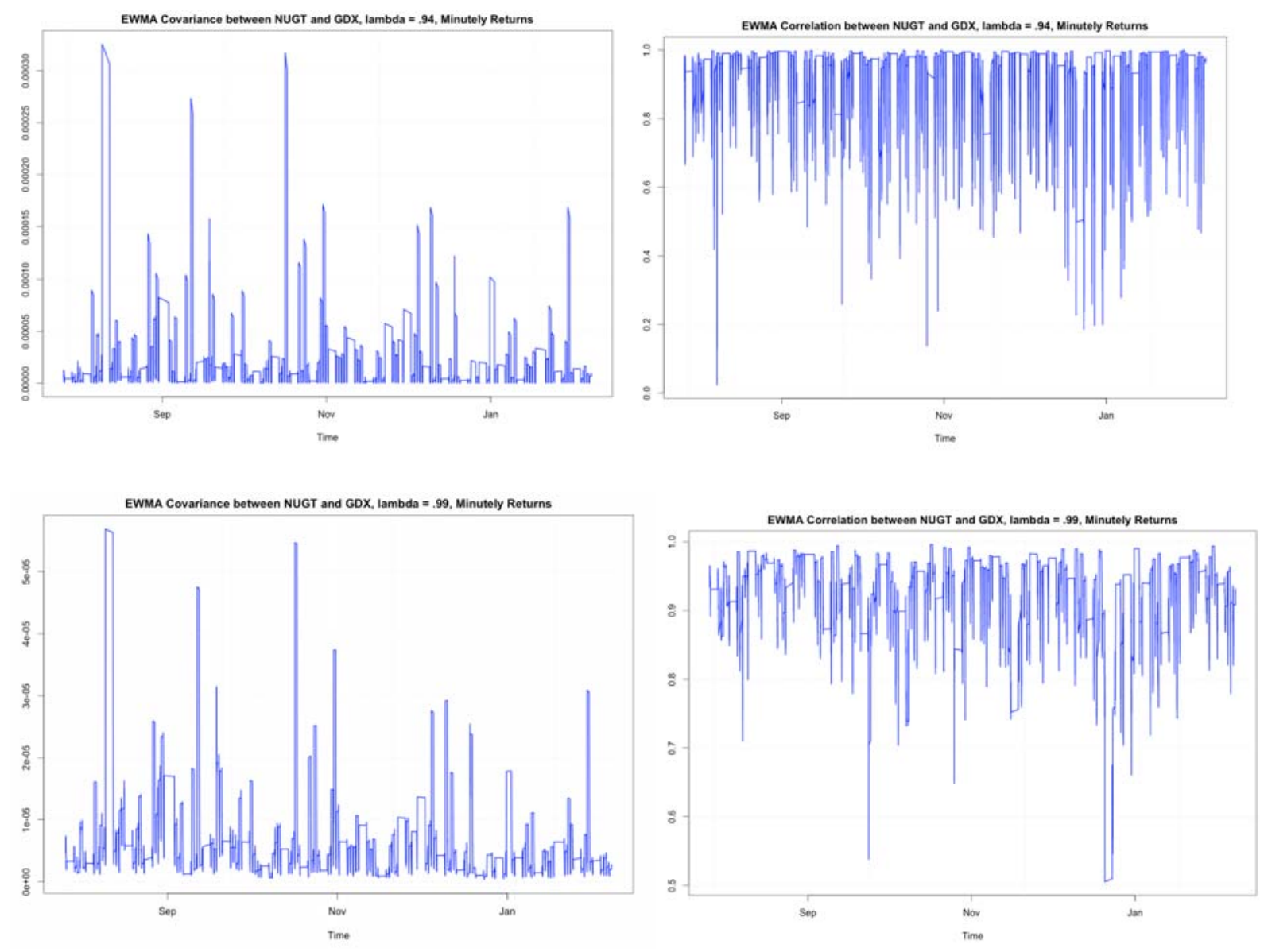

\section{GDX/XME}
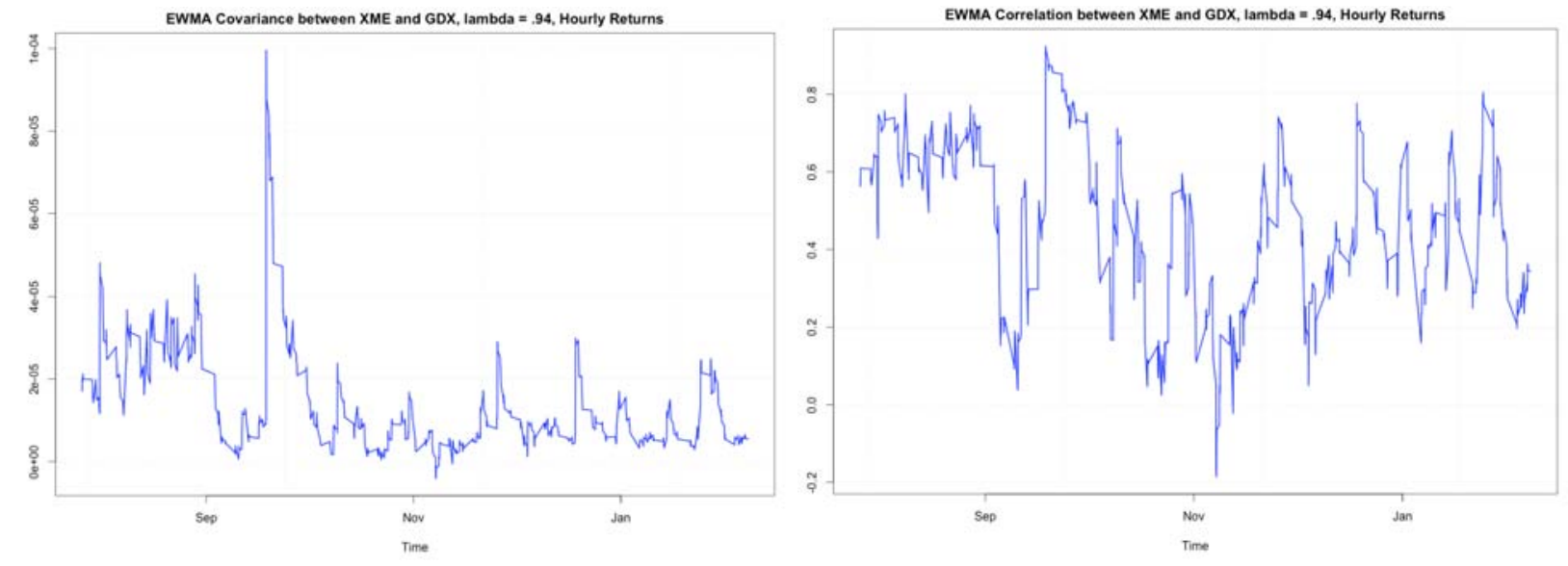

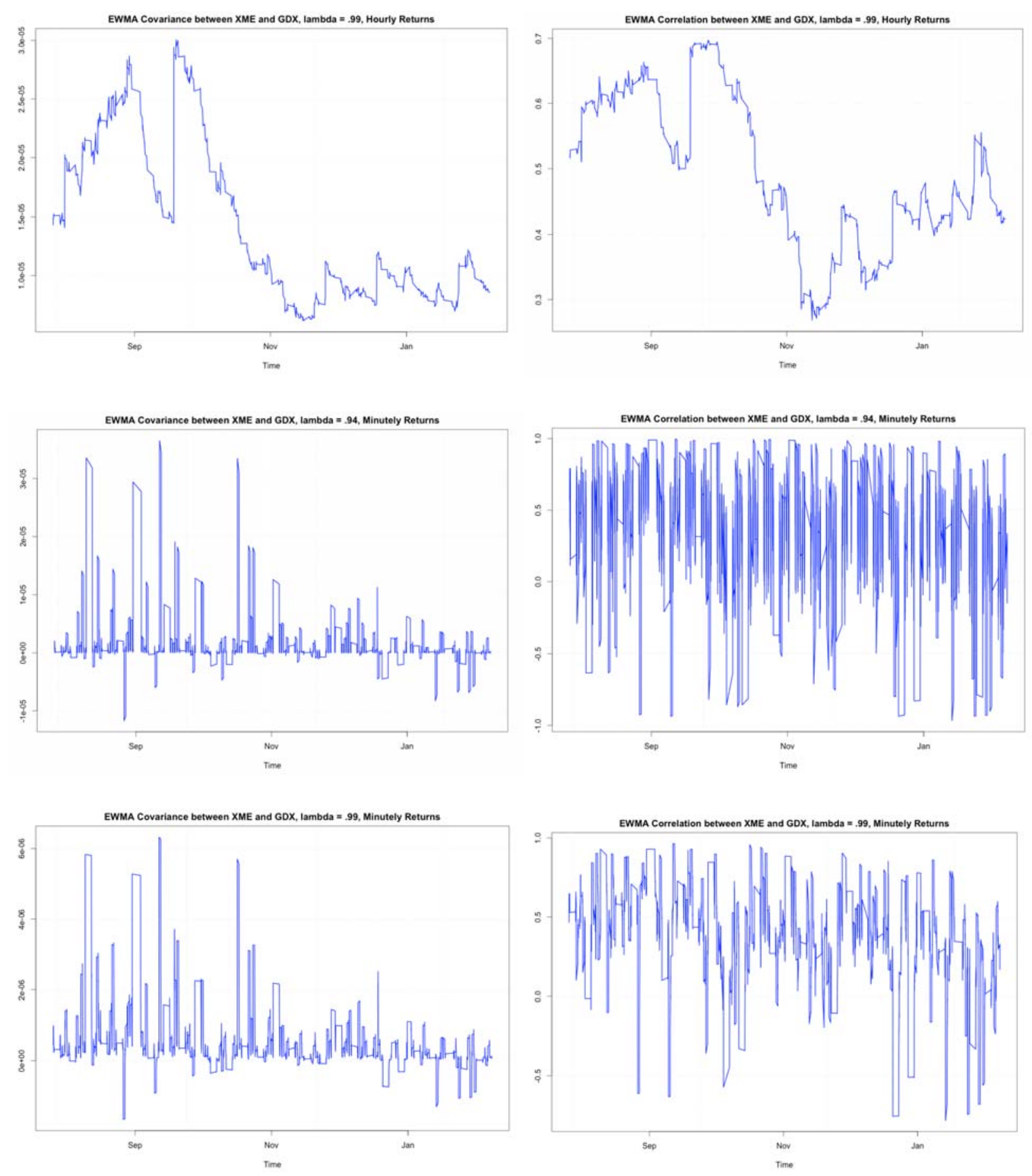


\section{URE/IYR}
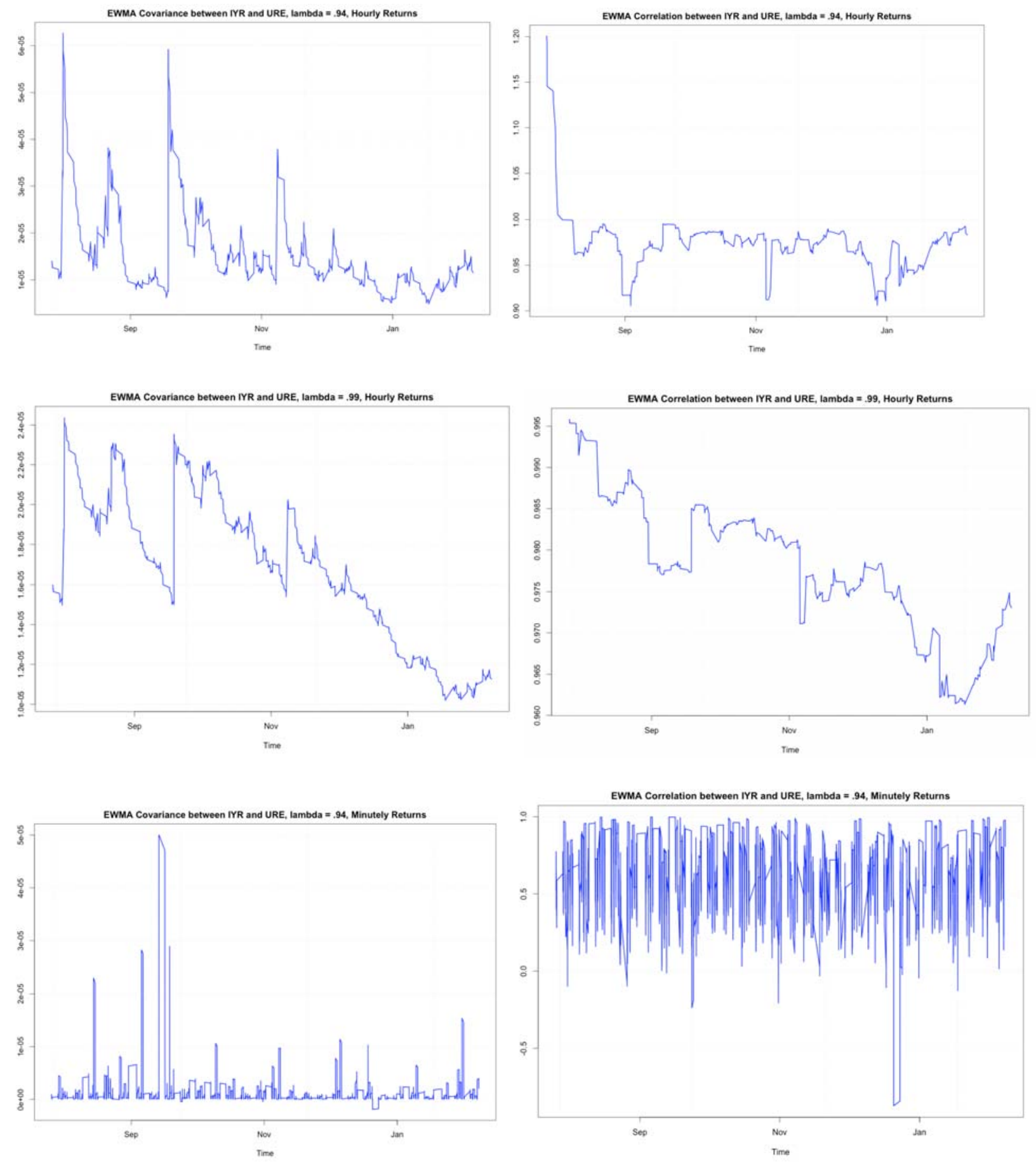

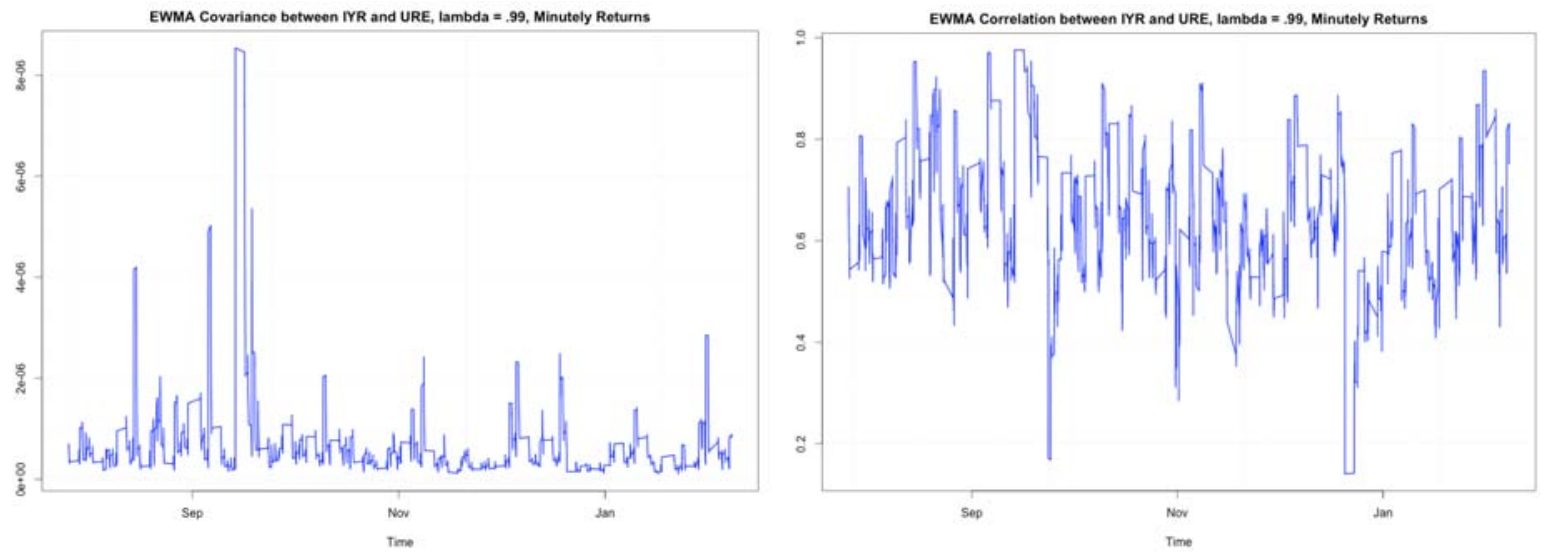

\section{ERY/XLF}
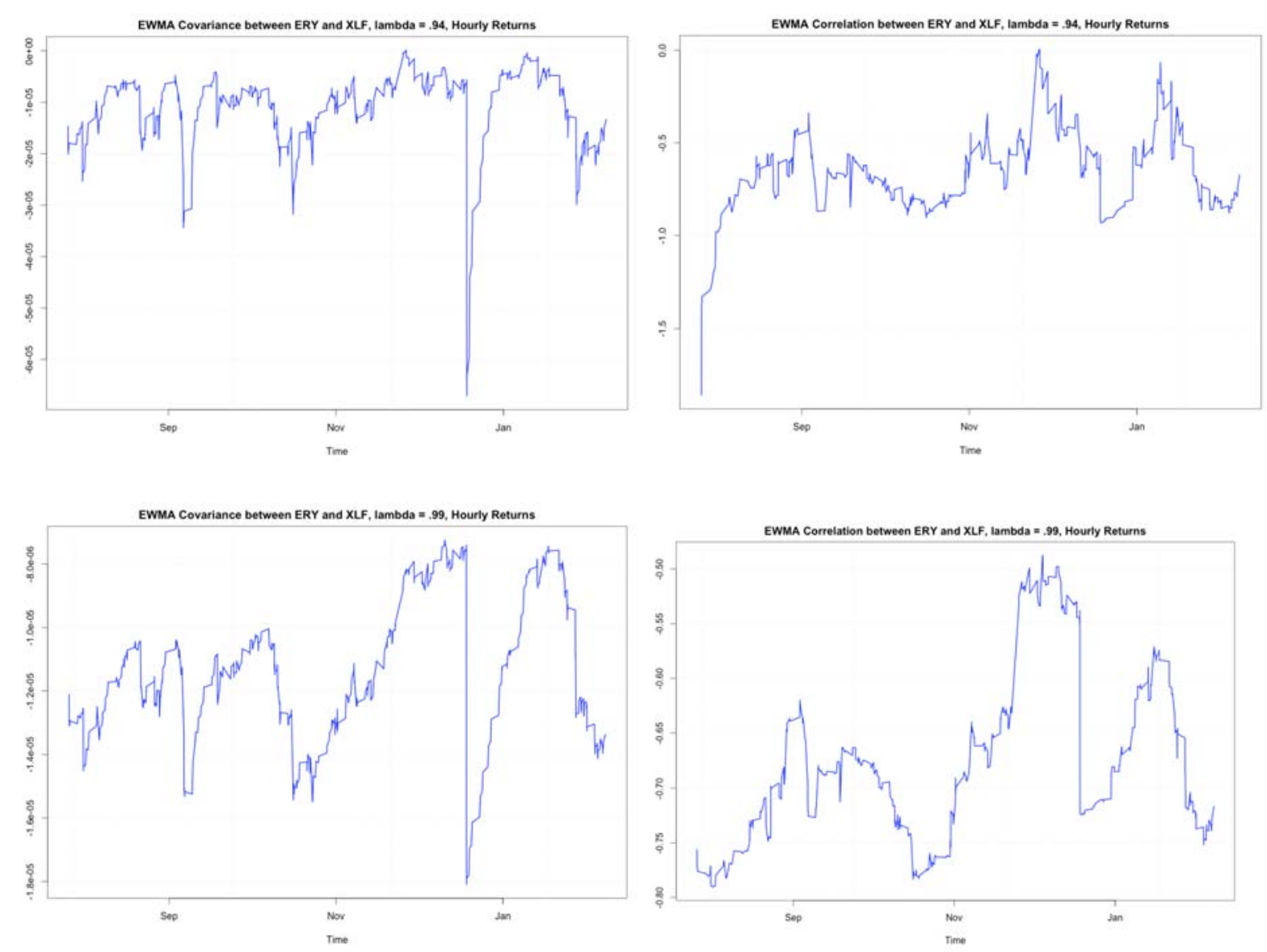

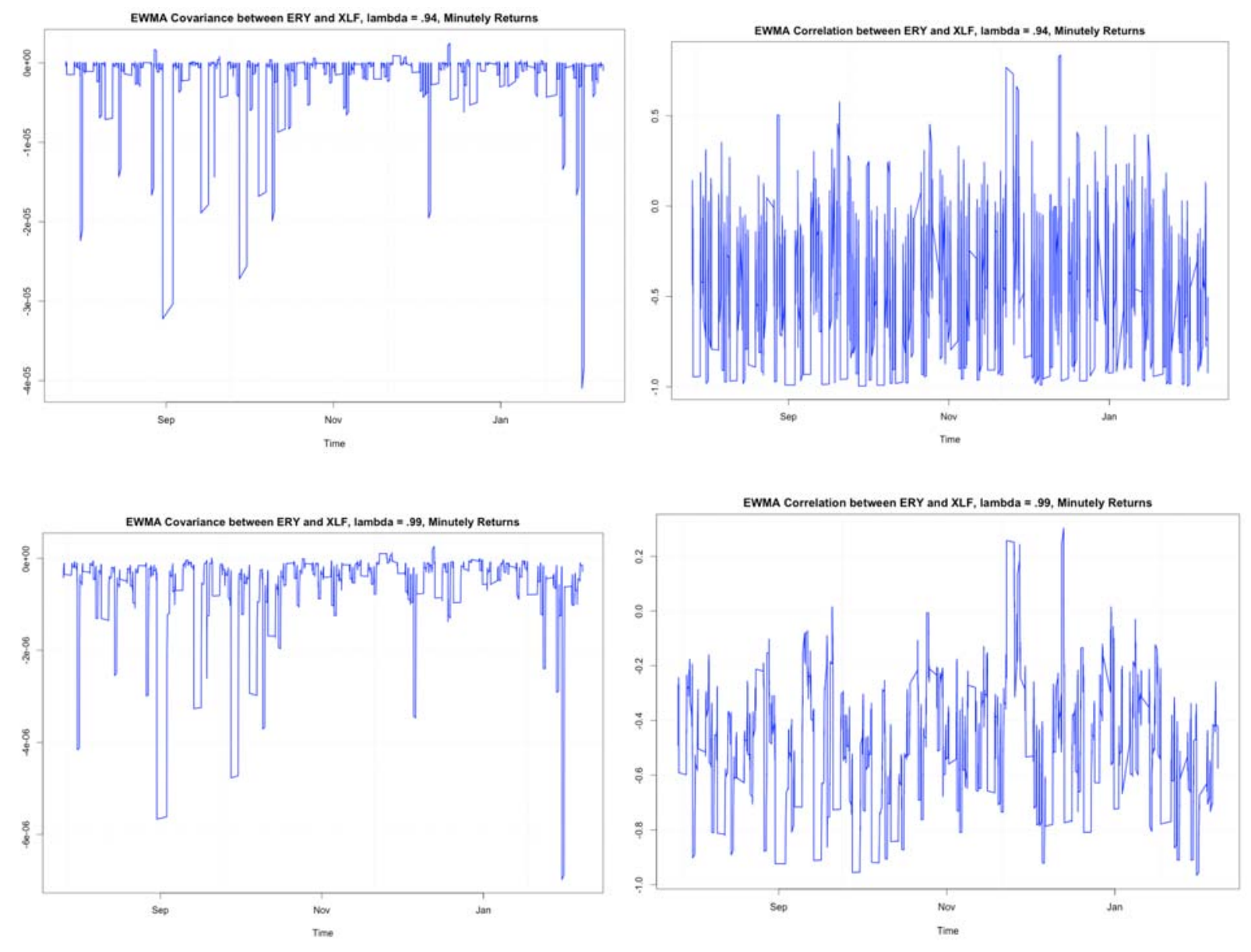

\section{UYG/XLI}
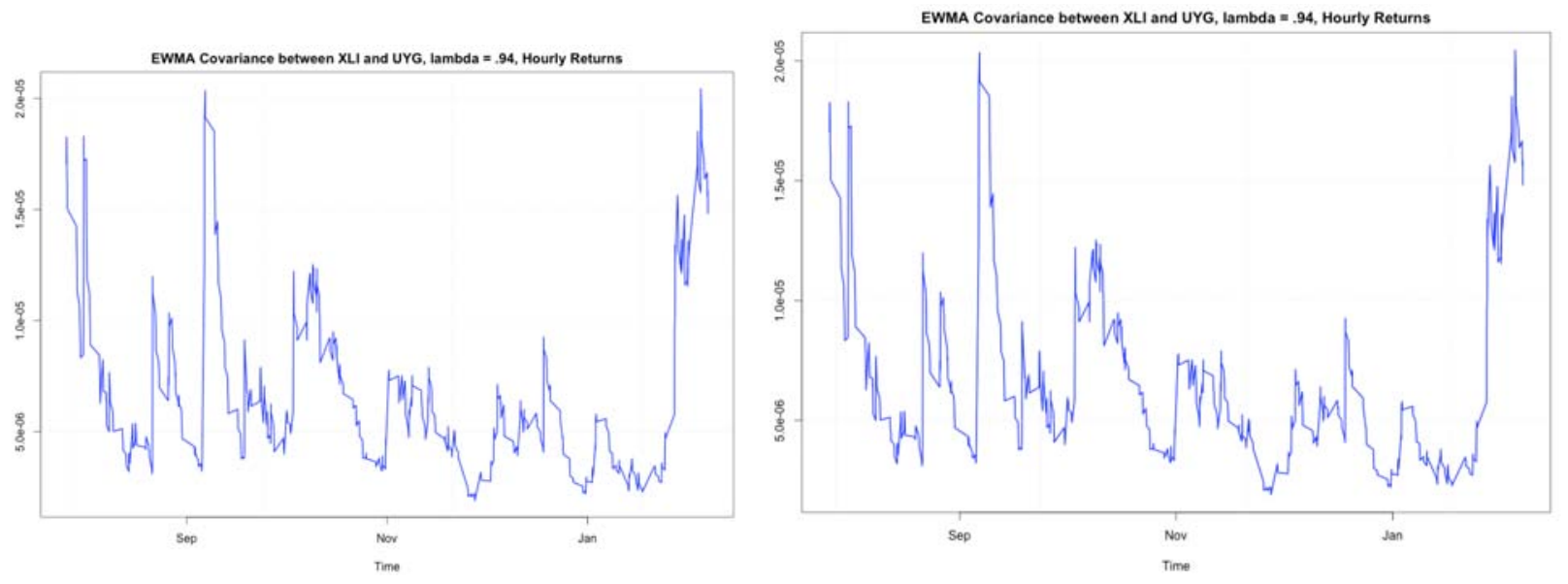

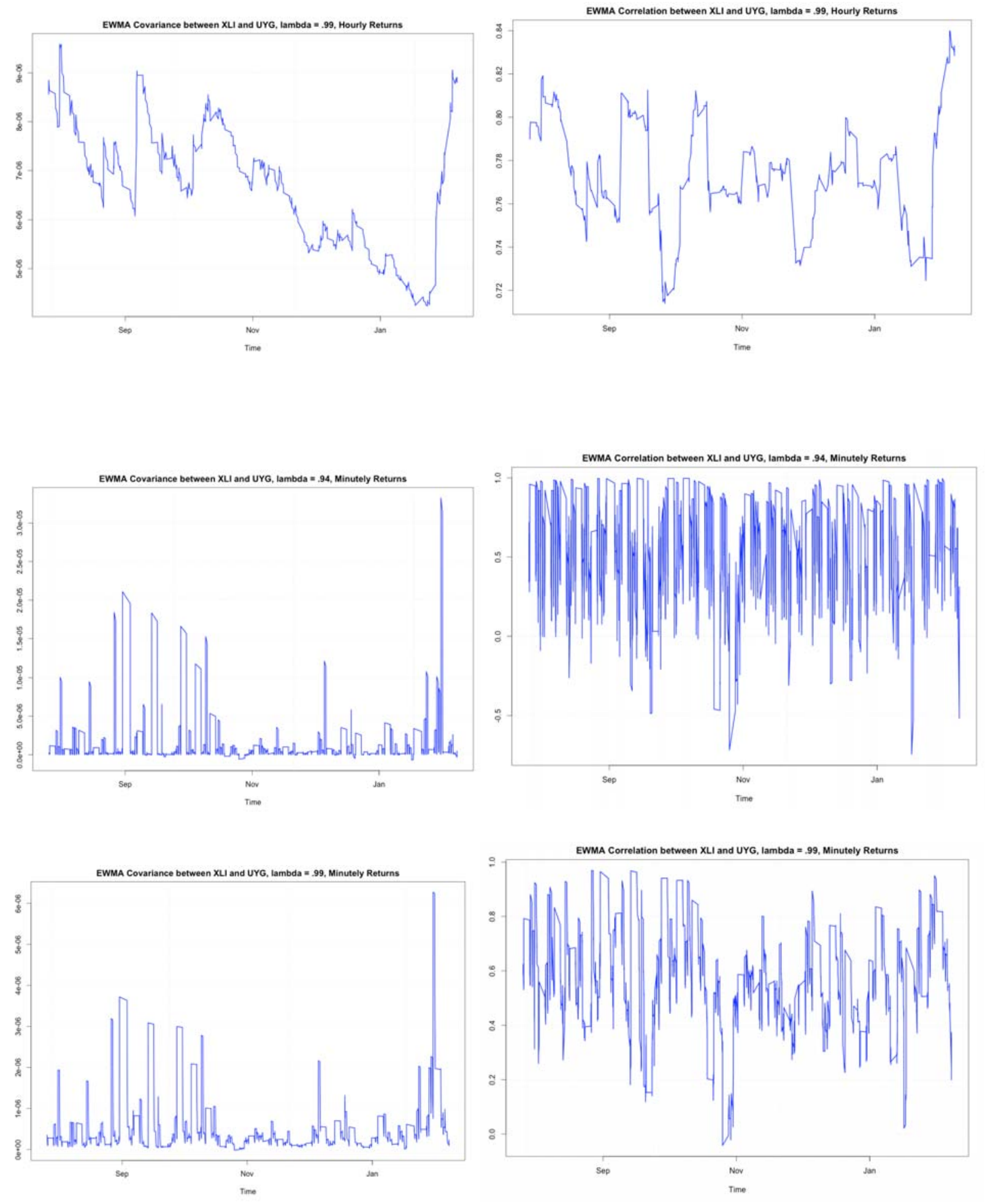


\section{DIG/XLE}
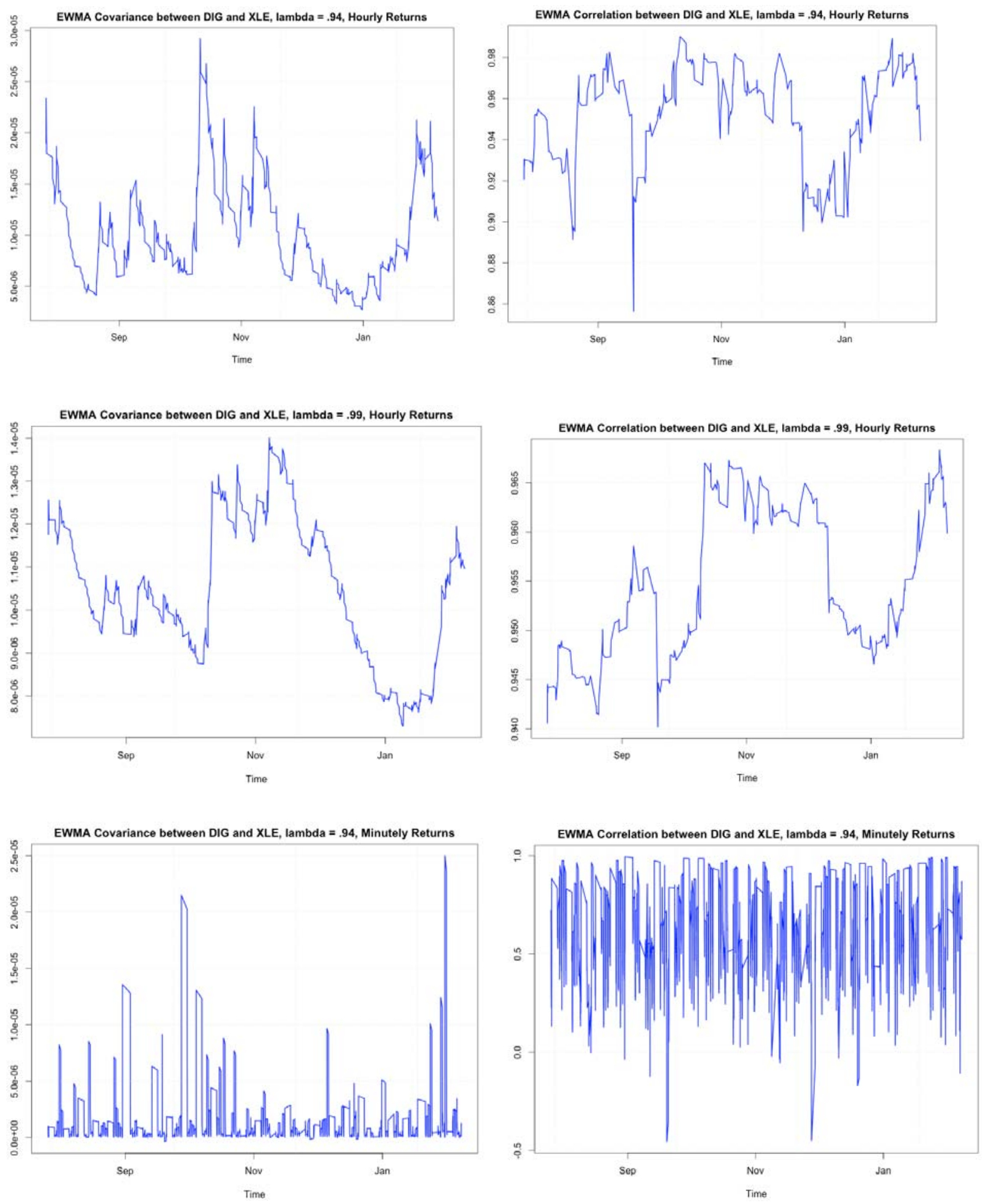

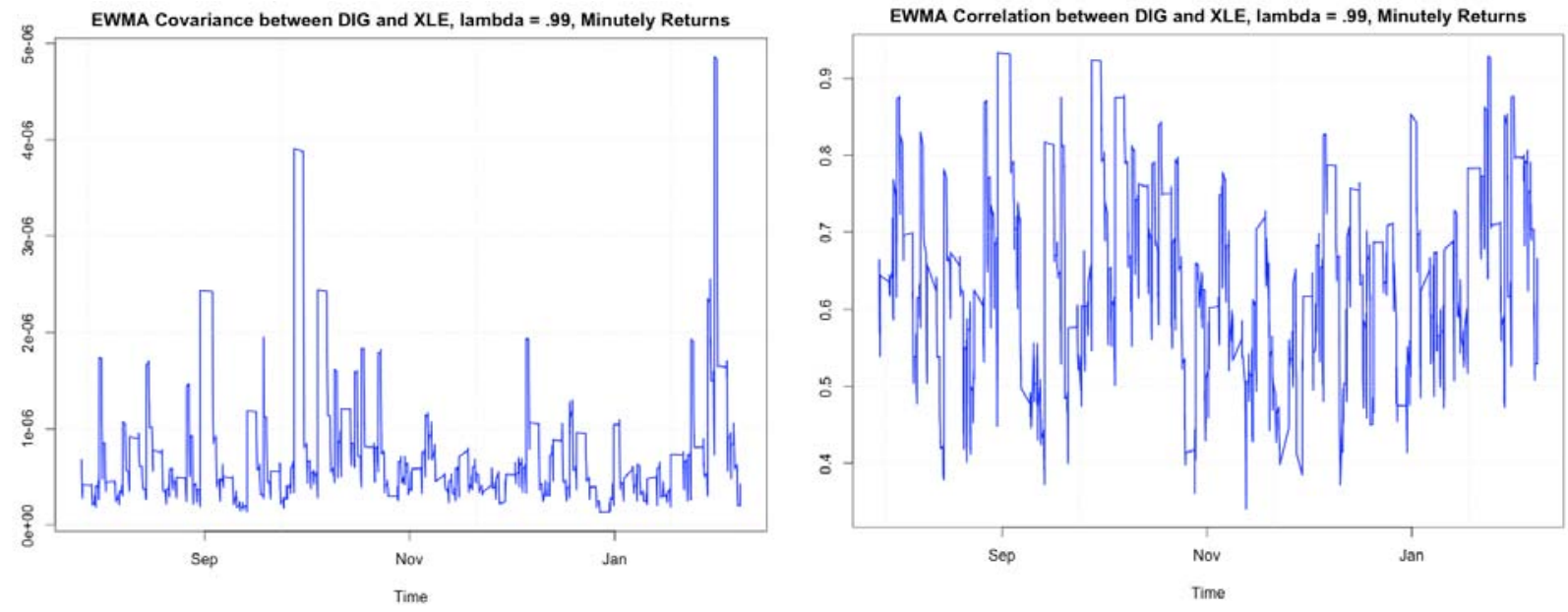

\section{MSCI EAFE}

\section{EFA/DPK}
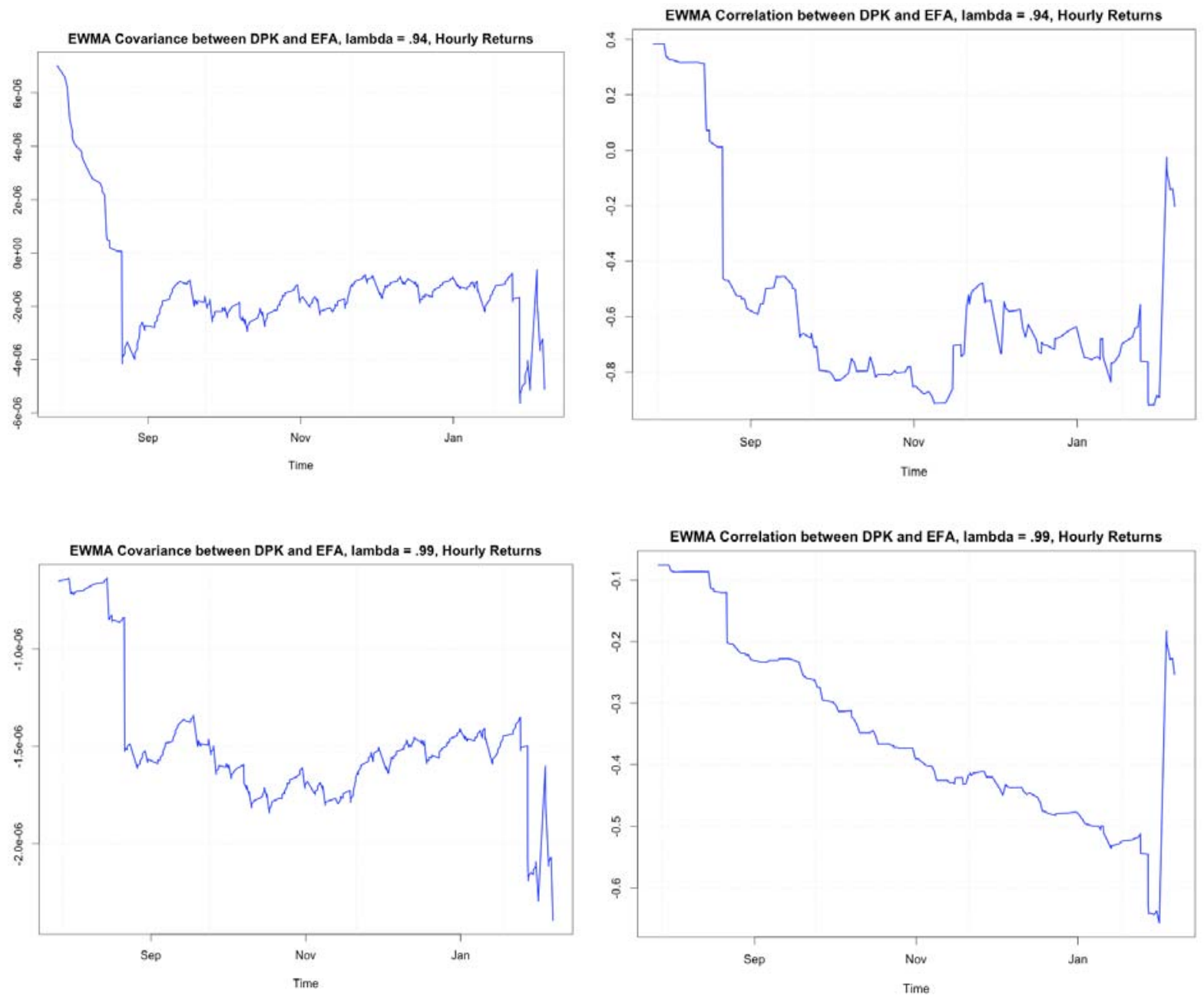

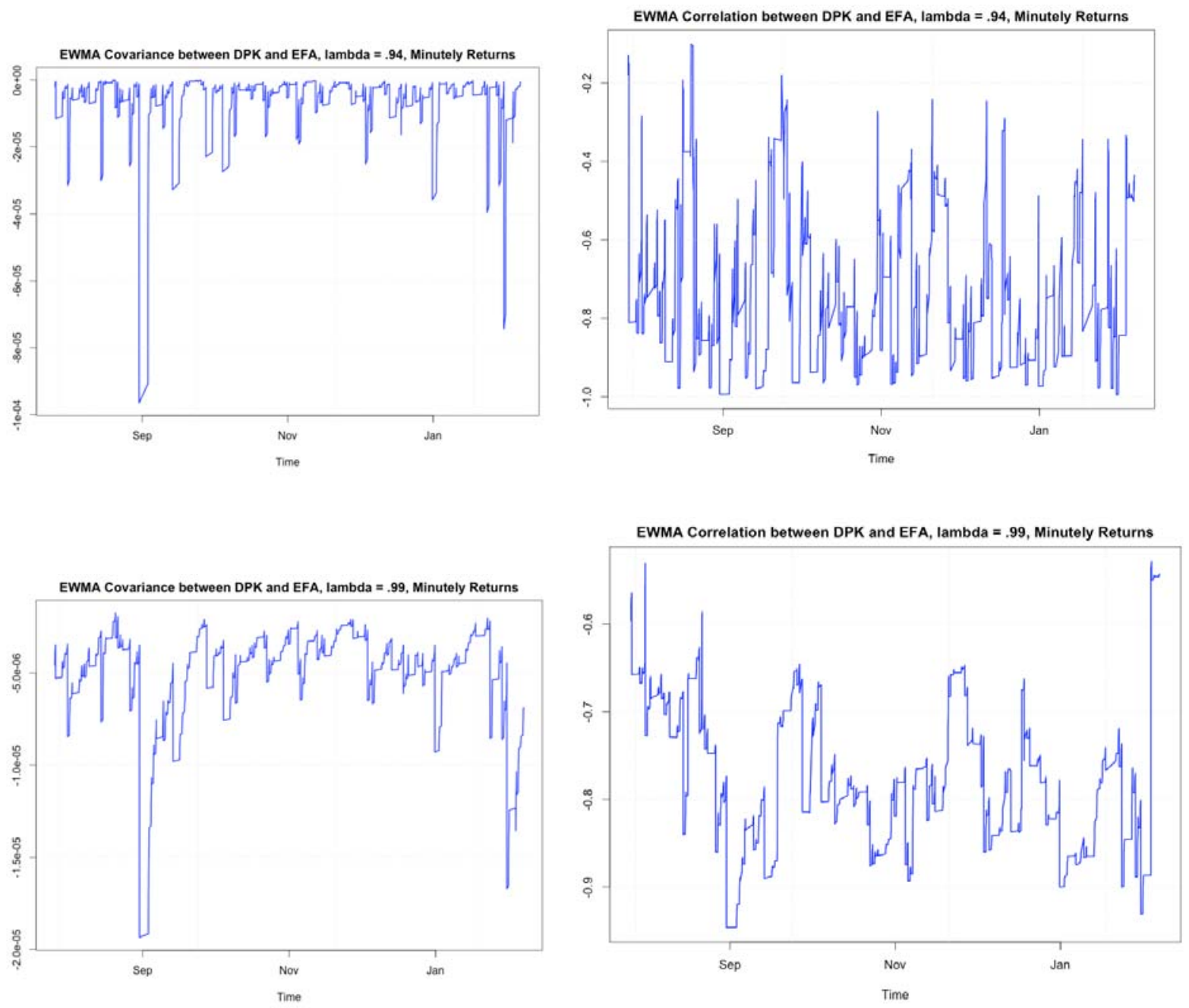

\section{EFA/DZK}
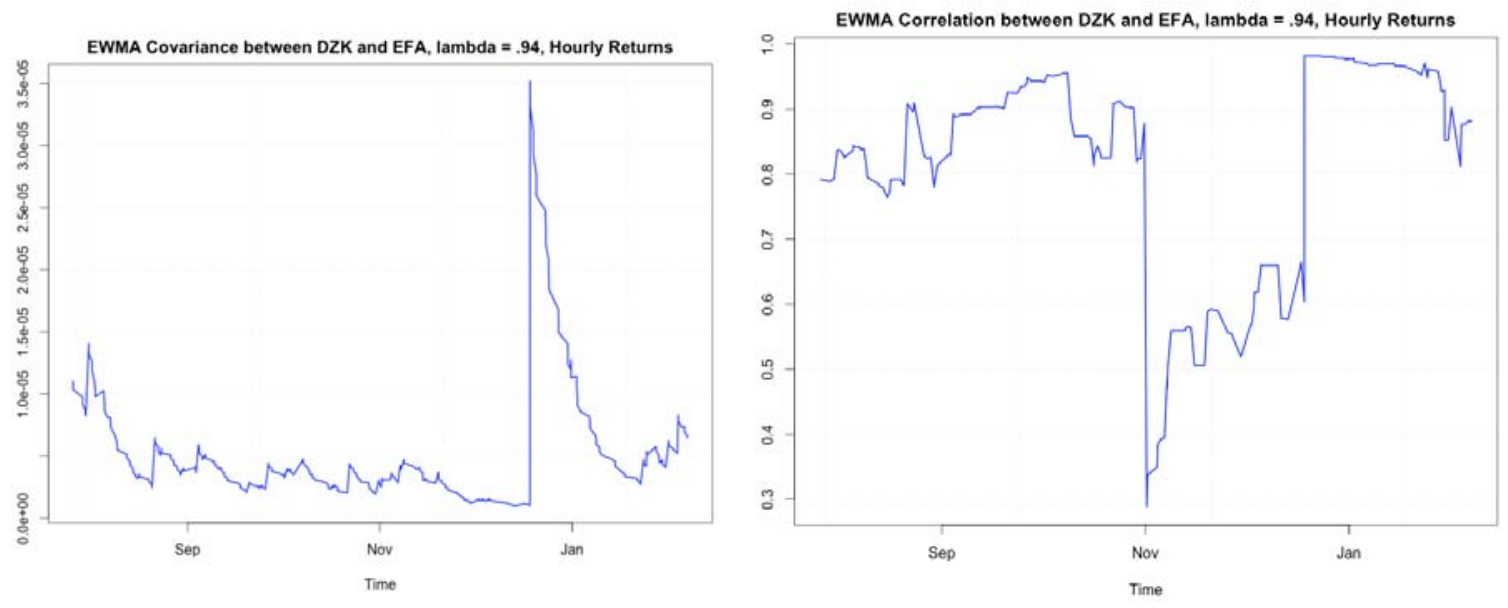

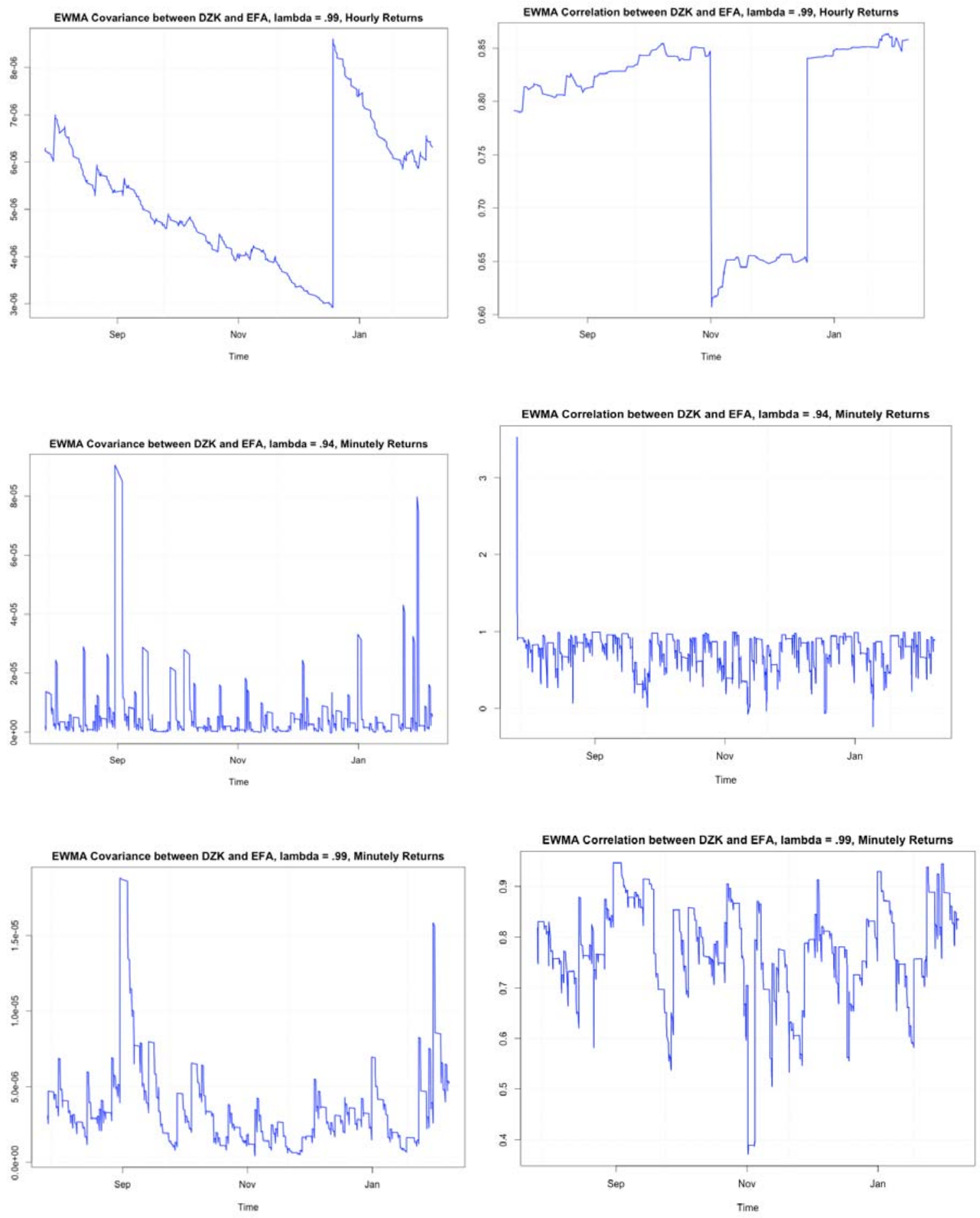


\section{MSCI Emerging Markets}

\section{EEM/EDZ}
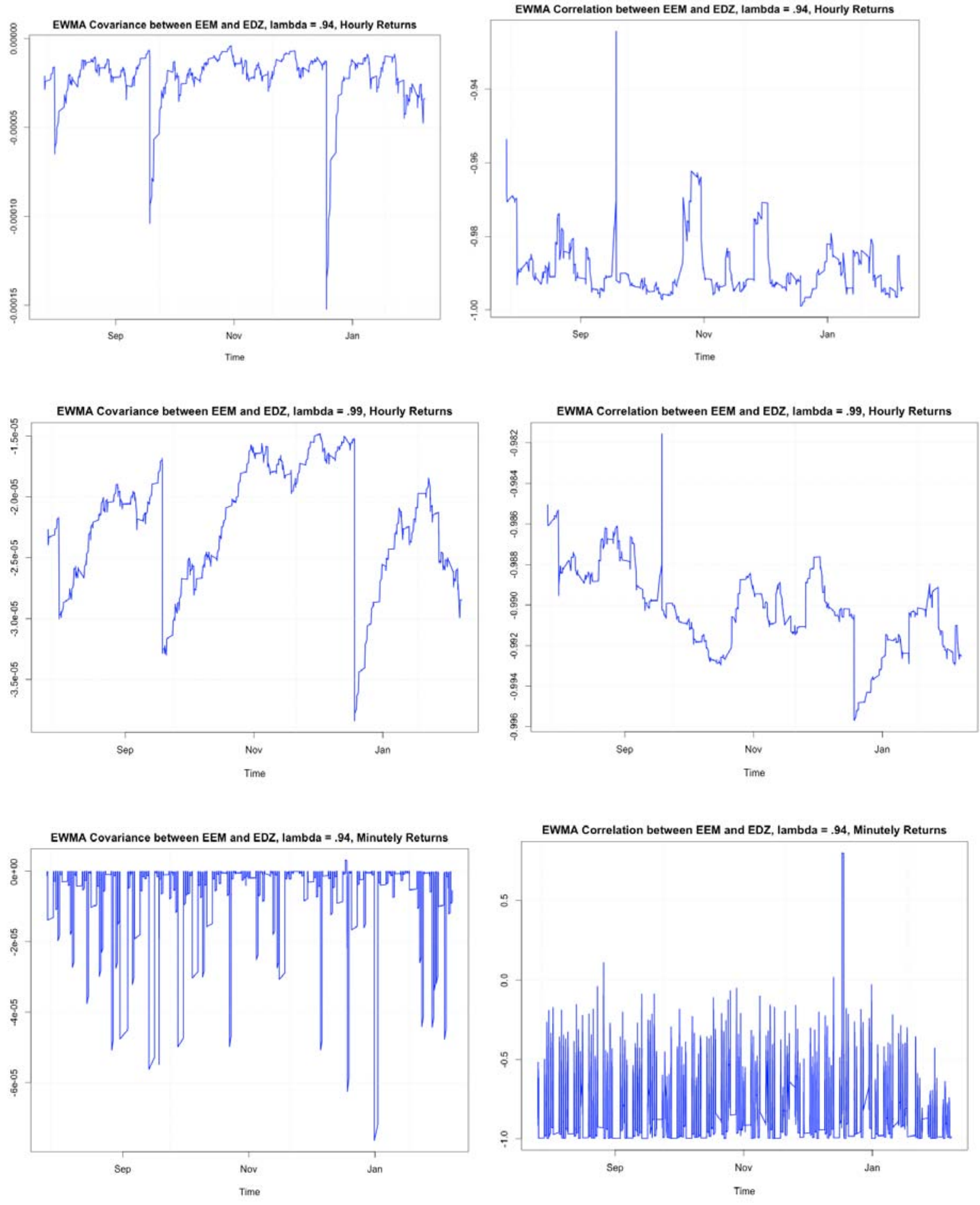

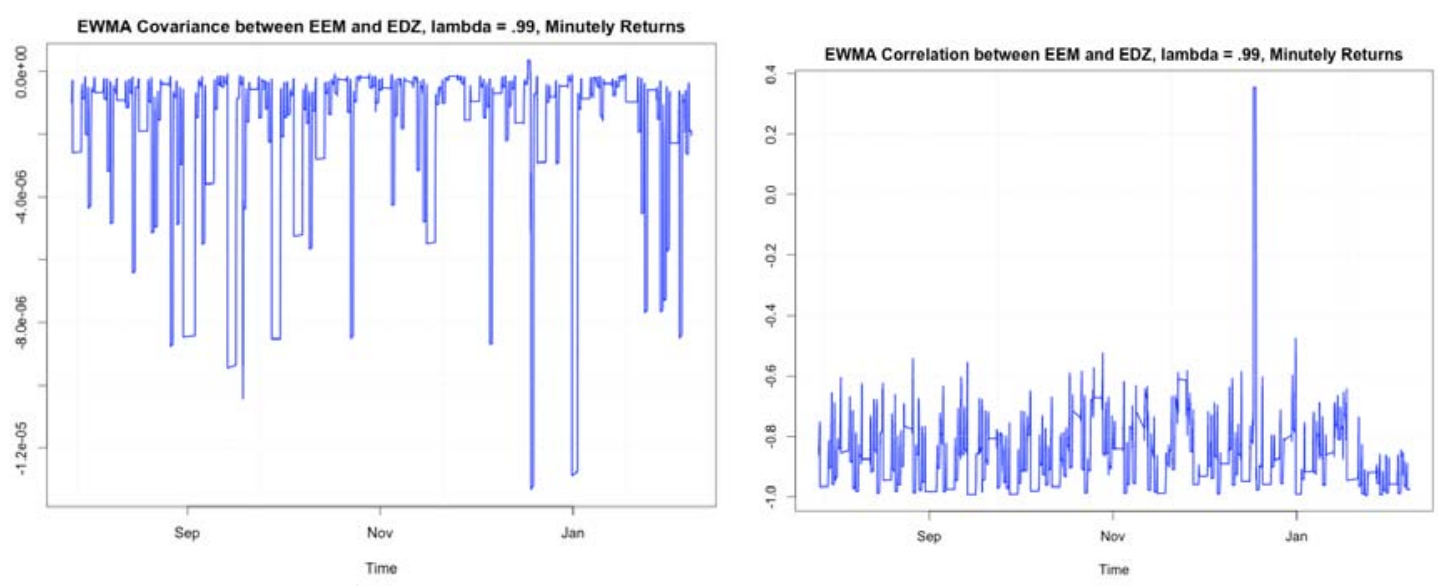

\section{EEM/EDC}
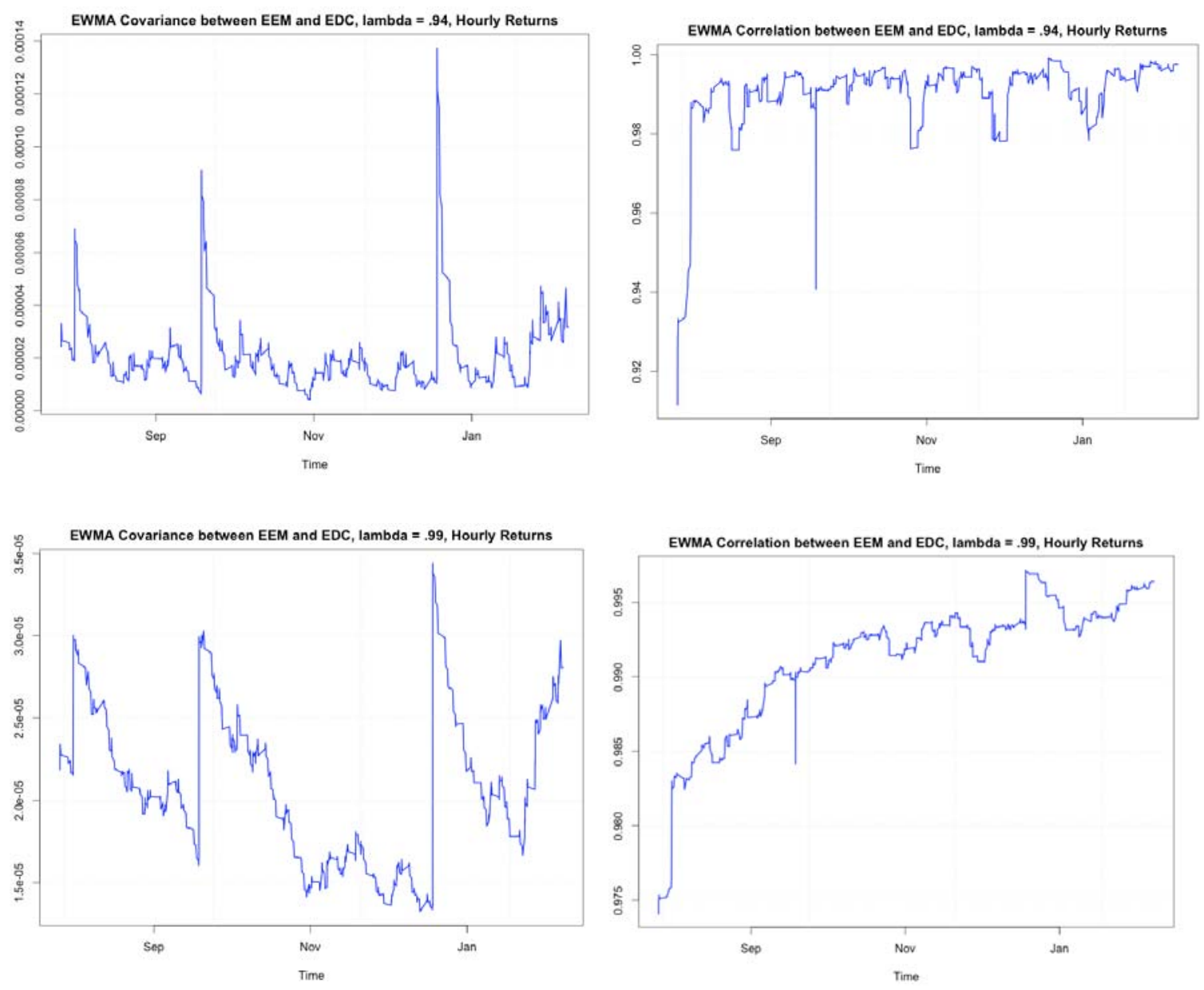

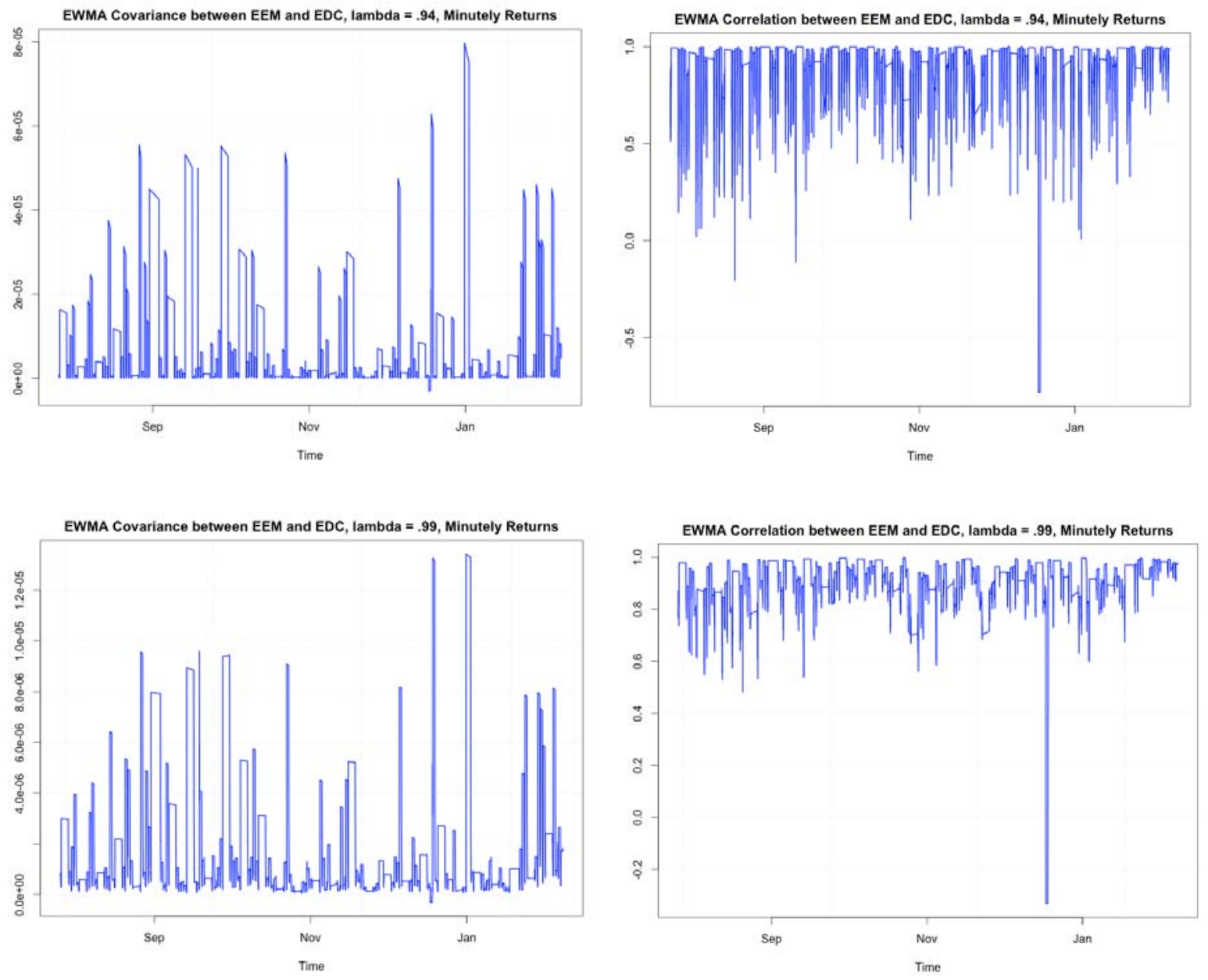
Appendix III

\begin{tabular}{|c|c|c|c|c|c|c|c|}
\hline \multicolumn{8}{|c|}{ SPY (S\&P 500) } \\
\hline Periodicity & Mean & Std Dev & Median & Min & Max & Skew & Kurtosis \\
\hline Hourly & 0 & 0 & 0 & -0.01 & 0.02 & 0.64 & 8.3 \\
\hline Daily & 0 & 0.01 & 0 & -0.02 & 0.02 & -0.39 & 1.96 \\
\hline \multicolumn{8}{|c|}{ SSO } \\
\hline Periodicity & Mean & Std Dev & Median & Min & $\operatorname{Max}$ & Skew & Kurtosis \\
\hline Hourly & 0 & 0 & 0 & $\begin{array}{l}-0.02 \\
\end{array}$ & 0.03 & 0.61 & 8.52 \\
\hline Daily & 0 & 0.01 & 0 & -0.05 & 0.03 & -0.49 & 2.52 \\
\hline \multicolumn{8}{|c|}{ SDS } \\
\hline Periodicity & Mean & Std Dev & Median & Min & Max & Skew & Kurtosis \\
\hline Hourly & 0 & 0 & 0 & -0.03 & 0.02 & -0.69 & 8.75 \\
\hline Daily & 0 & 0.01 & 0 & -0.03 & 0.04 & 0.3 & 1.72 \\
\hline \multicolumn{8}{|c|}{ MDY } \\
\hline Periodicity & Mean & Std Dev & Median & Min & Max & Skew & Kurtosis \\
\hline Hourly & 0 & 0 & 0 & -0.01 & 0.01 & 0.22 & 3.77 \\
\hline Daily & 0 & 0.01 & 0 & -0.04 & 0.02 & -1.01 & 3.04 \\
\hline \multicolumn{8}{|c|}{ DIA (Dow Jones Industrial Average) } \\
\hline Periodicity & Mean & Std Dev & Median & Min & Max & Skew & Kurtosis \\
\hline Hourly & 0 & 0 & 0 & -0.01 & 0.01 & 0.42 & 6.87 \\
\hline Daily & 0 & 0.01 & 0 & -0.02 & 0.02 & -0.23 & 1.45 \\
\hline \multicolumn{8}{|c|}{ SRS } \\
\hline Periodicity & Mean & Std Dev & Median & Min & Max & Skew & Kurtosis \\
\hline Hourly & 0 & 0.01 & 0 & -0.05 & 0.03 & -1.02 & 13.9 \\
\hline Daily & 0 & 0.02 & 0 & -0.07 & 0.04 & -0.62 & 2.1 \\
\hline \multicolumn{8}{|c|}{ DDM } \\
\hline Periodicity & Mean & Std Dev & Median & Min & Max & Skew & Kurtosis \\
\hline Hourly & 0 & 0 & 0 & -0.02 & 0.03 & 0.58 & 9.11 \\
\hline Daily & 0 & 0.01 & 0 & -0.04 & 0.03 & -0.24 & 1.54 \\
\hline \multicolumn{8}{|c|}{ DXD } \\
\hline Periodicity & Mean & Std Dev & Median & Min & Max & Skew & Kurtosis \\
\hline Hourly & 0 & 0 & 0 & -0.03 & 0.02 & -0.51 & 6.95 \\
\hline Daily & 0 & 0.01 & 0 & -0.03 & 0.04 & 0.1 & 1.47 \\
\hline \multicolumn{8}{|c|}{ GDX } \\
\hline Periodicity & Mean & Std Dev & Median & Min & Max & Skew & Kurtosis \\
\hline Hourly & 0 & 0.01 & 0 & -0.03 & 0.06 & 0.86 & 8.15 \\
\hline
\end{tabular}




\begin{tabular}{|c|c|c|c|c|c|c|c|}
\hline Daily & 0 & 0.02 & 0 & -0.07 & 0.1 & 0.78 & 3.27 \\
\hline \multicolumn{8}{|c|}{ NUGT } \\
\hline Periodicity & Mean & Std Dev & Median & Min & $\operatorname{Max}$ & Skew & Kurtosis \\
\hline Hourly & 0 & 0.02 & 0 & -0.08 & 0.16 & 0.67 & 6.87 \\
\hline Daily & -0.01 & 0.07 & -0.01 & -0.22 & 0.27 & 0.59 & 2.9 \\
\hline \multicolumn{8}{|c|}{ XME } \\
\hline Periodicity & Mean & Std Dev & Median & Min & Max & Skew & Kurtosis \\
\hline Hourly & 0 & 0 & 0 & -0.01 & 0.03 & 0.34 & 2.5 \\
\hline Daily & 0 & 0.01 & 0 & -0.03 & 0.04 & -0.02 & 0.29 \\
\hline \multicolumn{8}{|c|}{ URE } \\
\hline Periodicity & Mean & Std Dev & Median & Min & Max & Skew & Kurtosis \\
\hline Hourly & 0 & 0.01 & 0 & -0.03 & 0.05 & 0.65 & 11.25 \\
\hline Daily & 0 & 0.02 & 0 & -0.04 & 0.07 & 0.43 & 1.54 \\
\hline \multicolumn{8}{|c|}{ IYR } \\
\hline Periodicity & Mean & Std Dev & Median & Min & Max & Skew & Kurtosis \\
\hline Hourly & 0 & 0 & 0 & -0.01 & 0.02 & 0.8 & 10.48 \\
\hline Daily & 0 & 0.01 & 0 & -0.02 & 0.03 & 0.48 & 1.44 \\
\hline \multicolumn{8}{|c|}{ ERY } \\
\hline Periodicity & Mean & Std Dev & Median & Min & Max & Skew & Kurtosis \\
\hline Hourly & 0 & 0.01 & 0 & -0.05 & 0.03 & -0.19 & 3.35 \\
\hline Daily & 0 & 0.02 & 0 & -0.05 & 0.05 & 0.01 & 0.23 \\
\hline \multicolumn{8}{|c|}{ XLF } \\
\hline Periodicity & Mean & Std Dev & Median & Min & Max & Skew & Kurtosis \\
\hline Hourly & 0 & 0 & 0 & -0.01 & 0.02 & 0.41 & 7.09 \\
\hline Daily & 0 & 0.01 & 0 & -0.03 & 0.02 & 0.05 & 1.44 \\
\hline \multicolumn{8}{|c|}{ UYG } \\
\hline Periodicity & Mean & Std Dev & Median & Min & Max & Skew & Kurtosis \\
\hline Hourly & 0 & 0 & 0 & -0.02 & 0.04 & 0.47 & 7.28 \\
\hline Daily & 0 & 0.01 & 0 & -0.05 & 0.04 & -0.06 & 1.24 \\
\hline \multicolumn{8}{|c|}{ XLI } \\
\hline Periodicity & Mean & Std Dev & Median & Min & Max & Skew & Kurtosis \\
\hline Hourly & 0 & 0 & 0 & -0.01 & 0.02 & 0.33 & 4.86 \\
\hline Daily & 0 & 0.01 & 0 & -0.03 & 0.02 & -0.87 & 2.6 \\
\hline \multicolumn{8}{|c|}{ DIG } \\
\hline Periodicity & Mean & Std Dev & Median & Min & Max & Skew & Kurtosis \\
\hline Hourly & 0 & 0 & 0 & -0.01 & 0.03 & 0.16 & 3.38 \\
\hline Daily & 0 & 0.01 & 0 & -0.04 & 0.03 & -0.23 & 0.46 \\
\hline \multicolumn{8}{|c|}{ XLE } \\
\hline Periodicity & Mean & Std Dev & Median & Min & Max & Skew & Kurtosis \\
\hline
\end{tabular}




\begin{tabular}{|c|c|c|c|c|c|c|c|}
\hline $\begin{array}{c}\text { Hourly } \\
\text { Daily }\end{array}$ & $\begin{array}{l}0 \\
0\end{array}$ & $\begin{array}{c}0 \\
0.01 \\
\end{array}$ & $\begin{array}{l}0 \\
0\end{array}$ & $\begin{array}{l}-0.01 \\
-0.02 \\
\end{array}$ & $\begin{array}{l}0.02 \\
0.02\end{array}$ & $\begin{array}{c}0.14 \\
-0.16 \\
\end{array}$ & $\begin{array}{l}2.93 \\
0.32 \\
\end{array}$ \\
\hline \multicolumn{8}{|c|}{ EFA } \\
\hline Periodicity & Mean & Std Dev & Median & Min & Max & Skew & Kurtosis \\
\hline Hourly & 0 & 0 & 0 & -0.01 & 0.01 & 1.01 & 11.53 \\
\hline Daily & 0 & 0.01 & 0 & -0.02 & 0.03 & 0.08 & 5.22 \\
\hline \multicolumn{8}{|c|}{ DPK } \\
\hline Periodicity & Mean & Std Dev & Median & Min & Max & Skew & Kurtosis \\
\hline Hourly & 0 & 0 & 0 & -0.07 & 0.02 & -5.97 & 81.86 \\
\hline Daily & 0 & 0.01 & 0 & -0.08 & 0.05 & -0.38 & 5.63 \\
\hline \multicolumn{8}{|c|}{ EEM } \\
\hline Periodicity & Mean & Std Dev & Median & Min & Max & Skew & Kurtosis \\
\hline Hourly & 0 & 0 & 0 & -0.01 & 0.03 & 1.54 & 15.18 \\
\hline Daily & 0 & 0.01 & 0 & -0.02 & 0.04 & 0.78 & 3.95 \\
\hline \multicolumn{8}{|c|}{ EDZ } \\
\hline Periodicity & Mean & Std Dev & Median & Min & Max & Skew & Kurtosis \\
\hline Hourly & 0 & 0.01 & 0 & -0.09 & 0.03 & -1.84 & 18.41 \\
\hline Daily & 0 & 0.03 & 0 & -0.14 & 0.06 & -1.08 & 5.31 \\
\hline \multicolumn{8}{|c|}{ EDC } \\
\hline Periodicity & Mean & Std Dev & Median & Min & Max & Skew & Kurtosis \\
\hline Hourly & 0 & 0.01 & 0 & -0.04 & 0.08 & 1.29 & 12.7 \\
\hline Daily & 0 & 0.03 & 0 & -0.07 & 0.13 & 0.7 & 3.79 \\
\hline
\end{tabular}


Appendix IV

\begin{tabular}{|l|c|c|}
\hline \multicolumn{3}{|c|}{ SPY/SSO, Hourly } \\
\hline & Estimate & $\boldsymbol{p}$ Value \\
\hline$\alpha_{1}$ & 0.013394 & 0.041361 \\
$\beta_{1}$ & 0.975224 & 0 \\
$\omega_{1}$ & 0 & 0.166947 \\
$\alpha_{2}$ & 0.001283 & 0.830426 \\
$\beta_{2}$ & 0.997261 & 0 \\
$\omega_{2}$ & 0 & 0.777758 \\
$\alpha_{J}$ & 0.001303 & 0.04373 \\
$\beta_{J}$ & 0.996426 & 0 \\
\hline
\end{tabular}

\begin{tabular}{|c|c|c|}
\hline \multicolumn{3}{|c|}{ SPY/SSO, Daily } \\
\hline & Estimate & $\boldsymbol{p}$ Value \\
\hline$\alpha_{1}$ & 0 & 0.999304 \\
$\beta_{1}$ & 0.999 & 0 \\
$\omega_{1}$ & 0 & 0.065066 \\
$\alpha_{2}$ & 0 & 0.999304 \\
$\beta_{2}$ & 0.999 & 0 \\
$\omega_{2}$ & 0 & 0.085014 \\
$\alpha_{\lrcorner}$ & 0.064628 & 0.045658 \\
$\beta_{\lrcorner}$ & 0.683022 & 0 \\
\hline
\end{tabular}

\begin{tabular}{|l|c|c|}
\hline \multicolumn{3}{|c|}{ SPY/MDY, Hourly } \\
\hline & Estimate & $\boldsymbol{p}$ Value \\
\hline$\alpha_{1}$ & 0.014914 & 0.036593 \\
$\beta_{1}$ & 0.976423 & 0 \\
$\omega_{1}$ & 0 & 0.287793 \\
$\alpha_{2}$ & 0.015065 & 0.017307 \\
$\beta_{2}$ & 0.97779 & 0 \\
$\omega_{2}$ & 0 & 0.206897 \\
$\alpha_{J}$ & 0.007116 & 0.554254 \\
$\beta_{J}$ & 0.93005 & 0 \\
\hline
\end{tabular}

\begin{tabular}{|c|c|c|}
\hline \multicolumn{3}{|c|}{ SPY/MDY, Daily } \\
\hline & Estimate & $\boldsymbol{p}$ Value \\
\hline$\alpha_{1}$ & 0 & 0.996865 \\
$\beta_{1}$ & 0.999 & 0 \\
$\omega_{1}$ & 0 & 0.008375 \\
\hline
\end{tabular}




\begin{tabular}{|c|c|c|}
\hline$\alpha_{2}$ & 0 & 0.999535 \\
$\beta_{2}$ & 0.999 & 0 \\
$\omega_{2}$ & 0 & 0.002125 \\
$\alpha_{\mathrm{J}}$ & 0.019714 & 0.465909 \\
$\beta_{\mathrm{J}}$ & 0.876048 & 0 \\
\hline
\end{tabular}

\begin{tabular}{|c|c|c|}
\hline \multicolumn{3}{|c|}{ DIA/DDM, Hourly } \\
\hline & Estimate & $\boldsymbol{p}$ Value \\
\hline$\alpha_{1}$ & 0 & 0.996865 \\
$\beta_{1}$ & 0.999 & 0 \\
$\omega_{1}$ & 0 & 0.008375 \\
$\alpha_{2}$ & 0.000353 & 0.97541 \\
$\beta_{2}$ & 0.997462 & 0 \\
$\omega_{2}$ & 0 & 0.83013 \\
$\alpha_{\mathrm{J}}$ & 0.006997 & 0.2135 \\
$\beta_{\mathrm{J}}$ & 0.955299 & 0 \\
\hline
\end{tabular}

\begin{tabular}{|c|c|c|}
\hline \multicolumn{3}{|c|}{ DIA/DDM, Daily } \\
\hline & Estimate & $\boldsymbol{p}$ Value \\
\hline$\alpha_{1}$ & 0 & 0.993957 \\
$\beta_{1}$ & 0.999 & 0 \\
$\omega_{1}$ & 0 & 0.031109 \\
$\alpha_{2}$ & 0 & 0.986721 \\
$\beta_{2}$ & 0.999 & 0 \\
$\omega_{2}$ & 0 & 0.020053 \\
$\alpha_{\mathrm{J}}$ & 0 & 0.99961 \\
$\beta_{\mathrm{J}}$ & 0.908934 & 0 \\
\hline
\end{tabular}

\begin{tabular}{|c|c|c|}
\hline \multicolumn{3}{|c|}{ GDX/NUGT, Hourly } \\
\hline & Estimate & $\boldsymbol{p}$ Value \\
\hline$\alpha_{1}$ & 0.005368 & 0.161547 \\
$\beta_{1}$ & 0.992364 & 0 \\
$\omega_{1}$ & 0 & 0.628005 \\
$\alpha_{2}$ & 0.005864 & 0.039313 \\
$\beta_{2}$ & 0.99213 & 0 \\
$\omega_{2}$ & 0 & 0.511097 \\
$\alpha_{\mathrm{J}}$ & 0.017127 & 0.50837 \\
$\beta_{\mathrm{J}}$ & 0.05366 & 0.838422 \\
\hline
\end{tabular}

\section{GDX/NUGT, Daily}




\begin{tabular}{|c|c|c|} 
& Estimate & $\boldsymbol{p}$ Value \\
\hline$\alpha_{1}$ & 0.047481 & 0.023668 \\
$\beta_{1}$ & 0.933183 & 0 \\
$\omega_{1}$ & 0.000006 & 0.644946 \\
$\alpha_{2}$ & 0.047085 & 0.385206 \\
$\beta_{2}$ & 0.932753 & 0 \\
$\omega_{2}$ & 0.000056 & 0 \\
$\alpha_{\mathrm{J}}$ & 0.036669 & 0.127851 \\
$\beta_{\mathrm{J}}$ & 0.927271 & 0 \\
\hline
\end{tabular}

\begin{tabular}{|c|c|c|}
\hline \multicolumn{3}{|c|}{ GDX/XME, Hourly } \\
\hline & Estimate & $\boldsymbol{p}$ Value \\
\hline$\alpha_{1}$ & 0.004621 & 0.016276 \\
$\beta_{1}$ & 0.993497 & 0 \\
$\omega_{1}$ & 0 & 0.504037 \\
$\alpha_{2}$ & 0.002864 & 0.28356 \\
$\beta_{2}$ & 0.995901 & 0 \\
$\omega_{2}$ & 0 & 0.746159 \\
$\alpha_{\mathrm{J}}$ & 0.00693 & 0.25668 \\
$\beta_{\mathrm{J}}$ & 0.984268 & 0 \\
\hline
\end{tabular}

\begin{tabular}{|c|c|c|}
\hline \multicolumn{3}{|c|}{ GDX/XME, Daily } \\
\hline & Estimate & $\boldsymbol{p}$ Value \\
\hline$\alpha_{1}$ & 0.047481 & 0.17264 \\
$\beta_{1}$ & 0.933183 & 0 \\
$\omega_{1}$ & 0.000006 & 0.49471 \\
$\alpha_{2}$ & 0.000016 & 0.99991 \\
$\beta_{2}$ & 0.997163 & 0 \\
$\omega_{2}$ & 0.000056 & 0.98594 \\
$\alpha_{J}$ & 0.066169 & 0.45684 \\
$\beta_{J}$ & 0.595686 & 0.62044 \\
\hline
\end{tabular}

\begin{tabular}{|c|c|c|}
\hline \multicolumn{3}{|c|}{ URE/IYR, Hourly } \\
\hline & Estimate & $\boldsymbol{p}$ Value \\
\hline$\alpha_{1}$ & 0.001939 & 0.140693 \\
$\beta_{1}$ & 0.996936 & 0 \\
$\omega_{1}$ & 0 & 0.946963 \\
$\alpha_{2}$ & 0.003112 & 0.038518 \\
$\beta_{2}$ & 0.995653 & 0 \\
$\omega_{2}$ & 0 & 0.757659 \\
\hline
\end{tabular}




\begin{tabular}{|l|c|c|}
\hline$\alpha_{\lrcorner}$ & 0.008763 & 0.579489 \\
$\beta_{J}$ & 0.872763 & 0 \\
\hline
\end{tabular}

\begin{tabular}{|l|c|c|}
\hline \multicolumn{3}{|c|}{ URE/IYR, Daily } \\
\hline & Estimate & $\boldsymbol{p}$ Value \\
\hline$\alpha_{1}$ & 0.000015 & 0.802389 \\
$\beta_{1}$ & 0.997674 & 0 \\
$\omega_{1}$ & 0.000006 & 0.990149 \\
$\alpha_{2}$ & 0.000202 & 0.577295 \\
$\beta_{2}$ & 0.997599 & 0 \\
$\omega_{2}$ & 0 & 0.999609 \\
$\alpha_{J}$ & 0.043311 & 0.531234 \\
$\beta_{J}$ & 0.866515 & 0.002283 \\
\hline
\end{tabular}

\begin{tabular}{|c|c|c|}
\hline \multicolumn{3}{|c|}{ XLF/ERY, Hourly } \\
\hline & Estimate & $\boldsymbol{p}$ Value \\
\hline$\alpha_{1}$ & 0.002288 & 0.807534 \\
$\beta_{1}$ & 0.990617 & 0 \\
$\omega_{1}$ & 0 & 0.413504 \\
$\alpha_{2}$ & 0.000377 & 0.944091 \\
$\beta_{2}$ & 0.997345 & 0 \\
$\omega_{2}$ & 0 & 0.667263 \\
$\alpha_{\lrcorner}$ & 0.010763 & 0.032923 \\
$\beta_{J}$ & 0.957029 & 0 \\
\hline
\end{tabular}

\begin{tabular}{|c|c|c|}
\hline \multicolumn{3}{|c|}{ XLF/ERY, Daily } \\
\hline & Estimate & $\boldsymbol{p}$ Value \\
\hline$\alpha_{1}$ & 0 & 0.86614 \\
$\beta_{1}$ & 0.999 & 0 \\
$\omega_{1}$ & 0 & 0.041172 \\
$\alpha_{2}$ & 0 & 0.998527 \\
$\beta_{2}$ & 0.999 & 0 \\
$\omega_{2}$ & 0.000001 & 0.079914 \\
$\alpha_{\lrcorner}$ & 0 & 0.997025 \\
$\beta_{J}$ & 0.881323 & 0 \\
\hline
\end{tabular}

\begin{tabular}{|l|c|c|}
\hline \multicolumn{3}{|c|}{ XLI/UYG, Hourly } \\
\hline & Estimate & $\boldsymbol{p}$ Value \\
\hline$\alpha_{1}$ & 0.030326 & 0.148715 \\
$\beta_{1}$ & 0.964077 & 0 \\
\hline
\end{tabular}




\begin{tabular}{|c|c|c|}
$\omega_{1}$ & 0 & 0.208102 \\
$\alpha_{2}$ & 0.002995 & 0.143937 \\
$\beta_{2}$ & 0.995985 & 0 \\
$\omega_{2}$ & 0 & 0.590802 \\
$\alpha_{J}$ & 0 & 0.99998 \\
$\beta_{J}$ & 0.920365 & 0.044086 \\
\hline
\end{tabular}

\begin{tabular}{|c|c|c|}
\hline \multicolumn{3}{|c|}{ XLI/UYG, Daily } \\
\hline & Estimate & $\boldsymbol{p}$ Value \\
\hline$\alpha_{1}$ & 0.000577 & 0.978282 \\
$\beta_{1}$ & 0.998408 & 0 \\
$\omega_{1}$ & 0 & 0.836537 \\
$\alpha_{2}$ & 0 & 0.758655 \\
$\beta_{2}$ & 0.999 & 0 \\
$\omega_{2}$ & 0 & 0.057714 \\
$\alpha_{\mathrm{J}}$ & 0 & 0.999959 \\
$\beta_{\mathrm{J}}$ & 0.909709 & 0 \\
\hline
\end{tabular}

\begin{tabular}{|c|c|c|}
\hline \multicolumn{3}{|c|}{ XLE/DIG, Hourly } \\
\hline & Estimate & $\boldsymbol{p}$ Value \\
\hline$\alpha_{1}$ & 0.028614 & 0.07011 \\
$\beta_{1}$ & 0.951 & 0 \\
$\omega_{1}$ & 0 & 0.11181 \\
$\alpha_{2}$ & 0.042396 & 0.24019 \\
$\beta_{2}$ & 0.895285 & 0 \\
$\omega_{2}$ & 0.000001 & 0.40892 \\
$\alpha_{\mathrm{J}}$ & 0 & 0.99994 \\
$\beta_{\mathrm{J}}$ & 0.909166 & 0 \\
\hline
\end{tabular}

\begin{tabular}{|c|c|c|}
\hline \multicolumn{3}{|c|}{ XLE/DIG, Daily } \\
\hline & Estimate & $\boldsymbol{p}$ Value \\
\hline$\alpha_{1}$ & 0.000001 & 0.999992 \\
$\beta_{1}$ & 0.998997 & 0 \\
$\omega_{1}$ & 0 & 0.983355 \\
$\alpha_{2}$ & 0 & 0.998519 \\
$\beta_{2}$ & 0.999 & 0 \\
$\omega_{2}$ & 0 & 0.022557 \\
$\alpha_{\mathrm{J}}$ & 0 & 0.9996 \\
$\beta_{\mathrm{J}}$ & 0.921222 & 0.006323 \\
\hline
\end{tabular}




\begin{tabular}{|l|c|c|}
\hline \multicolumn{3}{|c|}{ EFA/DPK, Hourly } \\
\hline & Estimate & $\boldsymbol{p}$ Value \\
\hline$\alpha_{1}$ & 0.02003 & 0.596063 \\
$\beta_{1}$ & 0.969356 & 0 \\
$\omega_{1}$ & 0 & 0.857214 \\
$\alpha_{2}$ & 0.133643 & 0.000001 \\
$\beta_{2}$ & 0.865357 & 0.000051 \\
$\omega_{2}$ & 0.000001 & 0.82034 \\
$\alpha_{\lrcorner}$ & 0 & 0.999809 \\
$\beta_{J}$ & 0.91434 & 0.000008 \\
\hline
\end{tabular}

\begin{tabular}{|c|c|c|}
\hline \multicolumn{3}{|c|}{ EFA/DPK, Daily } \\
\hline & Estimate & $\boldsymbol{p}$ Value \\
\hline$\alpha_{1}$ & 0 & 0.979215 \\
$\beta_{1}$ & 0.999 & 0 \\
$\omega_{1}$ & 0 & 0.452804 \\
$\alpha_{2}$ & 0 & 0.996949 \\
$\beta_{2}$ & 0.999 & 0 \\
$\omega_{2}$ & 0 & 0.543718 \\
$\alpha_{\mathfrak{J}}$ & 0 & 0.999543 \\
$\beta_{\mathrm{J}}$ & 0.922913 & 0 \\
\hline
\end{tabular}

\begin{tabular}{|l|c|c|}
\hline \multicolumn{3}{|c|}{ EEM/EDZ, Hourly } \\
\hline & Estimate & $\boldsymbol{p}$ Value \\
\hline$\alpha_{1}$ & 0.002054 & 0.70583 \\
$\beta_{1}$ & 0.995735 & 0 \\
$\omega_{1}$ & 0 & 0.66797 \\
$\alpha_{2}$ & 0 & 0.99864 \\
$\beta_{2}$ & 0.999 & 0 \\
$\omega_{2}$ & 0 & 0 \\
$\alpha_{\lrcorner}$ & 0 & 0.99972 \\
$\beta_{J}$ & 0.940802 & 0 \\
\hline
\end{tabular}

\begin{tabular}{|l|c|c|}
\hline \multicolumn{3}{|c|}{ EEM/EDZ, Daily } \\
\hline & Estimate & $\boldsymbol{p}$ Value \\
\hline$\alpha_{1}$ & 0 & 0.999698 \\
$\beta_{1}$ & 0.999 & 0 \\
$\omega_{1}$ & 0 & 0.937775 \\
$\alpha_{2}$ & 0.999559 & 0 \\
$\beta_{2}$ & 0.999 & 0 \\
\hline
\end{tabular}




\begin{tabular}{|c|c|c|}
\hline$\omega_{2}$ & 0 & 0.972889 \\
$\alpha_{J}$ & 0.131764 & 0.729603 \\
$\beta_{J}$ & 0.760187 & 0.000076 \\
\hline
\end{tabular}

\begin{tabular}{|c|c|c|}
\hline \multicolumn{3}{|c|}{ EEM/EDC, Hourly } \\
\hline & Estimate & $\boldsymbol{p}$ Value \\
\hline$\alpha_{1}$ & 0.002096 & 0.044431 \\
$\beta_{1}$ & 0.995225 & 0 \\
$\omega_{1}$ & 0 & 0.042491 \\
$\alpha_{2}$ & 0.000088 & 0.99141 \\
$\beta_{2}$ & 0.997301 & 0 \\
$\omega_{2}$ & 0 & 0.625569 \\
$\alpha_{\mathrm{J}}$ & 0.023684 & 0.127106 \\
$\beta_{\mathrm{J}}$ & 0.921628 & 0 \\
\hline
\end{tabular}

\begin{tabular}{|c|c|c|}
\hline \multicolumn{3}{|c|}{ EEM/EDC, Daily } \\
\hline & Estimate & $\boldsymbol{p}$ Value \\
\hline$\alpha_{1}$ & 0 & 0.9973 \\
$\beta_{1}$ & 0.999 & 0 \\
$\omega_{1}$ & 0 & 0.62956 \\
$\alpha_{2}$ & 0 & 0.99725 \\
$\beta_{2}$ & 0.998999 & 0 \\
$\omega_{2}$ & 0.000001 & 0.5553 \\
$\alpha_{J}$ & 0.006629 & 0.59299 \\
$\beta_{J}$ & 0.955152 & 0 \\
\hline
\end{tabular}

